\title{
WestVirginiaUniversity
}

THE RESEARCH REPOSITORY @ WVU

Graduate Theses, Dissertations, and Problem Reports

2005

\section{The design of a rotor blade test facility}

Jason W. Gill

West Virginia University

Follow this and additional works at: https://researchrepository.wvu.edu/etd

\section{Recommended Citation}

Gill, Jason W., "The design of a rotor blade test facility" (2005). Graduate Theses, Dissertations, and Problem Reports. 3202.

https://researchrepository.wvu.edu/etd/3202

This Thesis is protected by copyright and/or related rights. It has been brought to you by the The Research Repository @ WVU with permission from the rights-holder(s). You are free to use this Thesis in any way that is permitted by the copyright and related rights legislation that applies to your use. For other uses you must obtain permission from the rights-holder(s) directly, unless additional rights are indicated by a Creative Commons license in the record and/ or on the work itself. This Thesis has been accepted for inclusion in WVU Graduate Theses, Dissertations, and Problem Reports collection by an authorized administrator of The Research Repository @ WVU. For more information, please contact researchrepository@mail.wvu.edu. 


\title{
The Design of a Rotor Blade Test Facility
}

\author{
Jason W. Gill \\ Thesis submitted to the \\ College of Engineering and Mineral Resources \\ at West Virginia University \\ in partial fulfillment of the requirements for the degree of \\ Master of Science \\ in \\ Mechanical Engineering \\ James E. Smith, Ph.D., Chair \\ Wade W. Huebsch, Ph.D. \\ Jacky C. Prucz, Ph.D. \\ Department of Mechanical and Aerospace Engineering
}

Morgantown, West Virginia

2005

Keywords: Propeller, Rotor, Static, Testing, V-22 


\title{
Abstract \\ The Design of a Rotor Blade Test Facility
}

\author{
Jason W. Gill
}

The Mechanical and Aerospace Engineering Department has developed a need for test facilities related to rotorcraft, specifically facilities capable of testing scaled rotorcraft models and experimental propellers and rotors. A design was completed to fill these needs.

The design included several factors; aerodynamic conditions during operation, flexibility of application, ease and cost of construction, and safety. The aerodynamic conditions involved in the testing of rotors or propellers in static conditions were investigated. Other testing involving downwash impingement on wings was considered and incorporated into the design.

In addition, the design of the power transmission components was completed. This included the power requirements for testing, drivetrain components, and selection of electric motor and controller for use. Finite element analysis of the facility's frame in static loading conditions was completed in Pro/Mechanica to determine response to operational loads. 


\section{Acknowledgements}

I'm surprised that I made it this far, and I have a great deal of people to thank for it. Sorry if I missed you, there's only so much space...First off, I'd like to thank my research advisor Dr. James E. Smith for teaching me about the "real" world and for making me a more rounded engineer (even if it kills me!). I'll take your lessons with me, and I know they'll serve me well. I'd also like thank Dr. Wade Huebsch who provided a great deal of aerodynamic theory assistance when I needed it most and for always making time for me throughout my career at WVU when he didn't have it. Thanks also goes to Dr. Jacky Prucz, who throughout my undergraduate and graduate career was willing to help me in many ways, as an advisor, an employer, and a consulting engineer. And to the former and current members of CIRA, thanks for your help along the way, you made it hard to work and easy to laugh.

To The Crew (you know who you are), who over the years have always been behind me. You guys are my physiatrists, sounding boards, best of friends, and surrogate family. It would have been a miserable ride without you.

And finally, to my family... To my wife Angel, who never for an instant wavered in her support. Thanks for all the advice, even when I didn't want to hear it but was needed anyways. Thanks for putting up with my mood swings, and for keeping me from quitting. I love you. To Eric, my brother, for making time to jam, keeping my music tastes updated, and for being a sympathetic ear when I needed it. And to my parents, Chester and Sharon Gill...Dad, thanks for teaching me to never quit, it's made more of a difference in my life than you know. Mom, what can I say, without you, I never would have achieved so much. Thanks for pushing me when I needed it, and for worrying when you didn't have too. Thank you for being the person you are, for your willingness to give everything you have for your family. I hope I Made Mom Proud. 


\section{Table of Contents}

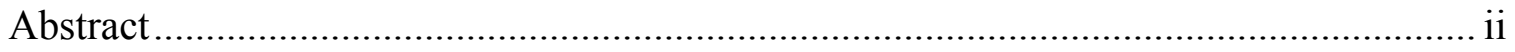

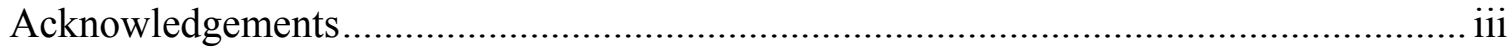

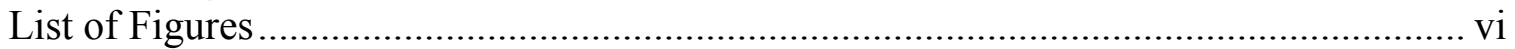

List of Figures- Appendix ........................................................................................ vii

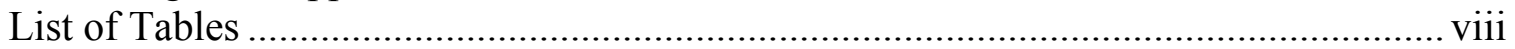

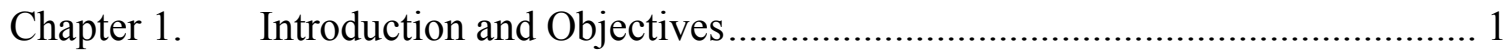

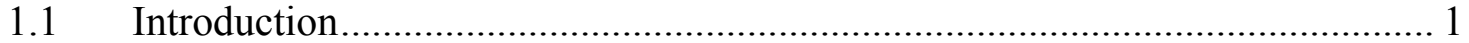

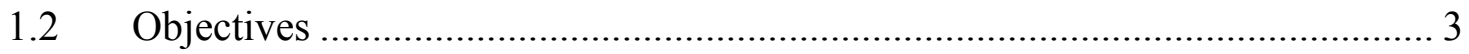

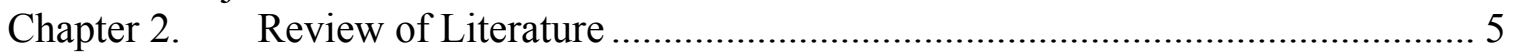

$2.1 \quad$ Introduction of Topics............................................................................ 5

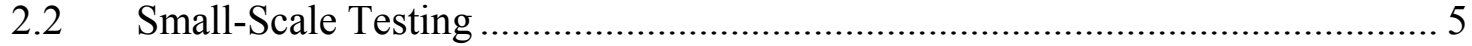

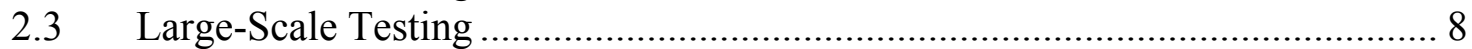

2.4 Propeller and Rotor Wake Characteristics ................................................. 17

Chapter 3. Aerodynamic Design …………………........................................ 21

3.1 Initial Use Considerations ........................................................................ 21

3.2 Scaling Parameter Calculation................................................................... 21

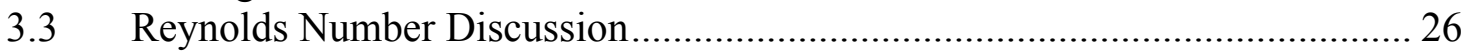

3.4 Scale Model Configuration Selection .............................................................. 26

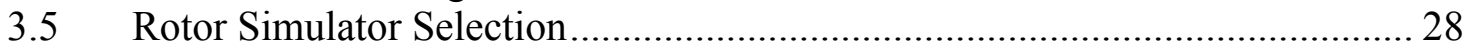

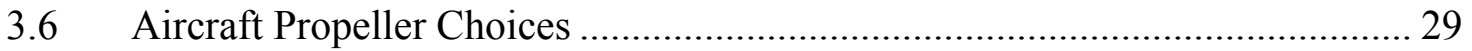

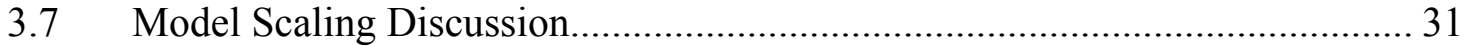

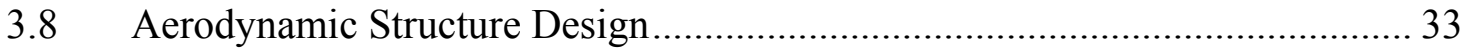

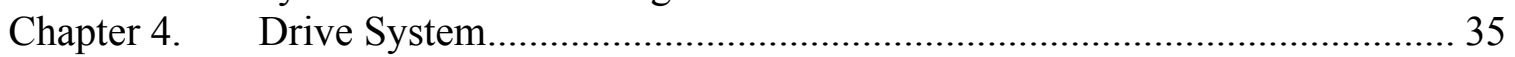

4.1 Internal Combustion Engine Consideration.................................................... 35

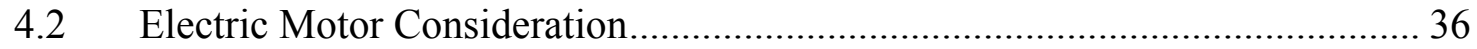

4.3 Mechanical Power Transmission .................................................................. 44

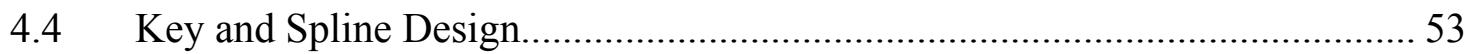

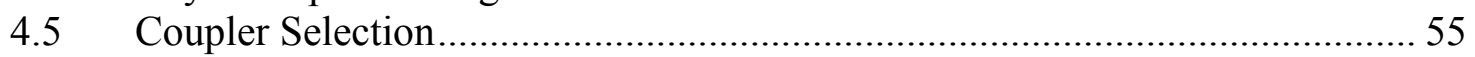

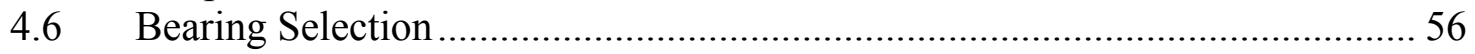

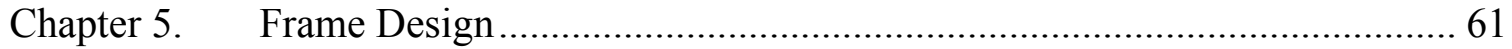

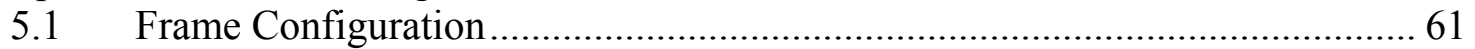

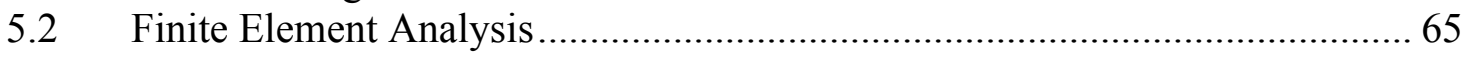

Chapter 6. Conclusion and Recommendations...................................................... 72

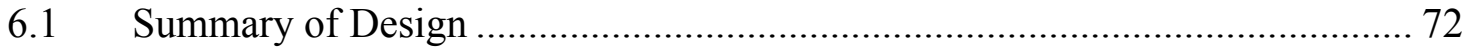

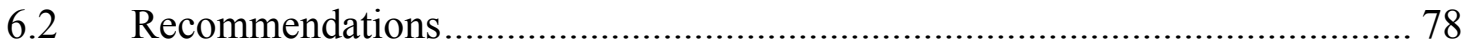

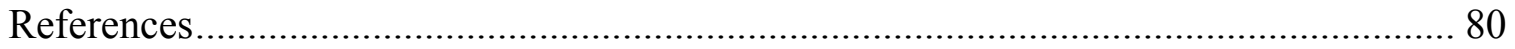

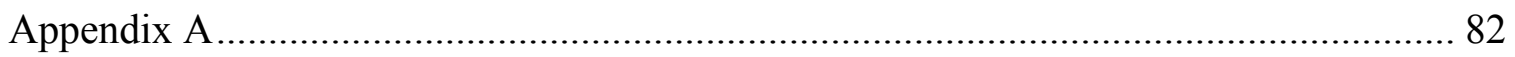

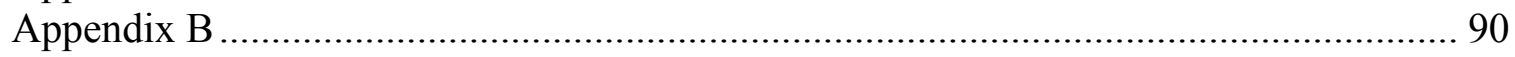

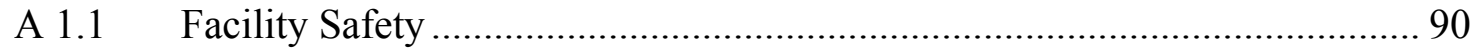

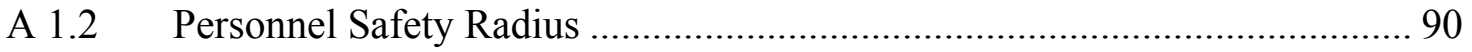

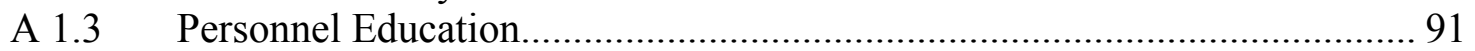

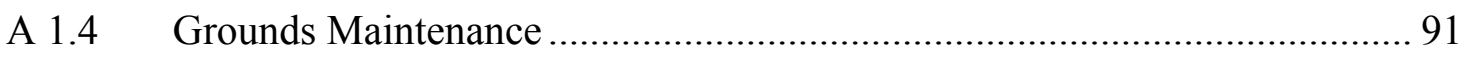

A 1.5 Emergency Stop Procedures …………….............................................. 91 


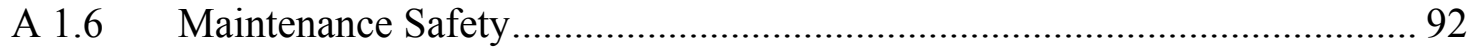

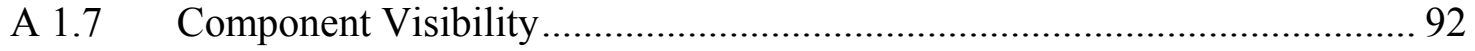

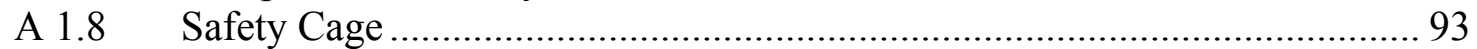




\section{List of Figures}

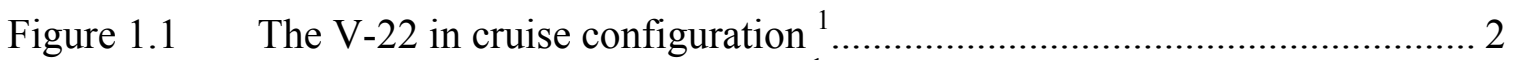

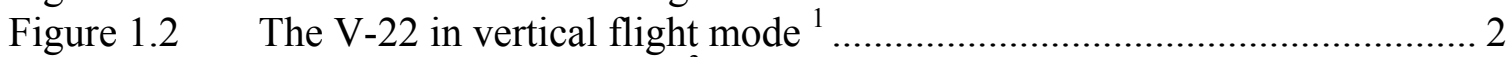

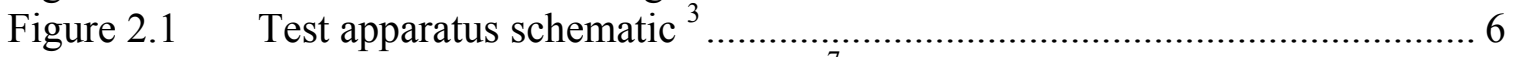

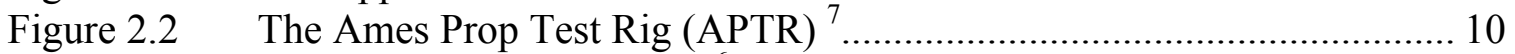

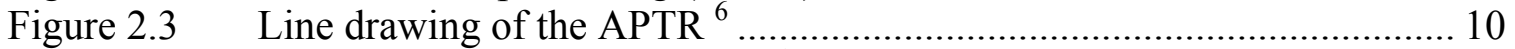

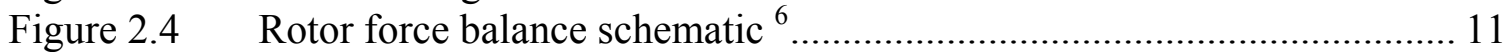

Figure 2.5 Wake rake implementation for wake measurement ${ }^{6}$............................. 12

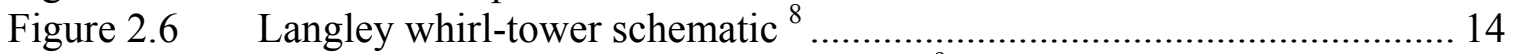

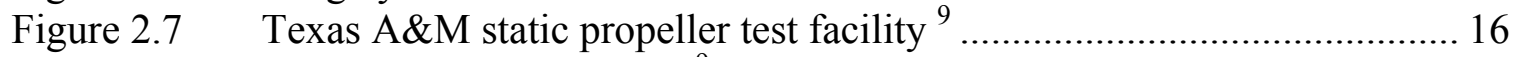

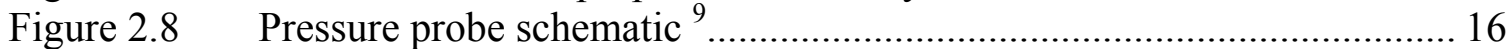

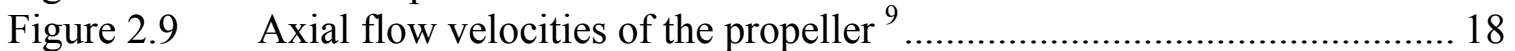

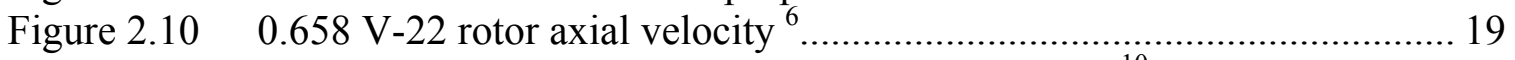

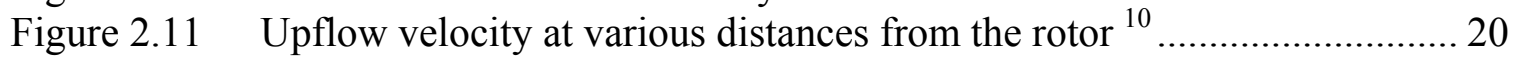

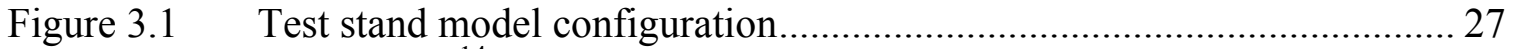

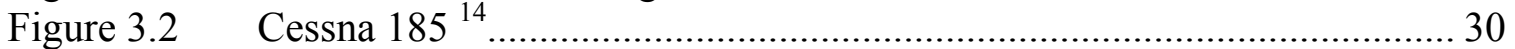

Figure 4.1 Motor Master interface .................................................................... 38

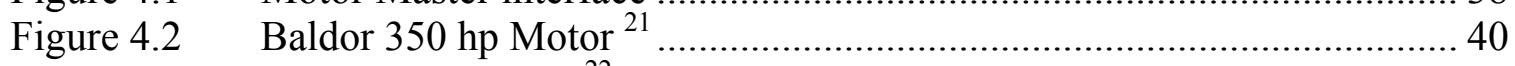

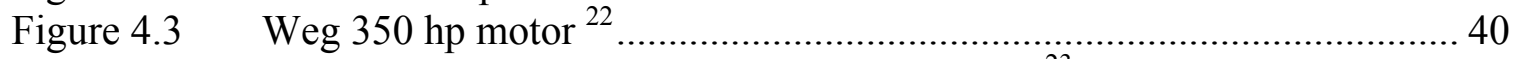

Figure 4.4 Weg SSW-03 soft-start controller, 100-800 hp ${ }^{23}$................................ 41

Figure 4.5 Weg CFW-09 Vectrue Inverter, 1.5-500 hp ${ }^{24}$...................................... 42

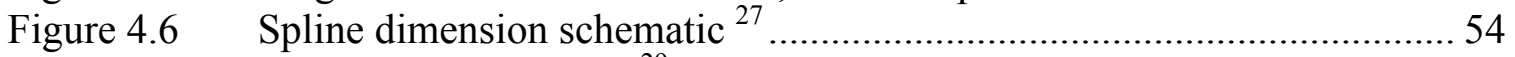

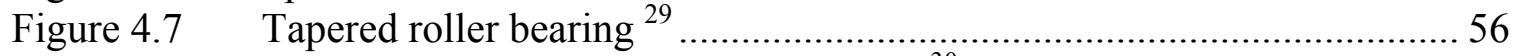

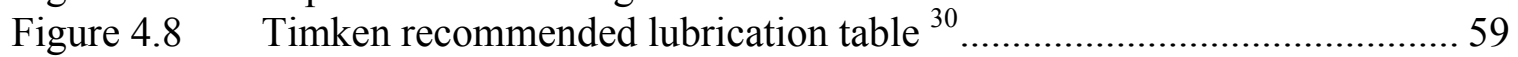

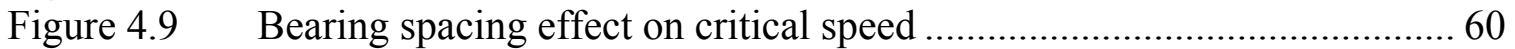

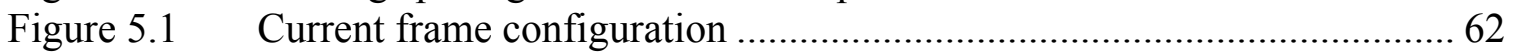

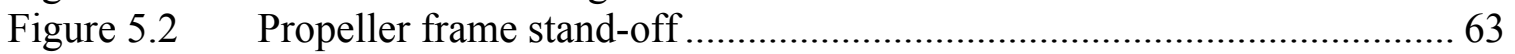

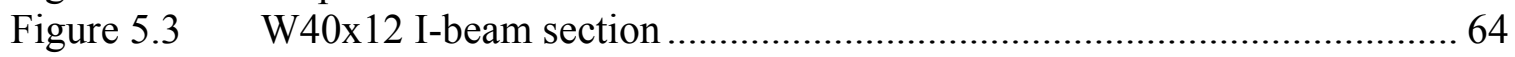

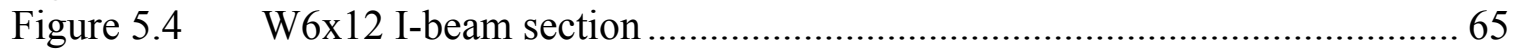

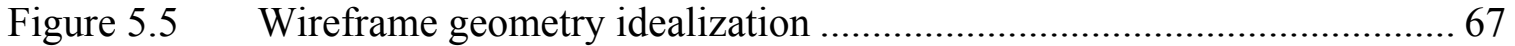

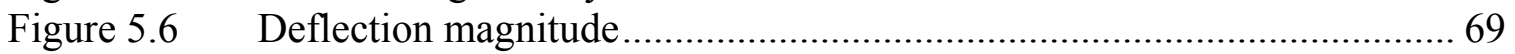

Figure 5.7 Von Mises stress visualization....................................................... 70

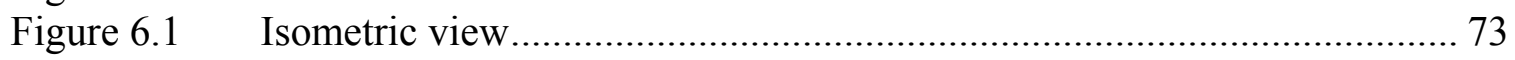

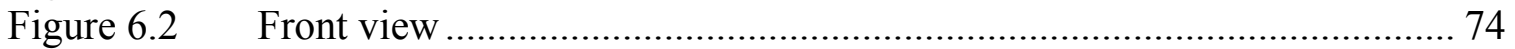

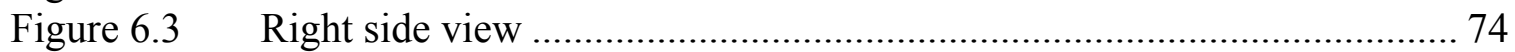

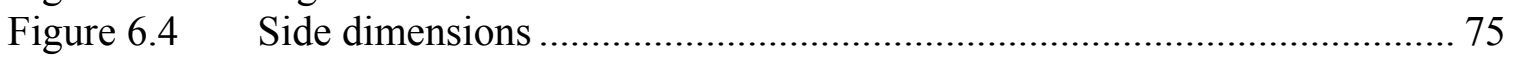

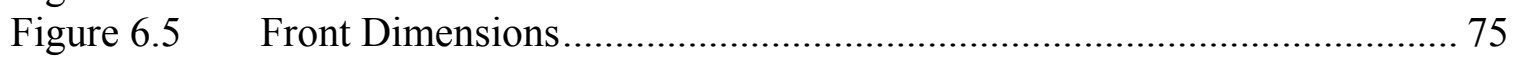

Figure 6.6 Motor mounting rear detail ........................................................... 76

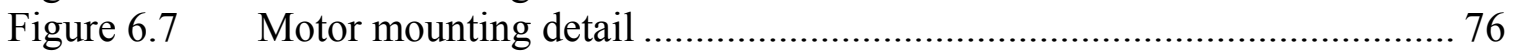

Figure $6.8 \quad$ Front main bearing and standoff..................................................... 77 


\section{List of Figures- Appendix}

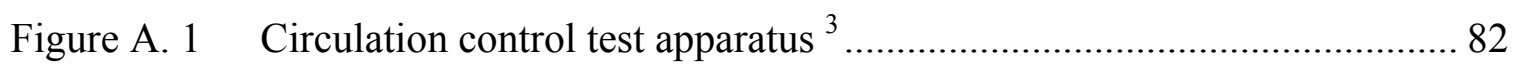

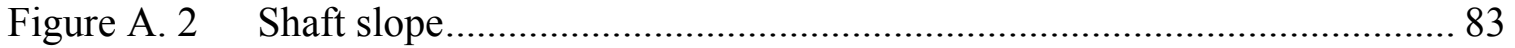

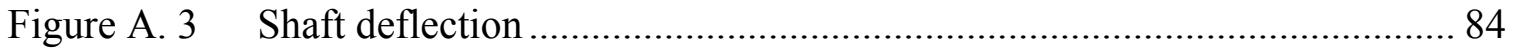

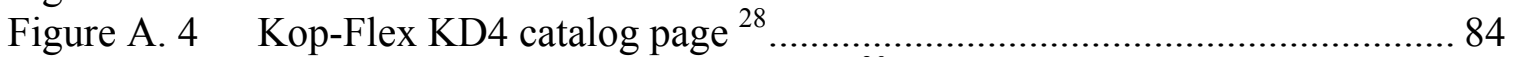

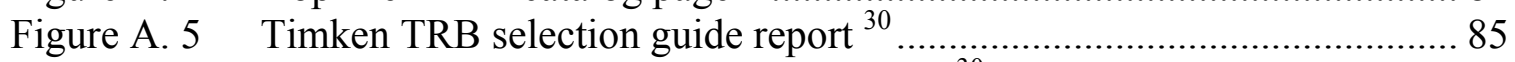

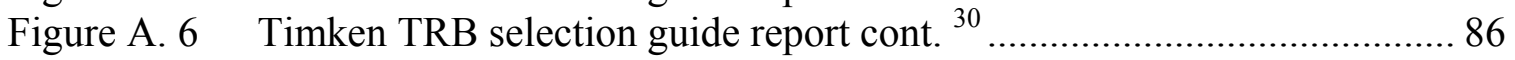

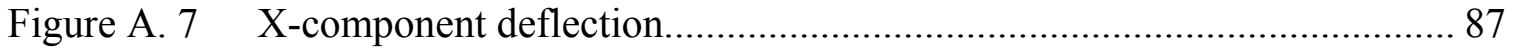

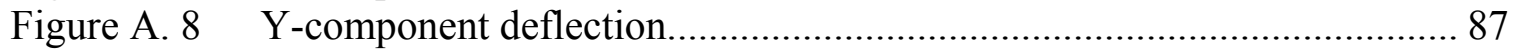

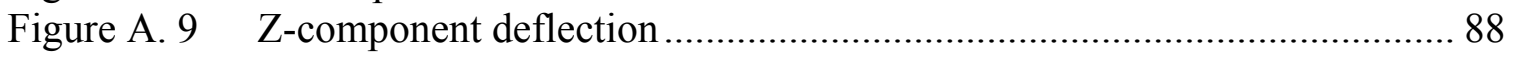

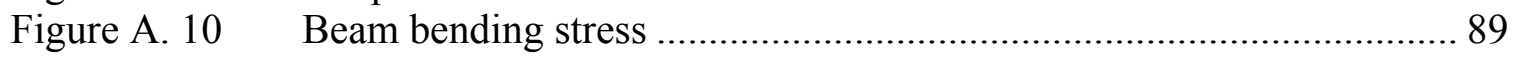

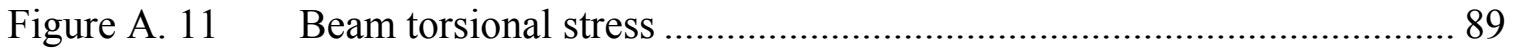




\section{List of Tables}

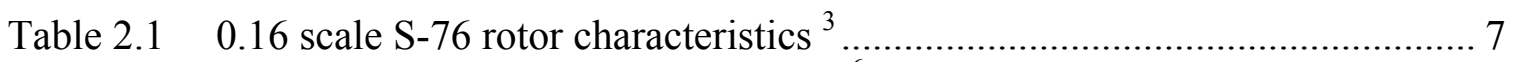

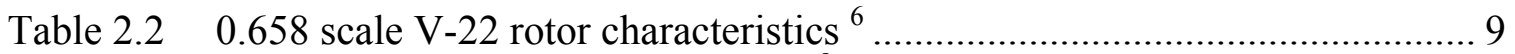

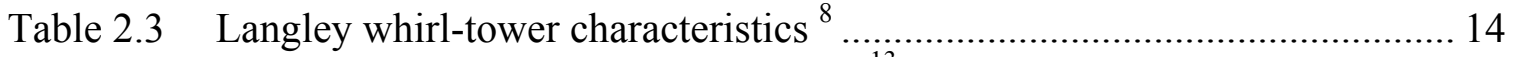

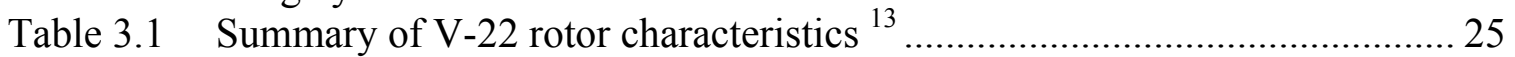

Table 3.2 McCauley 2A34C66 propeller specifications .......................................... 31

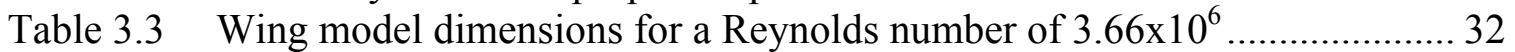

Table 4.1 Motor requirements................................................................................. 38

Table 4.2 A selection of 350 horsepower, 3 phase AC induction motors.................... 40

Table 4.3 Minimum variable frequency drive requirements................................... 43

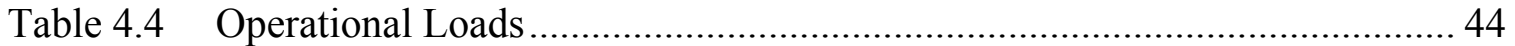

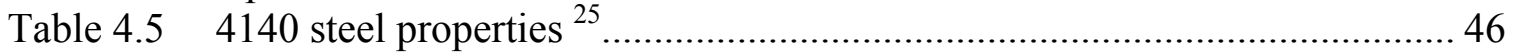

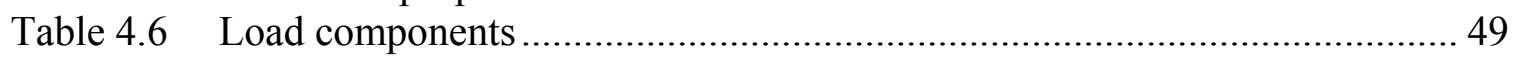

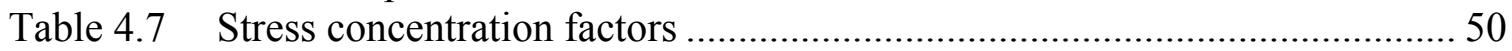

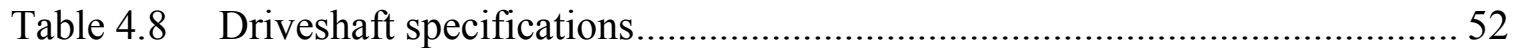

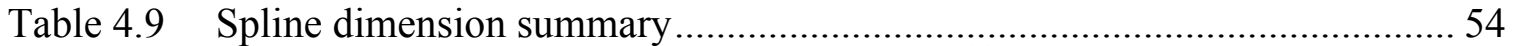

Table 4.10 Kop-Flex KD4 153 coupler specifications ${ }^{28}$.......................................56

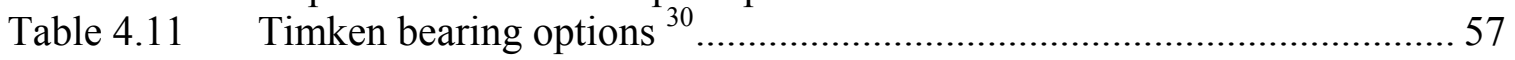

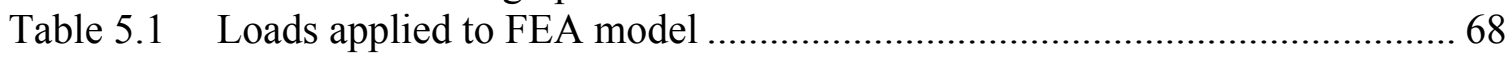

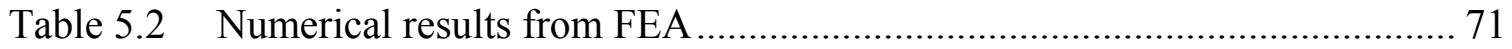

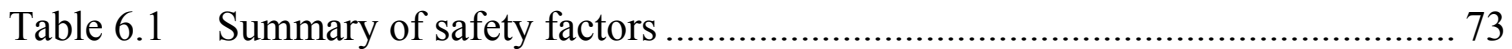

Table 6.2 Recommended operational limits ......................................................... 73 


\section{Chapter 1. Introduction and Objectives}

\subsection{Introduction}

The purpose of this research was to develop a new aerodynamic test facility for the Department of Mechanical and Aerospace Engineering (MAE), specifically for the testing of large-scale models related to rotorcraft. The original impetus for this design was downwash reduction research related to Bell's V-22 Osprey, a tilt-rotor military cargo transport as seen in Figures 1.1 and 1.2 that has been completed in the Department's closed-loop low-speed wind tunnel [2].

This work focused on the implementation of circulation controlled lift augmentation during the hovering flight regime. The purpose was to determine whether circulation control could effectively reduce the downwash spreading effect caused by airflow separation around the perimeter of the wing thereby increasing the effective vertical take-off (VTO) load capacity of the aircraft.

Further testing was required to verify this hypothesis but the facilities available to

the Department were unable to provide the desired results. In addition to this interest, other research involving advancements in rotorblade design were ongoing within the Department and required a testing facility as well, creating a need for the following design. 


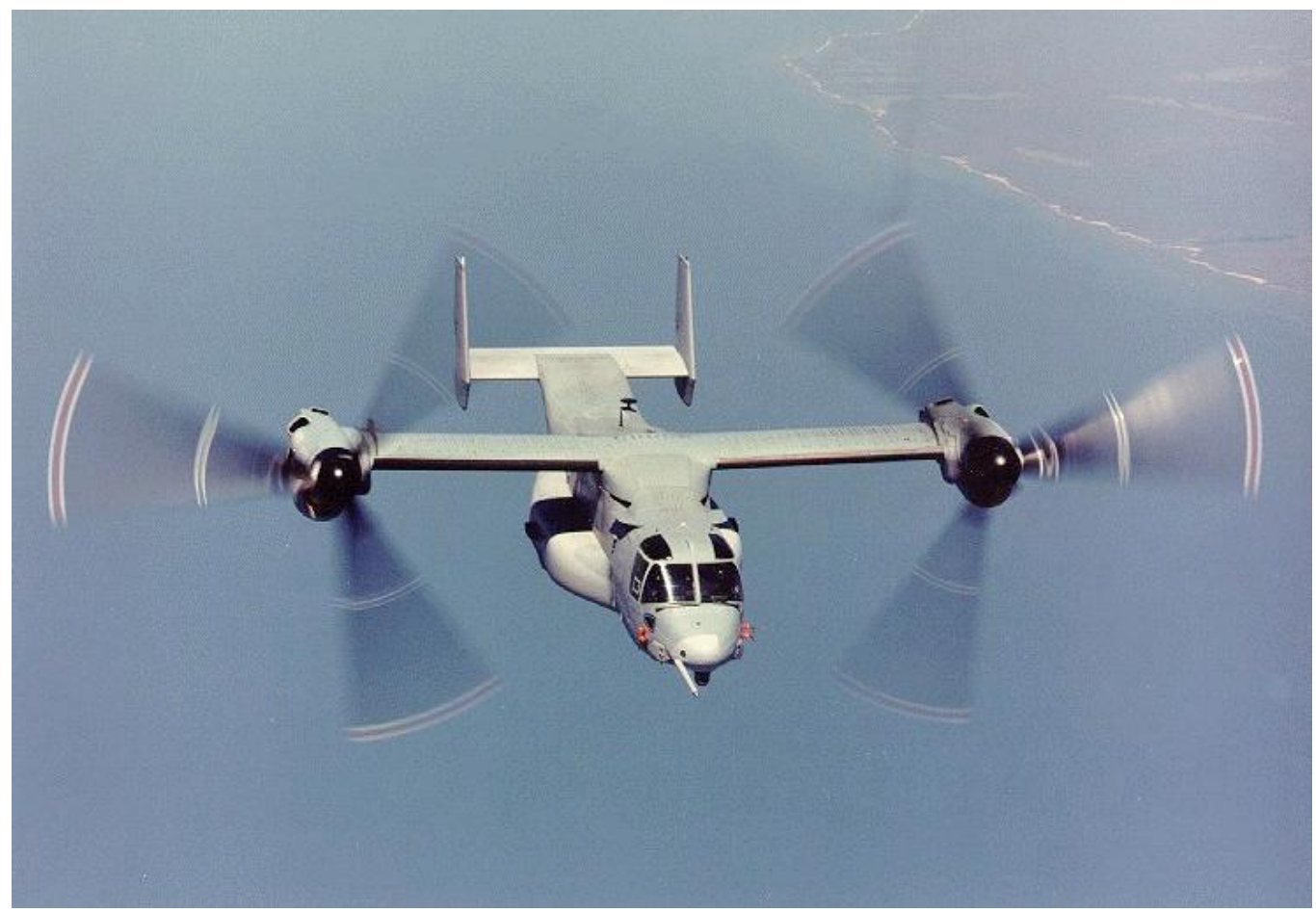

Figure 1.1 The V-22 in cruise configuration ${ }^{1}$

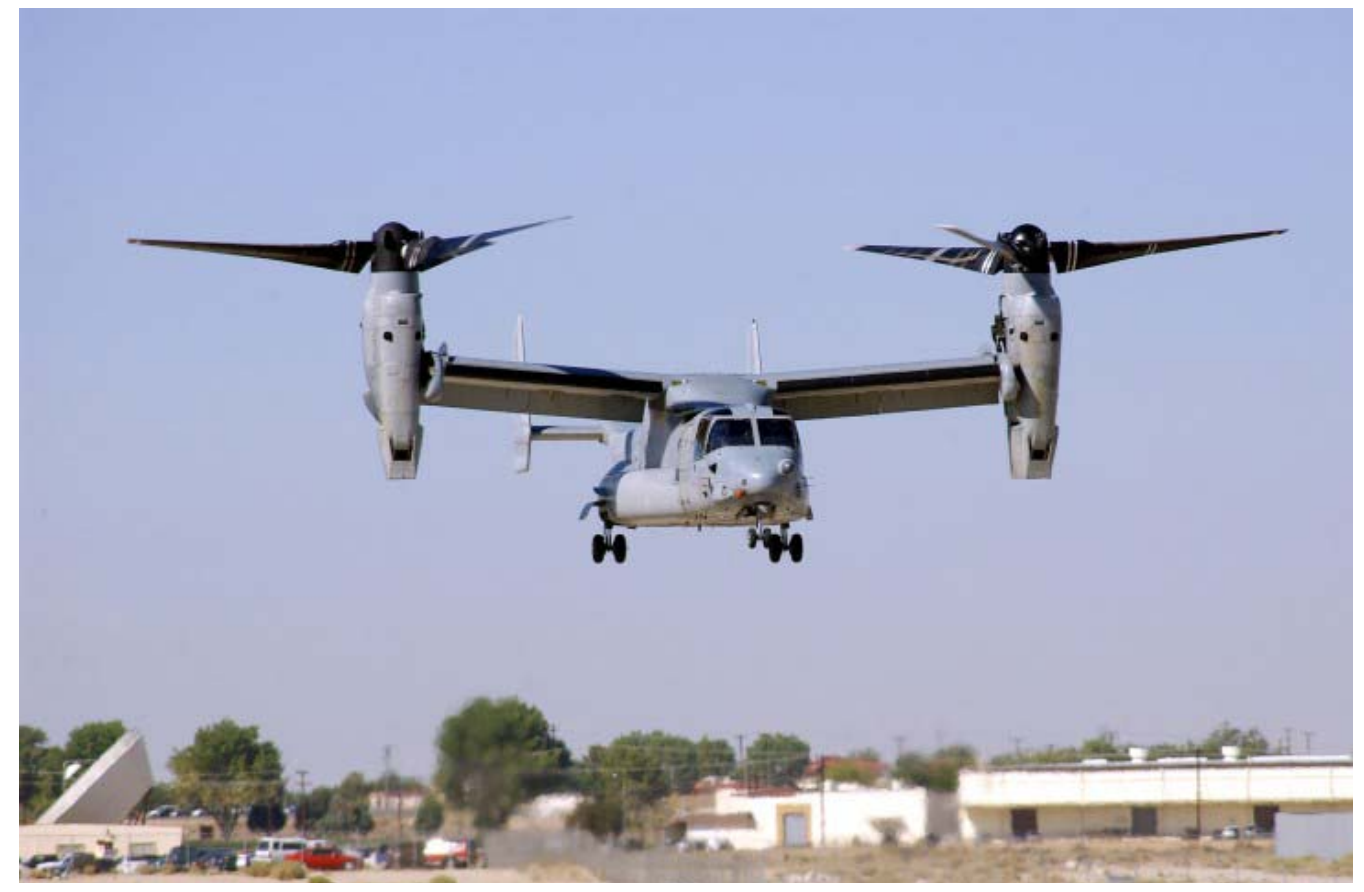

Figure 1.2 The V-22 in vertical flight mode ${ }^{1}$ 
Several operating conditions were then considered. The first is what aerodynamic environment would be required to complete the current V-22 research involving circulation control. Essentially, what scales and types of test models would be required

for dynamic scaling and were these options feasible in terms of size and cost. And second, what other types of rotorcraft research could be done if this facility was constructed.

\subsection{Objectives}

With these requirements in mind, several design goals began to take shape. First, the facility, when fitted with a properly scaled V-22 model should provide more useful data than possible with the current MAE aerodynamic facilities. This meant closer dynamic scaling, and therefore more realistic results. Secondly, it should be flexible enough in design and construction that it could be readily modified for other projects related to rotorcraft. This could include blunt body wake interaction and propeller/rotor design and testing.

In addition to the above, the construction of the facility must also be relatively cost effective and simple, allowing for quick construction and minimal financial burden on the College. And even before this, it must be a safe facility, so that usage throughout the years would not degrade safety precautions and would allow for meaningful research for years to come. 
The objectives were as follows:

1. Design a facility that can continue V-22 research with greater similarity to actual flow conditions

2. Provide testing options for other rotorcraft models

3. Allow for future propeller/ rotor research

4. Design the facility with safety in mind

With these objectives in mind, a preliminary design was created. The test apparatus upon initial consideration would have to be large in order to provide geometric scaling on the order of a quarter of the actual size of the V-22 with provisions for testing small-scale rotating propellers or rotors. 


\section{Chapter 2. Review of Literature}

\subsection{Introduction of Topics}

In order to properly design a test facility, the study of other working test facilities

must be researched. A study was done of previous testing for the V-22 and other general rotorcraft configurations. This section was broken into two main categories, small-scale and large-scale test facilities. Finally, a basic study of propeller and rotor wake characteristics was completed for comparison purposes during testing.

\subsection{Small-Scale Testing}

Often times, when aerodynamic parameter scaling is not necessary, smaller models and test apparatus can be constructed. This often occurs when research is undertaken to discover the nature of a phenomenon instead of attempting to apply the research results directly to a product.

An example of these tests conditions was found in circulation control research completed by Felker et al. [3]. Essentially, a circulation control airfoil with leading and trailing edge blowing slots was suspended above a four bladed prop rotor as seen in Figure 2.1. An additional photo can be found in the Appendix A, Figure A.1.

The test occurred at the NASA Ames Outdoor Aerodynamic Research Facility. The facility consisted of a 30 square meter concrete pad with a below ground framing system for attaching model supports. The control room with data acquisition systems was located underground, presumably for safety reasons. Another important fact is that the 
facility was remotely located away from other buildings to help eliminate aerodynamic interference other than that found from the ground plane.

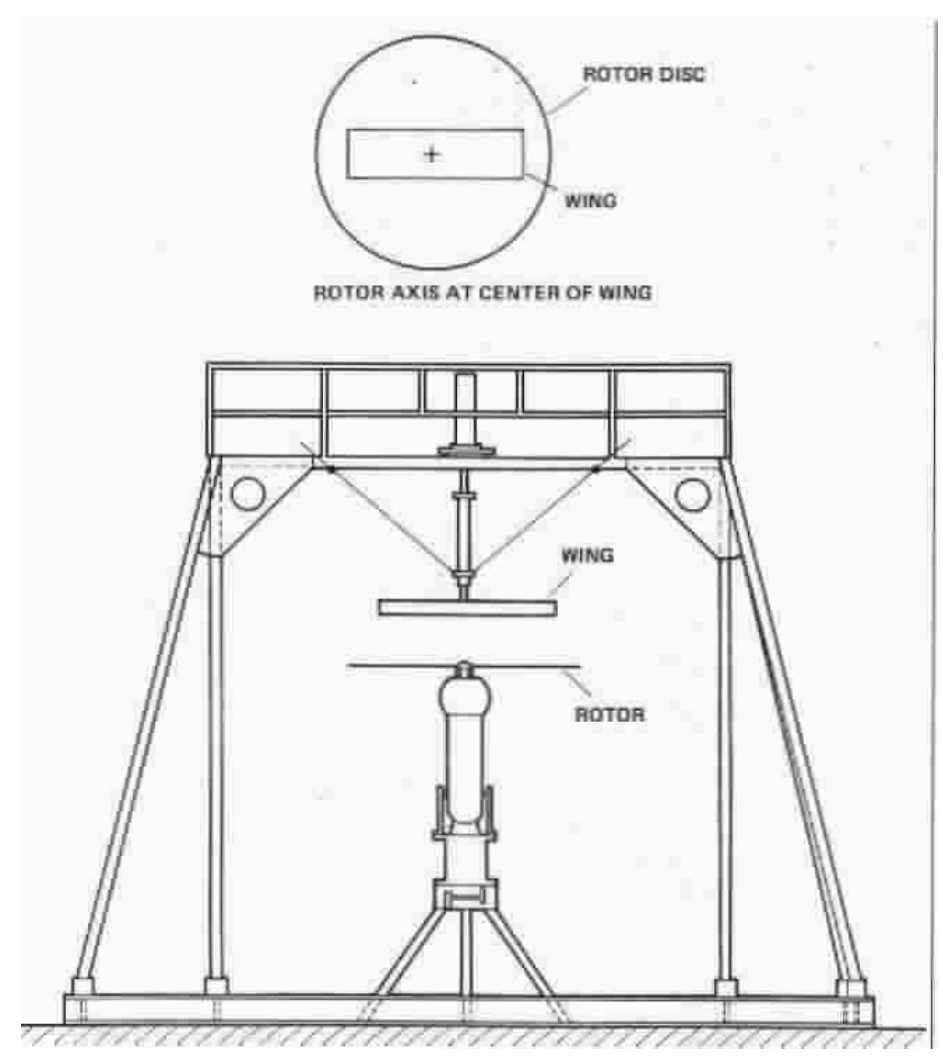

Figure 2.1 Test apparatus schematic ${ }^{3}$

The rotor used was a 0.16 scale model of the Sikorsky S-76 rotor system. The rotor blades were dynamically and geometrically similar to the blades used on the aircraft with the exception of the blade tips which were square instead of tapered and swept as found on the actual aircraft. A summary table of the rotor characteristics is found below in Table $2.1[3]$. 
Table $2.1 \quad 0.16$ scale S-76 rotor characteristics ${ }^{3}$

\begin{tabular}{|c|c|}
\hline Radius & $3.5 \mathrm{ft}$ \\
\hline Blade Chord & $0.206 \mathrm{ft}$ \\
\hline Airfoils & SC1095/SC1095R 8 \\
\hline Number of Blades & 4 \\
\hline Twist & $-10^{\circ}$, linear \\
\hline Rotor Solidity & 0.0751 \\
\hline
\end{tabular}

To clarify, the rotor solidity is defined by Equation 2.1 [4] below. It is essentially the ratio of total blade area to total disk area.

$$
\text { Rotor Solidity }=\frac{N c}{\pi R}
$$

Where $N$ is the number of blades, $c$ is the blade chord and $R$ is the blade radius. The rotor hub itself was instrumented by a six-component strain gage balance to measure steadystate rotor moments and loads. In addition, single component load cells were installed in the support struts of the rotor system as a redundant measurement of rotor thrust.

This configuration was noted to immerse the model fully in the rotor wake creating chordwise flow over the wing, but not spanwise flow as also found in tilt-rotor aircraft. Also, the distance from the rotor to the model was 0.4 rotor radii, similar to the ratio found on the XV-15 and V-22 aircraft. The model itself was instrumented along the upper and lower surfaces with chordwise pressure taps and a six component strain gage to measure forces and moments.

The advantages to a test configuration of this type are the relatively small footprint of the facility and the reduction of the chances of rotor-wash causing damage 
downstream. However, the rotor inflow area and the area above the model are both within interference regions of propeller inflow and wake regions.

\subsection{Large-Scale Testing}

The NASA Technical Memorandum, "Wing Force and Surface Pressure Data from a Hover Test of a 0.658 -Scale V-22 Rotor and Wing" [5] provided another testing concept by placing a large working model of the V-22 rotor system and wing into the 40 x 80 foot section of the NASA Ames Research Center wind tunnel in a horizontal orientation. The tunnel test section was configured in such a fashion so that free air was able to reach the rotors, minimizing inflow restrictions. Other sections of the tunnel were closed to prevent the spinning rotor from "driving" the wind tunnel and adding unwanted free stream velocity to the rotor inflow. Since only one rotor was available, testing was completed with a ground plane that helped mimic the effect of the other side of the aircraft.

The rotor system used in this case was taken from the Ames Prop Test Rig [6]. This rotor system is based on the Bell Model 300 rotor hub with the addition of considerable instrumentation to accurately measure the thrust and torque of the rotor. A summary of the rotor characteristics is found below in Table 2.2 [6]. 
Table $2.2 \quad 0.658$ scale V-22 rotor characteristics ${ }^{6}$

\begin{tabular}{|c|c|}
\hline Radius & $12.5 \mathrm{ft}$ \\
\hline Blade Chord (average) & 1.678 \\
\hline Airfoils & $\mathrm{XN}-28, \mathrm{XN}-18, \mathrm{XN}-12, \mathrm{XN}-09$ \\
\hline Number of Blades & 3 \\
\hline Twist & $-47.5^{\circ}$ (non linear, see Fig 2.3) \\
\hline Rotor Solidity & 0.114 \\
\hline Tip Speed & $790 \mathrm{ft} / \mathrm{s}$ \\
\hline
\end{tabular}

This horizontal test configuration lends itself well to V-22 research of this type because the ground plane used to simulate the fuselage and the other side of the aircraft is quite large. To suspend a model of that size and weight in a configuration as seen in [3] would be nearly impossible without the gantry holding the model influencing the test results.

The test rig at the NASA Ames research facility was used as much as possible as an example of optimum test facilities. Testing related directly to the rotor used above was completed at the Ames Outdoor Aerodynamic Research Facility [6] using the Ames Prop Test Rig (APTR) as seen in Figure 2.2. Three sets of blades, the original XV-15 blades, the advanced technology blades (ATB) for the XV-15, and the 0.658 scale blades for the V-22 were tested. In addition, ATB blades were fitted with three different tip configurations to test their effects on rotor performance. 


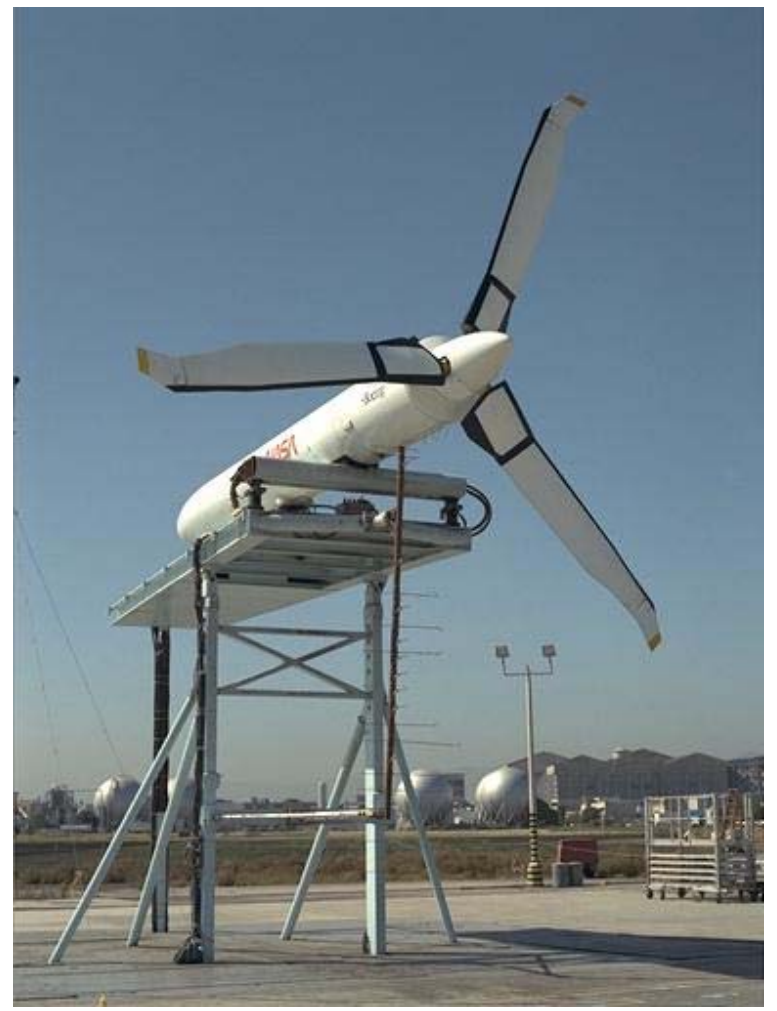

Figure 2.2 The Ames Prop Test Rig (APTR) ${ }^{7}$

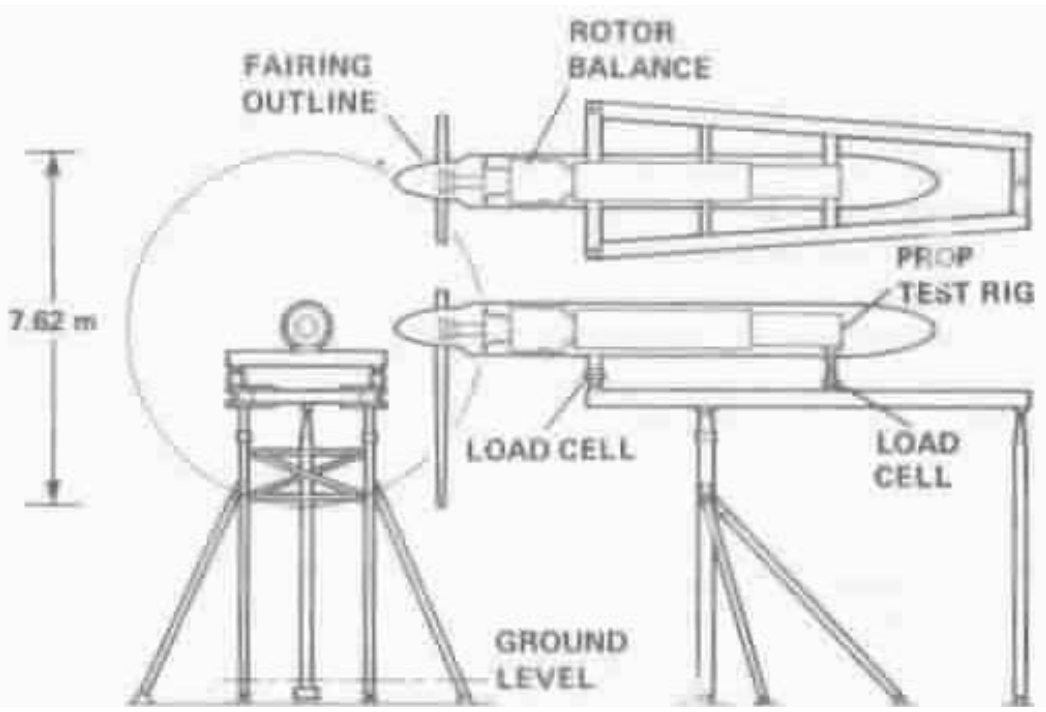

Figure 2.3 Line drawing of the APTR ${ }^{6}$ 
Felker, et al. [6] state that the APTR is capable of supplying 2494 horsepower at $625 \mathrm{rpm}$. The rotor height was 1.76 radii from the ground to minimize ground effects on the rotor. It was also mentioned that the framework of the test rig provided very little obstruction to rotor wake, ensuring high-quality isolated-rotor results. This geometric height ratio was specified for the current design.

Figure 2.3 shows the location of instrumentation for force and moment measurement. The schematic of the rotor balance, designed by J. Mayer and H. Silcox of the Boeing Vertol Co., is seen in Figure 2.4.

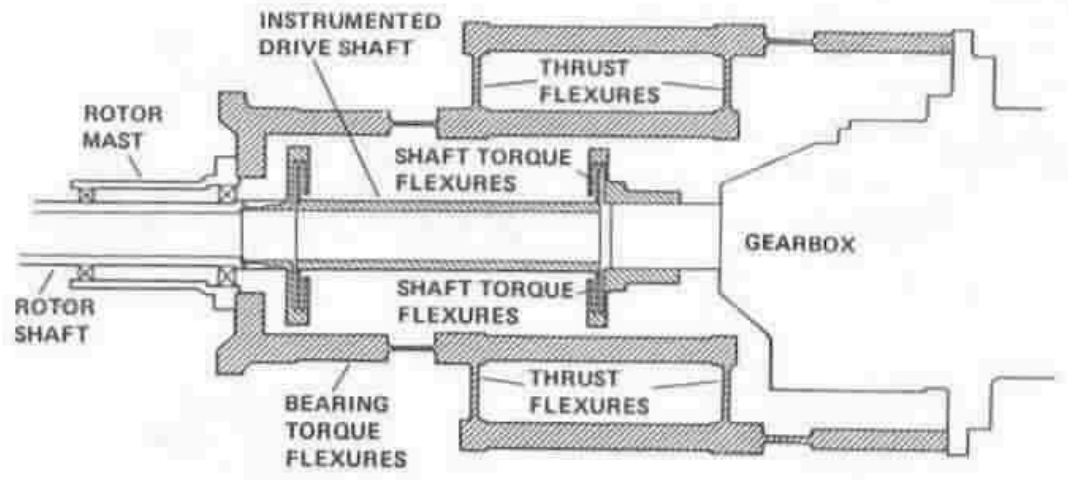

Figure 2.4 Rotor force balance schematic ${ }^{6}$

It is stated that there are two paths for the thrust load to travel; through the rotor balance and through the instrumented drive shaft. Felker et al. [6] indicate that the drive shaft is "compliant" in the axial direction and state that it only carried $3 \%$ of the rotor thrust. The rotor thrust balance was found to be accurate to within $11.24 \mathrm{lb}$ up to 11,240 lb $(0.1 \%)[6]$. The instrumented driveshaft shared the same axial force accuracy when compensated for torque interaction. The torque measurement was accurate to within 4.8 $\mathrm{lb} \cdot \mathrm{ft}$ which was stated as less than $0.3 \%$ of the maximum torque capacity of the shaft of 
$1953 \mathrm{lb} \cdot \mathrm{ft}$ [6]. Bearing torque was measured by subtracting the torque measured from the bearing torque flexures from the shaft torque.

A redundant set of load cells was installed as a check to the main rotor balance [6]. Both systems were monitored at all times to ensure their working condition. Overall accuracy was found to be within $45 \mathrm{lbs}$ or $0.3 \%$ of the maximum thrust generated and within $4.8 \mathrm{lb} \cdot \mathrm{ft}$ or $0.3 \%$ of the maximum torque generated [6]. This overall force measurement scheme was seen as an example of what could be implemented in the future design of the Department's facility.

In addition to the force and torque measurements, a wake rake as seen in Figure 2.5 was implemented behind the rotor in an attempt to characterize wake velocity profiles and rotor tip vortex geometry. The rake placement was 0.4 radii behind the rotor with an unstated number of probes.

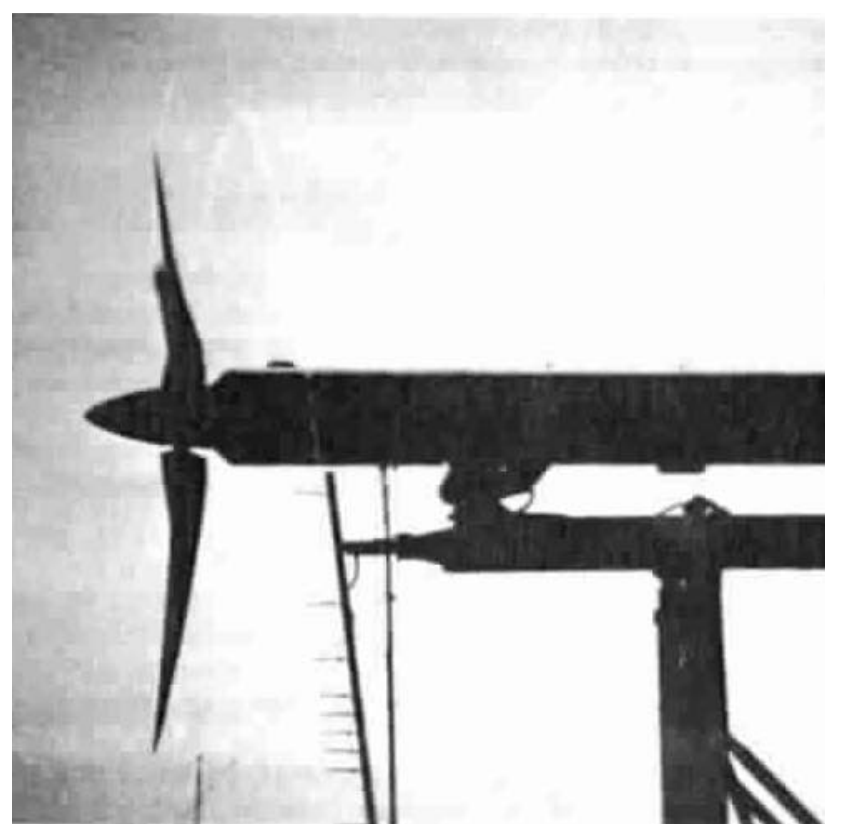

Figure 2.5 Wake rake implementation for wake measurement ${ }^{6}$ 
Since testing was done outdoors, weather effects were present. To try and mitigate the effects of wind, testing was limited to days when the wind velocity was less than three knots. Wind speed and direction was measured from a sensor located 16 rotor radii upstream from the intake side of the rotor, at the rotor's height and at a $45^{\circ}$ angle to the rotor axis. A wind correction equation was derived by W. Johnson of NASA Ames and M. A. McVeigh of Boeing Vertol Co. for the power coefficient as seen in Equation 2.2 and $2.3[6]$.

$$
\begin{gathered}
C_{p, \text { Corrected }}=C_{p}-\left(\mu_{z} C_{T}-\mu_{x} C_{H}\right)-K\left(\lambda_{i}-\lambda_{H}\right) C_{T} \\
\lambda_{H}{ }^{4}=\lambda_{i}{ }^{2}\left\lfloor\mu_{x}{ }^{2}+\left(\mu_{z}+\lambda_{i}\right)^{2}\right\rfloor
\end{gathered}
$$

Where $C_{P}$ and $C_{T}$ are the power and thrust coefficients respectively, $\mu_{z}$ is the axial wind velocity ratio, axial wind/ $V_{T i p}, \mu_{x}$ is the lateral wind velocity ratio, lateral wind/ $V_{T i p}, K$ is the ideal power ratio to actual power ratio, $\lambda_{i}$ is the ideal induced velocity ratio, $V_{i} / V_{H}$, and $\lambda_{H}$ is the ideal induced velocity ratio, $V_{i} / V_{H}$. This wind correction may have future applications to test results when wind conditions at the planned test site are evaluated.

Rotor blade testing related directly for application to helicopters, the UH-1H (Huey), was completed by Mantay, et al. [8] using the Langley whirl-tower. The testing involved a new rotor tip configuration (Ogee) meant to increase the efficiency of the rotor while reducing the recognizable sound a $\mathrm{UH}-1 \mathrm{H}$ makes during flight. The tower was used to "verify the structural integrity and the Ogee design as well as provide performance, acoustics, and flow visualizations." A schematic of the tower is seen in Figure 2.6. This 
was an example of the vertical test configuration. A summary of the whirl-tower characteristics is found in Table 2.3 [8].

Table 2.3 Langley whirl-tower characteristics ${ }^{8}$

\begin{tabular}{|c|c|}
\hline Power and Dimensions & Value \\
\hline Rotor Height from Ground & $42 \mathrm{ft}$ \\
\hline Available Power & $1500 \mathrm{hp}$, Electric \\
\hline Instrumentation & Description \\
\hline Thrust & Load cells \\
\hline Torque & Strain-gage bridge \\
\hline Angular Velocity & Photo counter \\
\hline Thrust Correction & Strain-gage bridge \\
\hline Collective Pitch Angle & Potentiometer \\
\hline Ambient Temperature & Thermocouple \\
\hline Atmospheric Pressure & Barometer \\
\hline Blade loads & Strain-gage bridge \\
\hline
\end{tabular}

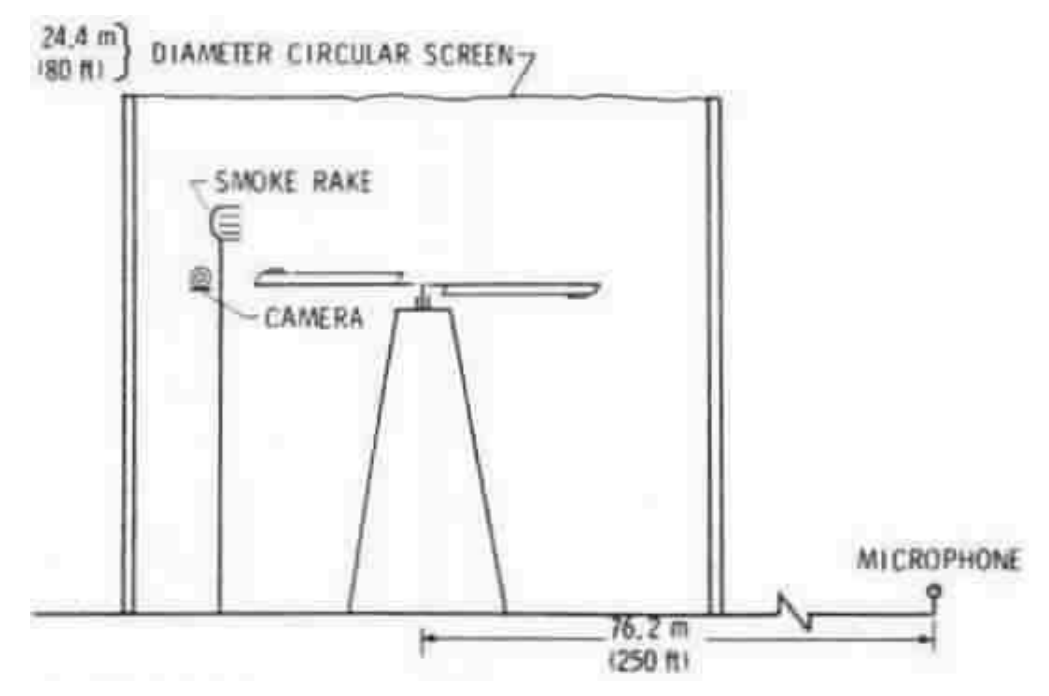

Figure 2.6 Langley whirl-tower schematic ${ }^{8}$

Mantay et al. [8] did not state whether the testing was to determine hover characteristics in ground-effect (IGE) hover or out of ground-effect hover (OGE). With a rotor height of only $42 \mathrm{ft}$, blowing downward would place the rotor in IGE hover. It was assumed that the test stand was blowing upward, eliminating the ground interference. 
One of the more interesting static thrust test facilities as found in Figure 2.7 was constructed at Texas A\&M University [9]. At the time, the drive for research was that extensive hovering helicopter rotor research had been completed but very little had been done on propellers in static conditions. Realizing that VTOL rotorcraft may use rotors that are a balance between rotors and propellers, a test stand was created to test propellers and early VTOL rotors in this flight condition.

The test-stand implemented two 275 horsepower marine engines coupled through a differential to power the test propeller. The differential allowed there to be differences in motor rpm during startup. The drivetrain design also featured the use of an over-run clutch that allowed the propeller to spin freely in the event that a mechanical failure occurred that would jam the propeller driveshaft causing damage to the propeller assembly or drive system. The propeller coupler was instrumented with strain gages for thrust and torque measurement and a slip ring comutator relayed data to the acquisition system. This measurement configuration was seen as a possible solution to the current facility.

A moveable static pressure probe array as seen in Figure 2.8 was used to capture various wake characteristics at different locations and orientations, providing information about the axial and tangential flow velocities upstream and downstream of the propeller. The entire probe assembly was motorized and instrumented such that the probe location was displayed in the control room in inches and fractions of inches. There were also variable speed controls to allow fast or slow traverse of the probe. It was reported that the probe could be placed to within 1/16 inch of any location both in the radial and axial direction [9]. This illustrated an interesting measurement option for the current design. 


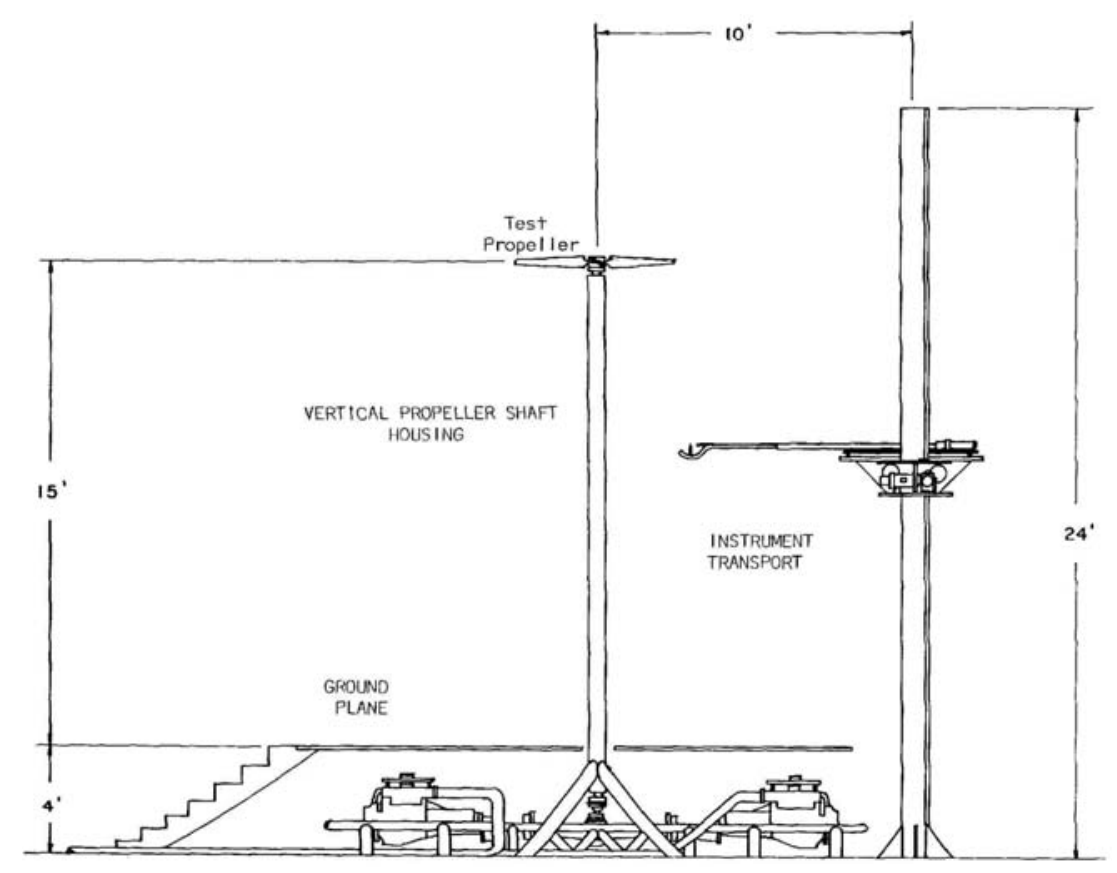

Figure 2.7 Texas A\&M static propeller test facility ${ }^{9}$
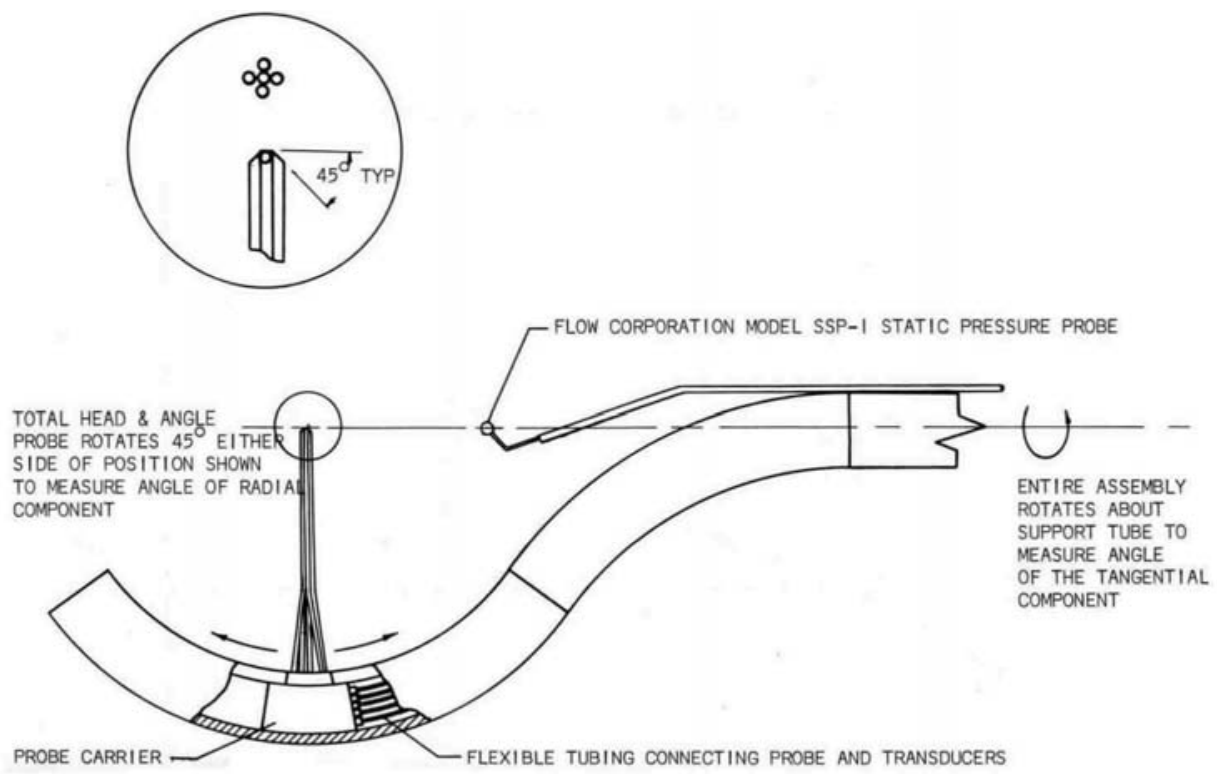

Figure 2.8 Pressure probe schematic ${ }^{9}$ 


\subsection{Propeller and Rotor Wake Characteristics}

Inflow and outflow characteristics of the propeller can affect test results in different ways depending on the testing undertaken. As an example, if one tests a helicopter rotor in a vertical configuration with thrust facing downward, the thrust interaction with the ground will reduce the power required to produce that thrust [4]. If testing the performance of a rotor in the same configuration with thrust facing upward, the height of the rotor above the ground must be such that the inflow characteristics are not compromised by the ground plane. This is often why whirl-stands are typically located a distance above the ground and are mounted such that there are as little restrictions to inflow and outflow as possible. In addition, the axial and tangential flow velocities found from testing can provide information about the efficiency of the rotor [6].

Beginning with the work of Brusse et al. [9] the axial flow velocities of one of the propellers tested is found in Figure 2.9. The axes of the graphs are $\bar{w}$ and $\bar{r}$, which are defined as $w / \Omega r_{p}$ and $r / r_{p}$ respectively where $w$ is the flow velocity in the axial direction in $\mathrm{ft} / \mathrm{s}, \Omega$ is the angular velocity of the propeller in rpm, $r$ is the radial coordinate and $r_{p}$ is the radial coordinate along the propeller. Note the wake contraction that begins at $\bar{z}=$ $+1 / 10$ and continues to $\bar{z}=+2$ where $\bar{z}$ is equal to the distance below the propeller divided by the radius of the propeller. This phenomenon is further described in Chapter 3 . 


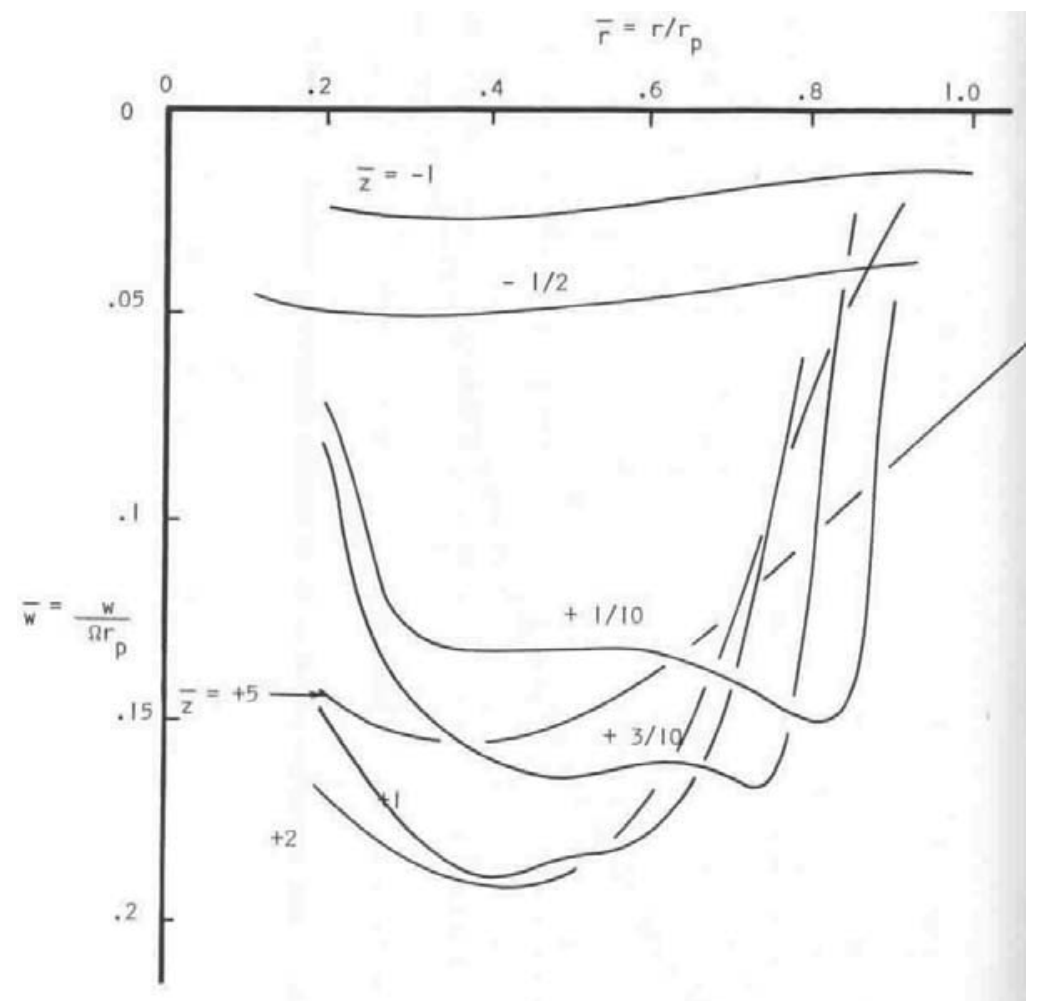

Figure 2.9 Axial flow velocities of the propeller ${ }^{9}$

For comparison, the axial flow velocities from [6] are presented in Figure 2.10 for the 0.658 scale $\mathrm{V}-22$ rotor. Note that the non-dimensionalization of the velocities is slightly different for the $\mathrm{V}-22$ case where the ratio of $V / V_{H}$ is used. $V$ is the downwash velocity and $V_{H}$ is the ideal induced velocity defined by $V_{H}=V_{t i p} \sqrt{\frac{C_{T}}{2}}$, where $C_{T}$ is the thrust coefficient. The velocity was measured at a distance of 0.4 rotor radii behind the rotor which is nearest to $\bar{z}=+3 / 10$ from [9]. 


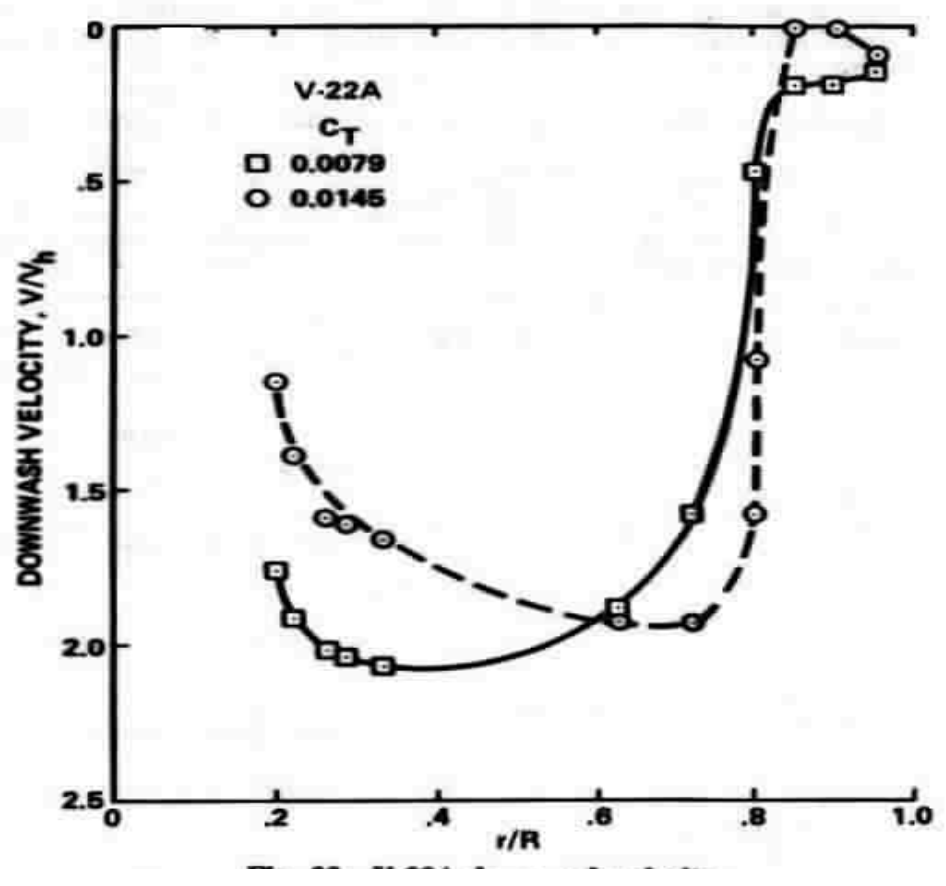

Figure 2.10 $0.658 \mathrm{~V}-22$ rotor axial velocity ${ }^{6}$

There are differences in the wake characteristics with the most obvious occurring from 0.8 to 0.6 of the radius where the $\mathrm{V}-22$ blade shows a marked increase in velocity up to $\mathrm{r} / \mathrm{R}$ of 0.75 and a drastic drop off thereafter while the propeller velocity troughs and peaks near the same radius ratio. It was stated in [6] that a more uniform distribution of velocity across the radius as seen in Figure 2.10 compared to Figure 2.9 indicated the greater efficiency of the V-22 rotor when compared to the propeller. There are some similarities in that the majority of axial velocity and therefore thrust is generated from 20 to 80 percent of both the propeller and rotor. This range can be explained by the loss of lift due to low blade speed at the root and by separation and vortex losses near the tips of the blades [4].

For the purpose of the proposed facilities' frame design, intake and exhaust flow patterns of the propeller became important because the structural members can affect the 
flow characteristics. In order to minimize this effect, structural supports must be far enough away from the propeller to not cause blockage issues but still be able to maintain structural integrity. Castles [10] created a basic method of computing these streamlines for a rotor in hover or low-speed vertical ascent.

Castles' analysis predicted upflow regions around the propeller with velocities on the order of a quarter of the downwash velocities 1.2 radii from the rotor disk. These upflow velocities are found to drop off rapidly when moving farther from the rotor radius as seen in Figure 2.11.

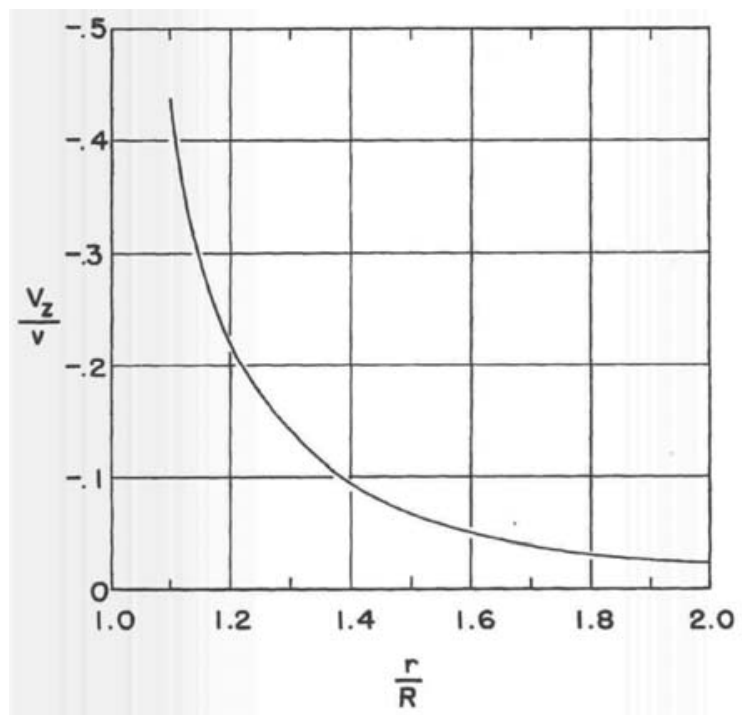

Figure 2.11 Upflow velocity at various distances from the rotor ${ }^{10}$

This information became valuable to the proposed frame design as seen in Chapter 3.8 in an attempt to reduce frame interference with propeller inflow. 


\section{Chapter 3. Aerodynamic Design}

\subsection{Initial Use Considerations}

The first consideration given to the aerodynamic design of the whirl-stand were the ideal conditions for scale model V-22 testing. The flight condition of interest at this stage of research is hover.

This design section, although created for V-22 downwash testing can be generalized for other testing purposes such as blunt-body wake interaction measurement by relating the geometry and scaling parameters involved to other testing. Of course, experimental details would dictate various changes in test apparatus and conditions but the scaling of models to freestream conditions is fundamental to effective testing [11].

\subsection{Scaling Parameter Calculation}

There are several scaling parameters often used in wind tunnel testing. The three primary parameters used most often are the Reynolds number, Mach number and Froude number [11] which are found below in Equations 3.1, 3.2, and 3.3 respectively [11].

$$
\begin{aligned}
& \operatorname{Re}=\frac{\rho V L}{\mu} \\
& M=\frac{V}{a} \\
& F r=\sqrt{\frac{V^{2}}{L g}}
\end{aligned}
$$


For these equations, $\rho$ is the density of air, $V$ is the average free stream velocity, $L$ is the characteristic length (for this experiment, the chord length), $a$ is the speed of sound, $g$ is gravity, and $\mu$ is dynamic viscosity.

The Froude number is important in instances where dynamic model movements and aerodynamics are coupled [11]. Since the planned testing involves static models in the hover configuration, the Froude number was an unimportant scaling parameter. The Mach number can be a critical factor in transonic and supersonic flight regimes [11], but average outflow velocities for propellers and rotors based on momentum theory calculations from Johnson [4] are approximately 14-20 percent of the speed of sound at sea level which are low enough to be considered incompressible flow conditions. The Reynolds number, therefore, was the most important similarity parameter [11].

In order to match the Reynolds number as closely as possible between the actual aircraft and the experimental model, sufficient free stream velocity and model size is required. In order to determine the approximate downwash velocity of a V-22 Osprey in hover, momentum theory was used. Momentum theory is the most simplified method for determining downwash [4]. It assumes that a propeller or rotor is “ $\ldots$ an actuator disk, which is a circular surface of zero thickness that can support a pressure difference and thus accelerate the air through the disk." [4].

This theory does not account for various propeller or blade geometries, wake geometry or the unsteady and turbulent nature of real propeller or rotor wakes [4]. It instead represents an idealized scenario where thrust is equally distributed across the surface of the disk [4]. Although it is farther removed from reality than other more 
complex theories, it provides a quick method of determining the best-case average wake velocity for a given propeller diameter if the airfoil characteristics of the blade are unknown [4].

Since the Bernoulli equation is based in momentum theory, it can be used to relate the work done on the fluid to produce a velocity. Equation 3.4 was derived from Bernoulli for this purpose to determine approximate outflow velocities. This equation assumes that the wake area stays constant before and after the disk and that there are no losses, meaning all work input is transferred to creating the pressure difference.

$$
V_{\text {out }}=\sqrt[3]{\frac{2 \dot{W}}{\rho A}}
$$

$\dot{W}$ is the rate of work done to the fluid, $\rho$ is the density and $A$ is the rotor disk area. However, this estimation does not account for wake contraction that occurs in an actual wake due to the pressure difference created by the high velocity air exiting the disk. Due to the simplifications in the derivation of Equation 3.4, the wake velocity at the disk is over predicted.

For a more exacting estimation, Equation 3.5 was found from [4]. Equation 3.5 is the momentum theory equation for downwash velocity at the rotor disk where $v$ is the disk velocity and $T$ is the thrust. In Equation 3.6 [4], the far wake downwash velocity, $w$, is doubled due to a decrease in wake area by $1 / 2$. 


$$
\begin{aligned}
& \frac{P}{T}=v=\sqrt{\frac{T}{2 \rho A}} \\
& w=\sqrt{\frac{T}{\frac{1}{2} \rho A}}
\end{aligned}
$$

The far wake is defined as a distance anywhere from $25-80 \%$ of the rotor radius below the disk [12]. The wing of the V-22 is located approximately 8 feet from the rotor making it $43 \%$ of the rotor radius below and within the distance considered immersed in the far wake.

A final momentum theory equation, Equation 3.7 from [4] was used that accounted for swirl induced in the wake. This correction included the thrust coefficient, Equation 3.8 [4], and increased the induced power estimation and outflow velocity by approximately $2 \%$ [4].

$$
\begin{gathered}
\frac{P}{T}=v=\frac{\sqrt{\frac{T}{2 \rho A}}}{\sqrt{1+C_{T} \ln \frac{C_{T}}{2}}} \\
C_{T}=\frac{T}{\rho A(\Omega r)^{2}}
\end{gathered}
$$

For Equation 3.8 [4], $\Omega$ is the angular velocity in $\mathrm{rad} / \mathrm{s}$, and $r$ is the disk radius. Rotor dimensions and disk area were found from Jane's All The Worlds Aircraft [13], as well as the rated horsepower for a single engine with values of $1134 \mathrm{ft}^{2}$ and $5890 \mathrm{hp}$ respectively. $10 \%$ of the rated power was subtracted to account for various in-aircraft 
losses such as power generation and mechanical losses [4]. This brings the available horsepower down to 5301. The thrust was found from the maximum vertical takeoff weight of $47500 \mathrm{lbs}$ and divided by two for each rotor to reach a thrust per rotor of 23750 lbs. Rotor angular velocity was converted from the tip speed of the rotors during hover which is $800 \mathrm{ft} / \mathrm{s}$ to a value of $44.41 \mathrm{rad} / \mathrm{s}$. Air density was found for the elevation of the proposed test facility with a value of $0.002281 \mathrm{slug} / \mathrm{ft}^{3}$. A summary of the rotor characteristics used for the calculations is found in Table 3.1 [13].

Table $3.1 \quad$ Summary of V-22 rotor characteristics ${ }^{13}$

\begin{tabular}{|c|c|}
\hline Diameter & $38 \mathrm{ft}$ \\
\hline Number of Blades & 3 \\
\hline Disk Area & $1134 \mathrm{ft}^{2}$ \\
\hline Tip Speed & $800 \mathrm{ft} / \mathrm{s}$ \\
\hline $\mathbf{C}_{\mathbf{T}}$ & 0.0129 \\
\hline
\end{tabular}

The thrust coefficient of the V-22 rotor given these parameters and Equation 3.8 [4] was found to be 0.012896 . The thrust coefficient was then substituted into Equation 3.7 [4] and the outflow velocity $v$ was solved for to yield an at-disk velocity of $70.07 \mathrm{ft} / \mathrm{s}$. This value was then multiplied by two for the far wake region, and the outflow velocity was calculated to be $140.15 \mathrm{ft} / \mathrm{s}$ or $95.6 \mathrm{mph}$.

With the approximate airflow velocities found for the rotor, characteristic length of the wing was decided to be the chord length of the V-22 with the flap extended to 67 degrees as would be the case if one simplified the geometry to a flat plate oriented perpendicular to the flow. With a wing chord length with flaps extended to 67 degrees of $7.39 \mathrm{ft}$ and a dynamic viscosity of $3.72 \times 10^{-7} \mathrm{lbf} \cdot \mathrm{s} / \mathrm{ft}^{2}$ a Reynolds number of $6.44 \times 10^{6}$ was found. 


\subsection{Reynolds Number Discussion}

Most times in wind tunnel aerodynamic testing, exact Reynolds number matching is impossible due to a host of difficulties such as the capabilities of facilities, model geometry, or cost limitations [11]. Often times, a suitable percentage of the Reynolds number can be achieved in order to obtain similar model response that can be corrected or scaled to match actual aircraft response [11]. If the Reynolds number is known and is within an acceptable percentage, correction factors can be applied. If not, model response can be seen as similar to the actual aircraft, and can in the worst case be used in parametric studies. Actual surface pressures, loads, moments, etc. can not be directly found from the model to scale up to the full sized aircraft in this case [11].

Upon consideration of the size of the given aircraft and the scope of the proposed test facility, an exact Reynolds number match would be nearly impossible due to the large size of the model and the facilities required to test a configuration of that size. The decision was then made to attempt to achieve a certain percentage of the actual Reynolds number. A goal was then set to design the facility and test conditions to achieve at least half the actual Reynolds number which means a model Reynolds number of at least $3.22 \times 10^{6}$.

\subsection{Scale Model Configuration Selection}

Ideally, a full scale model would be constructed and tested with a full scale rotor. However, acquisition of a $38 \mathrm{ft}$ rotor and a $5890 \mathrm{hp}$ turbine engine, combined with the model building made this scenario unrealistic. The only way to practically obtain useable 
results was to scale the model down to an appropriate size to reach $50 \%$ of the actual Reynolds number.

Many times, by splitting the model in half and replacing the half with a "ground plane", model cost and size can be reduced while not significantly affecting model response. The ground plane can also act as a mirror, simulating the other side of the aircraft and increase effective Reynolds number of the model [11].

It was therefore decided that a half model with a ground plane could provide a more realistic solution to the problem of large, cumbersome models. Vertically mounted propellers as seen in [3] and [9] were considered, but rejected due to the need for large gantry with instrumentation for models. Therefore a horizontal configuration as seen in Figure 3.1 was chosen. This allows for ground mounting of the model with the advantage that in-ground effect hover and out of ground effect hover conditions can be studied with the use of a wind barrier behind the model.

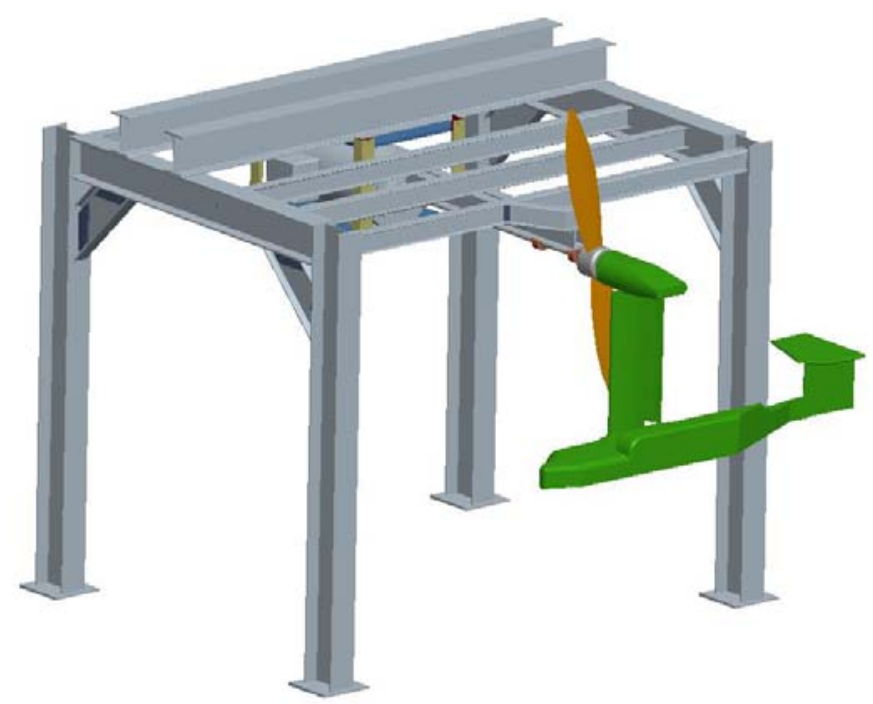

Figure 3.1 Test stand model configuration 


\subsection{Rotor Simulator Selection}

The next phase of design was to determine whether it was possible to obtain direct geometric scaling of the model between the rotor and wing from the original and still achieve the acceptable Reynolds number. Before the scale of the model could be decided, achievable propeller outflow velocities had to be calculated.

\subsubsection{Initial Rotor Configuration Consideration}

Research was done in the possible construction of scaled V-22 rotor blades to be used for testing. This would involve reducing the dimensions of the V-22 rotor while making corrections to the geometry to maintain the aerodynamic characteristics of the outflow. This would be the optimum case, as it would provide the most realistic downwash characteristics applied to the model [11].

However, rotor rpm for the dynamically scaled rotor would need to be increased above the full-scale operating rpm to produce the maximum wind velocity to increase Reynolds number up to the maximum achievable value. This would increase the number of pressure pulses over the wing surface per unit of time due to the blade passing overhead. In addition, designing and testing of the blade would add considerable cost and time to the project. This option was dropped from the current design process and was considered an option for later study. 


\subsubsection{Realistic Rotor Simulator Options}

The most widely available and perhaps most tested means of generating thrust with fluid is the propeller. Civil aviation propellers were looked to as a way to simulate the V-22's main rotors. It was thought that using pre-existing technology would provide a solution to the necessity of achieving acceptable Reynolds number while simulating the aerodynamic rotor effects of the downwash impinging on the wing.

It has been recognized that propeller wake geometry will be different that that found on the V-22. Mostly, the V-22 has considerable twist near the root of its blades to maximize the efficiency of the blade in regions where blade velocity is low [6]. Propeller twist is generally more linear [9] and produces less rounded velocity profiles as seen in the comparison of Figures 2.11 and 2.12.

It is unknown exactly how this will affect test results, though most likely, downwash velocity profile of the propeller from $0-20$ percent of the blade will be considerably lower than for a dynamically scaled blade due to the lower root twist of the propeller. Pressure and velocity readings under that section of blade overlap are recommended to be treated with scrutiny [12] and perhaps correction factors can be applied after results from testing are compared to other, larger scale research.

\subsection{Aircraft Propeller Choices}

Research of smaller civil passenger aircraft led to the choice of the Cessna A185E series as seen in Figure 3.2 due to its relatively large single propeller and realistic aircraft power. It was found to have a propeller diameter ranging from $82-88$ inches with an installed Continental IO-520-D engine producing $300 \mathrm{hp}$ at takeoff. [15]. The largest 
installed prop, 88 inches, helps model scaling because as the model size increases in proportion to the propeller, so does the Reynolds number, and therefore the accuracy of the results. In addition, since this aircraft entered the market in 1965, its operational history and maintenance are well documented. A number of these aircraft are still in service and therefore their parts can be obtained at reasonable cost.

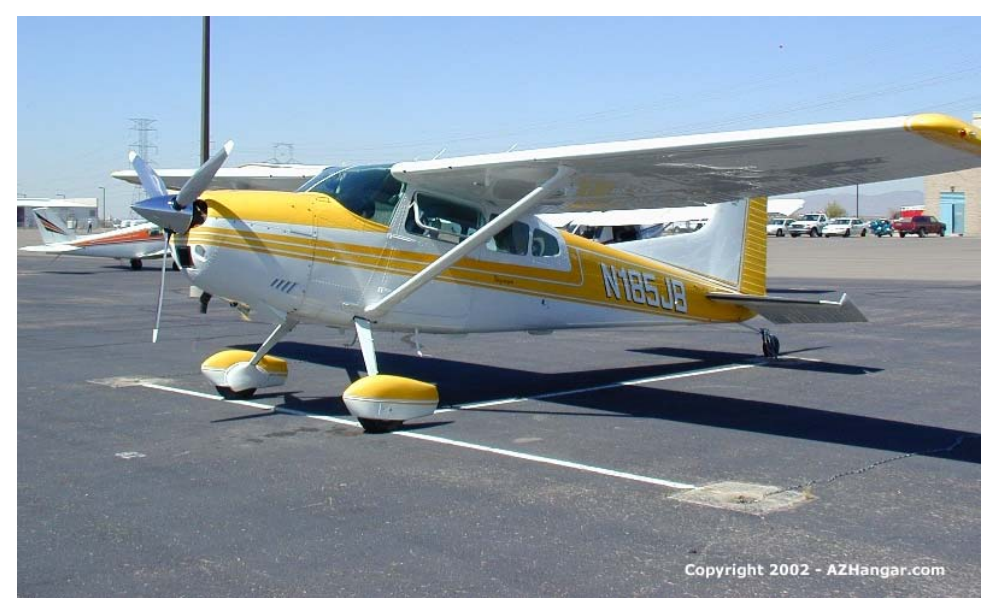

Figure 3.2 Cessna $185^{14}$

P. Ponk Aviation [16] conducted static thrust tests for this aircraft with various McCauley-Textron propellers to determine the effectiveness of various propeller sizes, configurations, and rpm. P. Ponk Aviation was contacted to determine the test conditions under which the data was taken but none was available. However, the thrust data collected was found to be reasonable based on the power output of the test plane and the diameters of the propellers tested when compared to momentum theory.

The outflow velocity calculations from Chapter 3.2 were repeated for the McCauley 2A34C66, a two-bladed, 88 inch diameter propeller. Given a thrust value of $1019 \mathrm{lbs}$, an angular velocity of $282 \mathrm{rad} / \mathrm{s}$, a disk area of $42.42 \mathrm{ft}^{2}$, and horsepower input 
of 300 , a thrust coefficient of 0.0099 was found. A summary table of the propeller characteristics calculated can be found in Table 3.2.

Table 3.2 McCauley 2A34C66 propeller specifications

\begin{tabular}{|c|c|}
\hline Diameter & $7.33 \mathrm{ft}$ \\
\hline Number of Blades & 2 \\
\hline Disk Area & $42.2 \mathrm{ft}^{2}$ \\
\hline Tip Speed (at 2700 rpm) & $1035 \mathrm{ft} / \mathrm{s}$ \\
\hline $\mathbf{C}_{\mathbf{T}}$ & 0.0099 \\
\hline
\end{tabular}

The outflow velocity was then calculated with an at-disk velocity of $74.7 \mathrm{ft} / \mathrm{s}$ and a far wake velocity of $149.4 \mathrm{ft} / \mathrm{s}$. Note that similar propellers in that size range will produce nearly that same velocity and that McCauley-Textron propellers provide a convenient option due to their ubiquity.

In addition to the outflow velocities, the power and torque requirements of the propeller were calculated to facilitate sizing of a proper drive motor. Equation 3.9 [17] was used to determine the torque required for the given power and rpm of 300 and 2700 respectively for the Continental IO-520-D engine during takeoff.

$$
\text { Horsepower }=\frac{\text { Torque } \times \text { RPM }}{5252}
$$

The result is that a minimum continuous torque of $583 \mathrm{lb} \cdot \mathrm{ft}$ at $2700 \mathrm{rpm}$.

\subsection{Model Scaling Discussion}

With a propeller outflow velocity found, a model Reynolds number was calculated. A spreadsheet was created that compared model Reynolds number based on the propeller outflow velocity to actual V-22 Reynolds number. 
It was found that there was no possibility of direct geometric scaling between the propeller and model due to the fact that a propeller out-flow velocity of $149.4 \mathrm{ft} / \mathrm{s}$ would require a 0.948 scale model for Reynolds number matching. This meant $36 \mathrm{ft}$ diameter propeller would need to be used. This was beyond the limits of the intended facility.

Due to these limits, the minimum acceptable Reynolds number chosen from Section 3.3 of $3.22 \times 10^{6}$ was used to determine the minimum model size to achieve this Reynolds number given the propeller outflow velocity. This led to the increase of the size of the model from 19.6 percent for direct geometric scaling with an 88 inch diameter propeller to 47.3 percent of the actual size, neglecting the scaling ratio between propeller and wing. Table 3.3 shows the V-22 wing model dimensions now needed for a Reynolds number of $3.66 \times 10^{6}$.

Table 3.3 Wing model dimensions for a Reynolds number of $3.66 \times 10^{6}$

\begin{tabular}{|c|c|}
\hline Scale & 0.473 \\
\hline Chord & $3.496 \mathrm{ft}$ \\
\hline Span & $8.99 \mathrm{ft}$ \\
\hline Thickness & $0.905 \mathrm{ft}$ \\
\hline
\end{tabular}

In the event that Reynolds number requirements are relaxed, a smaller model can be constructed that matches the scale relation between the rotor and wing more correctly. However, the introduction of rotor wake characteristics is an improvement over previous testing done by Riba [2]. 


\subsection{Aerodynamic Structure Design}

In order to provide quality testing conditions for both downwash simulation and rotor blade testing, the geometry of the frame had to be designed in such a fashion as to reduce the obstructions to the inflow of the propeller thereby reducing thrust and power variations as found in research by Gentry et al. [18]. Brusse et al. [9] and Castles [10] provided experimental and computational means of determining the location of inflow streamlines. Figures 2.9 and 2.11 provide the basic limitations.

In Figure 2.11 the axial inflow velocities of the propeller are found at 1.0 radii and 0.5 radii. At 1.0 radii behind the propeller, the inflow velocity is small enough, on the order of $20 \%$ of the wake velocity measured nearest the propeller to consider obstructions at that distance negligible. At 0.5 radii behind the propeller, the percentage increases to $40 \%$ of the near wake velocity. There would be effects from frame members if placed at this distance.

The other two geometric considerations are the width of the frame away from the propeller and the height of the propeller from the ground plane. Referring to Castles [10], Figure 2.13, the placement of forward support members if in the plane of the propeller should be located at least 1.5 rotor radii away to place them in an area of $7 \%$ wake velocity. Placement behind the propeller plane would reduce frame support wake immersion as well.

Finally, the minimum propeller height was found so that ground effects do not influence the propeller during testing. Referring to Felker et al. [6], the center of the rotor was placed 1.76 radii above the ground placing it in a region of velocity on the order of 
$5 \%$ of the wake velocity according to Figure 2.13 . Therefore, the minimum propeller height should be at least 1.76 radii above the ground plane.

However, from Section 3.7, to accommodate a full-span 0.473 scale wing would require at least 9 feet of height or 2.45 radii. With provision for a model base, the minimum propeller height was chosen to be 118 inches or 2.68 radii.

In summary, the following geometric constraints for the frame based on minimum inflow and wake interaction are as follows:

1. The distance from the rear of the propeller plane to the frame should be 1.0 radii for acceptable inflow restriction for propeller testing.

2. The front frame supports should be placed at least 1.5 radii radially away from the propeller. Increased distance behind the propeller plane is advantageous.

3. The minimum propeller height should be 1.76 radii.

It should be noted that these constraints are based on rotor blade testing where inflow restrictions should be reduced as much as possible in order to imitate free air conditions. For downwash testing using the lower half of the propeller, the support frame influences from behind the propeller on the wake should be negligible in that region. 


\section{Chapter 4. Drive System}

From section 3.6, the requirements for torque and horsepower were computed for the McCauley-Textron 88 inch propeller. Whatever power source used, it was meant to replicate the output of the Continental IO-520-D engine during takeoff. The two most obvious choices fall to electrical motors or internal combustion engines, with an internal combustion engine example found in Brusse et al. [9]. Both can provide the needed 300 $\mathrm{hp}$ and $583 \mathrm{lb} \cdot \mathrm{ft}$ of torque at $2700 \mathrm{rpm}$ although certain options are more convenient in the long run.

\subsection{Internal Combustion Engine Consideration}

Internal combustion (IC) engines can be had at relatively low cost and require very little infrastructure for installation. As long as the proper support lines are installed for engine cooling, exhaust, and fuel, the IC engine can provide the necessary power to drive the propeller.

However, there are multiple disadvantages. In order to maintain experimental integrity, the propeller rpm must be as close to constant as possible for the duration of the test. This means that what ever control scheme is used, it must be accurate to within a few rpm. This can be difficult if the engine must be retrofitted and instrumented with controls and even more so if some sort of transmission for gearing purposes must be used. There will also be power losses from the transmission that must be accounted for when sizing the engine. In addition, if other research is to be done, the rpm requirements may fall to some lower or higher value than the engine and transmission combination can provide quickly and without considerable cost. 
Finally, from a vibration standpoint, the internal combustion engine contains considerable reciprocating parts that create vibration during operation. These vibrations are transmitted from the engine mounts themselves and through the drive shaft.

\subsection{Electric Motor Consideration}

The electric motor can be vastly more efficient than the IC engine, (95\% compared to $30 \%$ if using diesel) and provide readily useable control. The reliability of these motors is excellent, owing to relative simplicity and robustness of design. These qualities are demonstrated by their extensive use in industry. In addition, the vibration issues presented earlier are reduced due to the lack of reciprocating parts. Since there are no cylinders to fire in an electric motor, vibrations emitted from the motor frame and driveshaft are minimal. The power transmission is generally very smooth and rpm can be controlled accurately with the proper equipment.

However, there are negatives associated with electric power. First, the initial investment price is substantially higher for the electric motor. A new internal combustion engine without support equipment may cost on the order of $\$ 10,000$ [19] while a new electric motor in the $350 \mathrm{hp}$ range alone will cost in the range of \$20-32,000 [20]. Most likely, due to the placement of the test facility, the needed power transmission and control lines will need to be installed. This will involve a certain amount of excavation and high voltage expertise in order to provide safe and reliable power. This will certainly lead to added expense as well.

The weight of an electric motor of this size is considerable as well, ranging from 2000-4000 lbs [20]. Since this large mass must be suspended from the test stand frame, 
the frame design must be robust enough to account for the dead weight, the torques applied, and the vibrations associated with operation.

With these considerations, the higher initial investment can be repaid by the added efficiency, control, and relative ease of maintenance of the electric motor as compared to an IC engine setup. Therefore, the electric motor was chosen as the best option for this application.

\subsubsection{Electric Motor Selection}

When dealing in high power electric motors, there are two commonly implemented types; the DC brushless and the more common $\mathrm{AC}$ induction. $\mathrm{DC}$ brushless motors can provide superior performance in terms of controllability, low-rpm torque, and weight but their cost can be higher. The test facility does not require fast-start capabilities so large low-rpm torque is not necessary. Nor is the reduced weight as facility structure can be designed to support the weight without penalties to performance. This led to the choice of AC induction motors. Further information about the motor choice can be found in [20].

There are a multitude of manufacturers for electric motors in the $350 \mathrm{hp}$ range. In order to reduce the time required compile a list of suitable manufacturers, a computer program called Motor Master +4.0 created by the United States Department of Energy was used to find the possible motor options. It essentially contains a database that can be searched through with parameters such as horsepower rating, voltage, RPM, and motor application. A picture of the interface is seen below in Figure 4.1. 


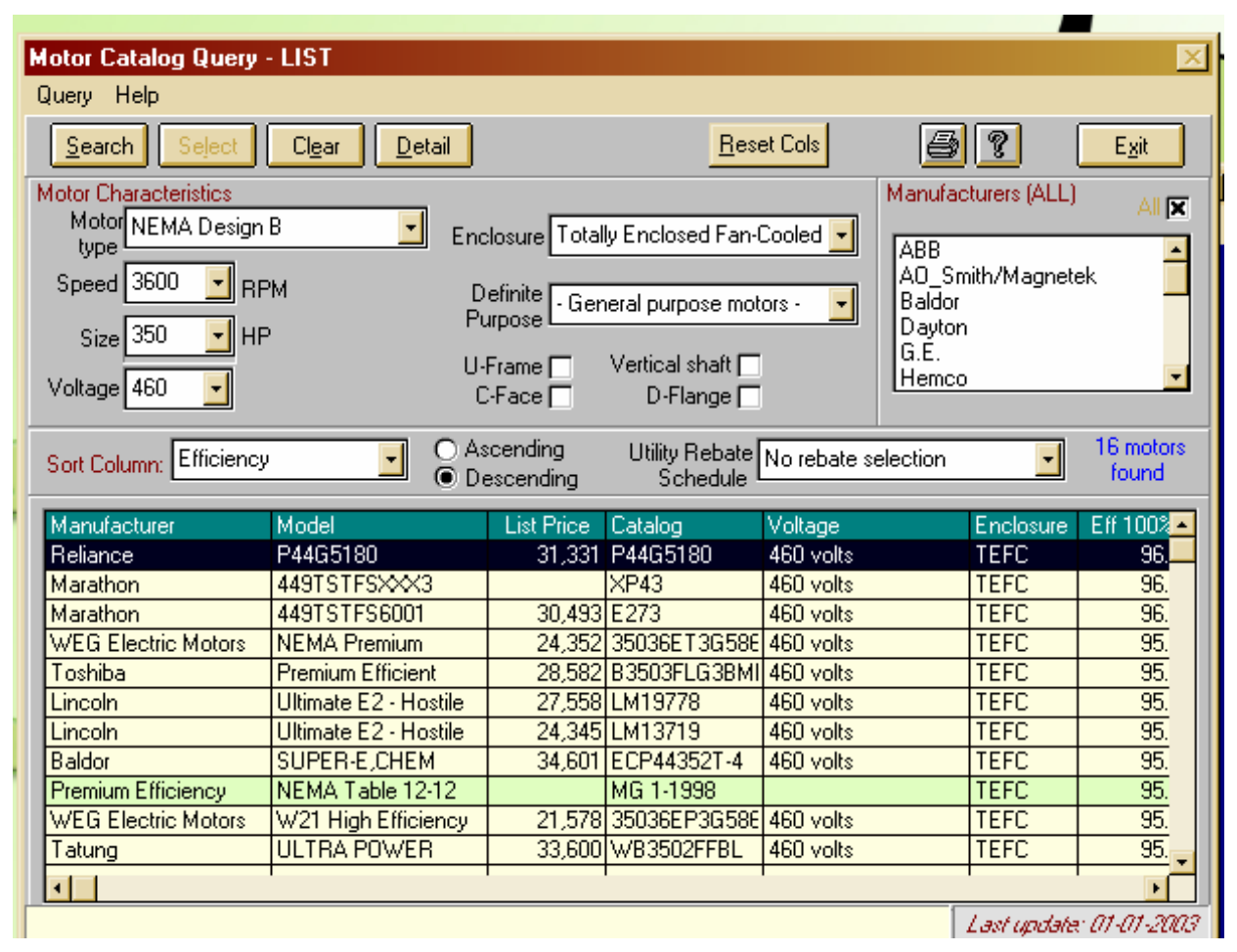

Figure 4.1 Motor Master interface

For convenience, the list of the motor requirements is listed below in Table 4.1. It contains the necessary requirements that were entered into Motor Master to produce a list of the possible motor options.

Table 4.1 Motor requirements

\begin{tabular}{|c|c|}
\hline Motor Specification & Value \\
\hline & \\
\hline NEMA Motor Design & $\mathrm{B}$ \\
\hline Power & $350 \mathrm{hp}$ \\
\hline Torque & $\geq 552 \mathrm{lb}-\mathrm{ft}$ \\
\hline RPM & $\geq 2700$ \\
\hline Voltage & 460 \\
\hline Purpose & General \\
\hline Cooling & TEFC \\
\hline
\end{tabular}




\subsubsection{Motor Enclosure Requirements}

There exist several choices for motor enclosures and cooling. Their proper selection is dependent on the conditions under which the motor operates. TEFC stands for Totally Enclosed Fan Cooled. This type is perhaps the most common type of cooling available. The motor is sealed to prevent moisture and dust from entering the casing and an external cooling fan provides forced air over cooling fins cast into the motor casing to reduce the temperature. Given that this motor would spend the majority of its time outdoors, it was best to have a motor that was sealed from the elements. There are limits to this enclose, however. TEFC does not sealed against high-pressure water and is not "explosion proof" meaning that the motor should not be washed down, or operated near places where flammable vapors or dust may accumulate.

\subsubsection{Motor Choices and Recommendations}

With the parameters entered into the program, sixteen motors were found to fit the requirements. A few motor manufacturers that are recommended are Lincoln, Baldor, Marathon, and Weg. Figures 4.2 and 4.3 from Baldor and Weg show the typical offerings. Table 4.2 provides a brief description of each and all should be seen as viable options for implementation. 


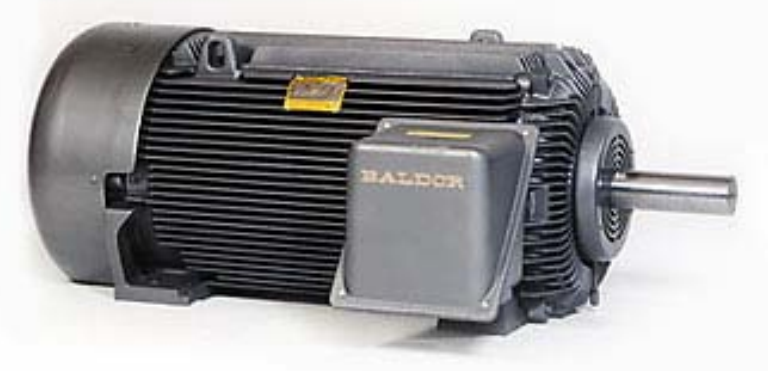

Figure 4.2 Baldor 350 hp Motor ${ }^{21}$

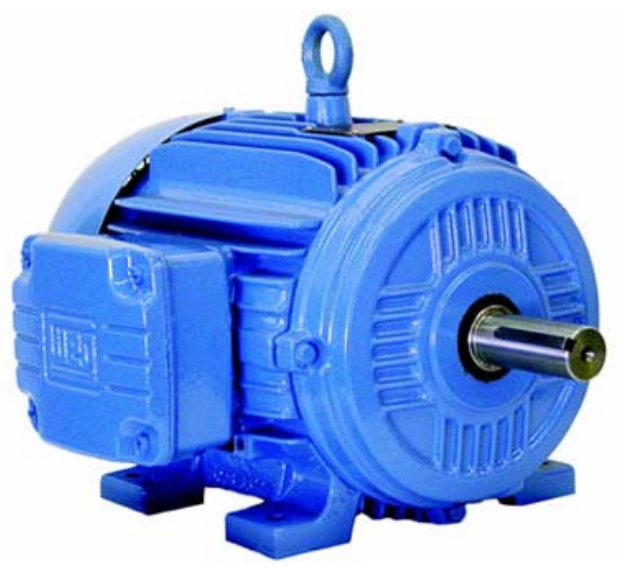

Figure 4.3 Weg $350 \mathrm{hp}$ motor $^{22}$

Table 4.2 A selection of 350 horsepower, 3 phase AC induction motors

\begin{tabular}{|c|c|c|c|c|}
\hline Manufacturer & Baldor & Marathon & Lincoln & Weg \\
\hline Model & M44352T-4 & 449TSTFS8001 & SF2B350TS64Y & $35036 E P 3 \mathrm{G} 5008 \mathrm{TS}$ \\
\hline Max Torque & N/A & $711 \mathrm{lb} \cdot \mathrm{ft}$ & $900 \mathrm{lb} \cdot \mathrm{ft}$ & $914 \mathrm{lb} \cdot \mathrm{ft}$ \\
\hline Voltage & 460 & 460 & 460 & 460 \\
\hline rpm & 3560 & 3570 & 3600 & 3570 \\
\hline Weight & $2300 \mathrm{lb}$ & $3050 \mathrm{lb}$ & $2185 \mathrm{lb}$ & $3169 \mathrm{lb}$ \\
\hline Retail Cost & $\$ 33,631$ & $\$ 23,486$ & $\mathrm{~N} / \mathrm{A}$ & $\$ 26,355$ \\
\hline
\end{tabular}




\subsubsection{Electric Motor Control Selection}

When dealing with high-power alternating current motors there are generally two methods of control. The first is to use a soft-start controller, the second a variable frequency drive. With the soft-start, initial and final operating voltages or currents can be input and the controller then increases or decreases that value (usually linearly) to the specified limit. Overload protection systems are often built into the controller to prevent damage to the motor or power supply.

This is the most basic control as it does not allow the user to dynamically change the rpm of the motor while in operation. Often, this type of controller is used in industry on mechanical brake presses where the motor is required to start and run with no real necessity for rpm control. For illustration purposes, the Weg SSW-03 soft start controller is seen in Figure 4.4.

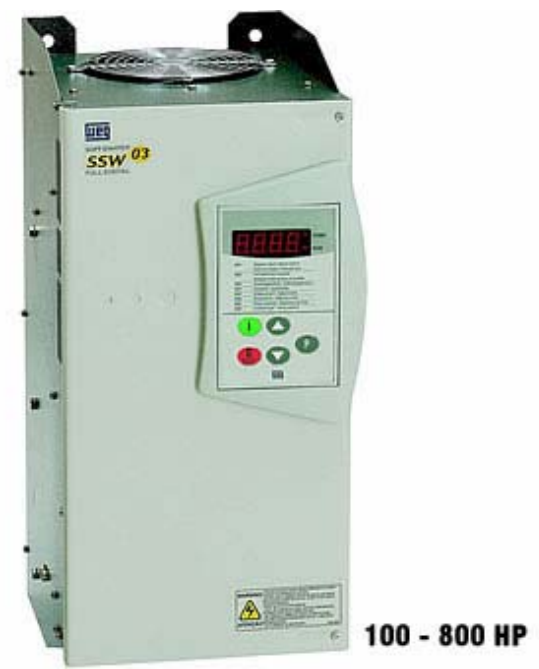

Figure 4.4 Weg SSW-03 soft-start controller, 100-800 hp ${ }^{23}$ 
The second option for control is the variable frequency drive (VFD). By controlling the frequency at which the coils of the electric motor are energized, the speed of the motor can be controlled dynamically during operation. Again, the overload protection is usually offered as well along with the important ability to control and monitor rpm.

Certain controllers contain tachometer inputs that allow the controller to self regulate RPM once it is set by the user. The accuracy of controller is dependent on the feedback used to control speed. With a 14-bit analog encoder, the rpm of the motor can be controlled to within $0.36 \mathrm{rpm}$ [24]. Again, for illustration purposes, the Weg CFW-09 Vectrue Inverter is show in Figure 4.5.

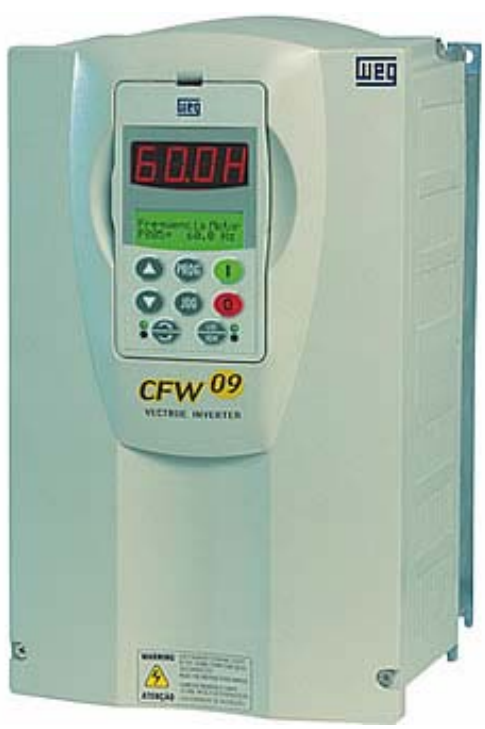

Figure 4.5 Weg CFW-09 Vectrue Inverter, $1.5-500 \mathrm{hp}^{24}$

When dealing with an electric motor of this power rating, the cost is high due to amount of electric current and voltage that must be safely controlled. A variable 
frequency drive can easily double the price of a soft-start module. As an example, the Weg SSW-03 retail cost is $\$ 7,261$, while the CFW-09 retail cost is $\$ 52,599$.

Other costs are incurred as well if the need for rapid dynamic braking is found as in the case of an emergency stop. The considerable power stored in the coils of the motor must be dissipated safely. This is usually done by use of a large bank of high-power resistors. Referring to Weg [24], the cost of the resistor bank for an application of this power is $\$ 6,733$ with an added $\$ 2,963$ for the dynamic braking module. Other manufacturers can be sourced for more economical solutions. Table 4.3 is a list of the requirements seen as needed for the application at hand. It should not be seen as an exhaustive list, as dialogue with the manufacturer's sales representative or engineer will lead to other design constraints that may lead to different, necessary controller options.

Table 4.3 Minimum variable frequency drive requirements

\begin{tabular}{|c|c|}
\hline Power & $350 \mathrm{hp}$ \\
\hline Voltage & 460 \\
\hline Speed range & $0-3000 \mathrm{rpm} \pm 3 \mathrm{rpm}$ \\
\hline Interface & Remote, $\mathrm{PC}$ \\
\hline Braking & $3000-0 \mathrm{rpm} \leq 10 \mathrm{sec}$ \\
\hline
\end{tabular}




\subsection{Mechanical Power Transmission}

With the propeller power and torque requirements specified, the drivetrain of the test stand was designed and evaluated. With the necessity for placing the drive motor a distance away from the propeller for aerodynamic purposes, the drivetrain remained relatively unchanged from one frame configuration to the next.

Initially, it was thought that placing the motor on the ground a distance away from the propeller could be implemented, with a belt system reaching vertically upward to the main drive shaft. The advantages included easy mounting and maintenance of the motor. However, to reduce the inflow restrictions before the propeller at much as possible, the motor placement was changed to be in-line with the propeller driveshaft, eliminating the need for belted connections but requiring a coupler between the motor driveshaft and the propeller driveshaft.

\subsubsection{Drive Shaft Load Specification}

The loads on the driveshaft were first estimated from the static thrust tests and horsepower and torque requirements of the propeller. The weight of the propeller and hub assembly was included as well. Table 4.4 contains the loads associated with operation.

Table 4.4 Operational Loads

\begin{tabular}{|c|c|}
\hline Load & Value \\
\hline Thrust & $1200 \mathrm{lb}$ \\
\hline Propeller Weight & $200 \mathrm{lb}$ \\
\hline Torque & $7200 \mathrm{lb} \cdot$ in \\
\hline Bending Moment & $1200 \mathrm{lb} \cdot$ in \\
\hline
\end{tabular}


The thrust was found from the operating parameters of the propeller at static conditions. The actual propeller weight is near $90 \mathrm{lbs}$ but $200 \mathrm{lb}$ was used in the event that future testing requires a different hub and blade setup. The torque was found from the relationship in Equation 3.9. The torque was converted to $\mathrm{lb}$ in for calculation purposes. The bending moment on the shaft was found by assuming that weight of the propeller was a point load concentrated 6 inches from the front bearing.

\subsubsection{Drive Shaft Material Selection}

Referencing Shigley [25], a list of acceptable shaft materials was collected. The most common are the ANSI 1020-1050 steels. Heat-treated steels, including 1340-50, $3140-50,4140$, and a few others can be used as well, but are more expensive. There are then several factors to consider:

1. Larger diameter shaft for fatigue resistance leads to added weight and cost

2. Larger diameter bearings for the shaft become expensive at required operating speed

3. Heat treating can increase the yield and ultimate strength

It is then desirable to use heat-treated steel if the cost is reasonable, as it can significantly adds to the life-span of the shaft. Of the above heat-treated steels, 4140 was chosen due to its availability. There are several options for using 4140 based on their heat treatments. For calculations, 4140 quenched and tempered steel with the following material properties was chosen. 
Table $4.5 \quad 4140$ steel properties ${ }^{25}$

\begin{tabular}{|c|c|}
\hline \multicolumn{2}{|c|}{ ANSI 4140 Q\&T steel } \\
\hline Ultimate Strength, $\mathbf{S}_{\mathbf{u t}}$ & $225 \mathrm{ksi}$ \\
\hline Yield Strength, $\mathbf{S}_{\mathbf{y}}$ & $208 \mathrm{ksi}$ \\
\hline Modulus of Elasticity, E & $2.92 \times 10^{6} \mathrm{psi}$ \\
\hline Brinell Hardness & 445 \\
\hline
\end{tabular}

\subsubsection{Drive Shaft Design Process}

\subsubsection{Geometric Constraints}

For the driveshaft design, several factors must be incorporated. Shigley [25] recommends that geometric constraints be addressed first. The geometric constraints pertain to the slope of the shaft with respect to the centerline of the bearings used. If the slope of the shaft under load is too great for the bearing, premature bearing failure will occur. Therefore, the shaft must be stiff enough to prevent excessive bending. Since all steels have comparable modulus of elasticity, shaft geometry is the only way to increase stiffness. A spreadsheet as found in the Appendix (Table A.2) using the Equations 4.1 and 4.2 from Budynas [26] were used to determine the deflection of the shaft given various driveshaft diameters. Equation 4.1 is for a cantilever beam with a point end load. Equation 4.2 is for a uniformly distributed load on a cantilever beam, used to simulate gravity load by entering weight of the shaft per unit length for the load. 


$$
\begin{gathered}
v_{p}=\frac{F x^{2}}{6 E I}(x-3 L) \\
v_{d}=\frac{w x^{2}}{24 E I}\left(4 L x-x^{2}-6 L^{2}\right)
\end{gathered}
$$

For Equation 4.1, $F$ is the point load, $x$ is the distance from the beam constraint, $E$ is the Young's modulus, $I$ is the moment of inertia, and $L$ is the total length of the beam. For Equation 4.2, $w$ is the distributed load value. The deflections due to the point load and the distributed load were summed to provide the total deflection.

The next step was to determine the slope of the shaft to see if it would interfere with the smooth operation of the bearings to be used. Equations 4.3 and 4.4 [26] were used for the point load and distributed load respectively.

$$
\begin{array}{r}
\theta_{p}=\frac{F x}{2 E I}(x-2 L) \\
\theta_{d}=\frac{w x}{6 E I}\left(3 L x-x^{2}-3 L^{2}\right)
\end{array}
$$

In both equations, $\theta$ is the slope of the shaft in radians. As before with the deflections, the results form the point and distributed load equations were summed to provide the total slopes. The slope of the shaft near the constraint was checked against Timken's recommended maximum bearing slope of 0.0005 radians [25] and a minimum shaft diameter of 1.49 inches was found. The spreadsheet and plots of the deflection and slope can be found in the Appendix in Figures A.3 and A.4. The next design step is to determine the diameter of the shaft with respect to strength constraints. 


\subsubsection{Strength Constraints}

For sufficing strength constrains, the Gerber failure criterion was used. Using the material properties from Table 4.3, the process was begun. Equation 4.5 [25] was used to solve for the diameter.

$$
d=\left(\frac{8 n A}{\pi S_{e}}\left\{1+\left[1+\left(\frac{2 B S_{e}}{A S_{u t}}\right)^{2}\right]^{\frac{1}{2}}\right\}\right)^{\frac{1}{3}}
$$

$n$ is the factor of safety, $S_{e}$ is the endurance strength, $S_{u t}$ is the ultimate strength and $A$ and $B$ are defined as:

$$
\begin{aligned}
& A=\sqrt{4\left(K_{f} M_{a}\right)^{2}+3\left(K_{f s} T_{a}\right)^{2}} \\
& B=\sqrt{4\left(K_{f} M_{m}\right)^{2}+3\left(K_{f s} T_{m}\right)^{2}}
\end{aligned}
$$

Where $K_{f}$ is the fatigue bending stress concentration factor, $M_{a}$ is the amplitude component of the moment, $M_{m}$ is the midrange component of the moment, $K_{f s}$ is the fatigue torsional stress concentration factor, $T_{a}$ is the amplitude component of torque, and $T_{m}$ is the midrange component torque.

The moments are define as found below. The torques $T_{a}$ and $T_{m}$ are defined in the same fashion. 


$$
\begin{aligned}
& M_{a}=\left|\frac{M_{\max }-M_{\min }}{2}\right| \\
& M_{m}=\frac{M_{\max }+M_{\min }}{2}
\end{aligned}
$$

$K_{f}$ and $K_{f s}$, the fatigue stress concentration factors, are found from stress concentration factors $K_{t}$ and $K_{t s}$ which are based on the shaft's loading conditions under bending and torsion respectively.

First the components of moments and torques were calculated. The bending moment applied to the shaft is fully reversed due to the fact that as the shaft rotates, positions on the shaft located 180 degrees from each other will experience opposite loading due to the weight of the propeller. This reduces the $M_{m}$ component to zero. Both torque components are present due to the assumption that the torque values will vary from the minimum value at rest to the maximum value at operation. The assumptions and load results are summarized below.

1. The moment loads are fully reversed due to shaft rotation

2. Torque load is not reversed but varies between zero and maximum torque

Table 4.6 Load components

\begin{tabular}{|c|c|}
\hline Load & Value \\
\hline $\mathbf{M}_{\mathbf{a}}$ & $1200 \mathrm{lb} \cdot$ in \\
\hline $\mathbf{M}_{\mathbf{m}}$ & 0 \\
\hline $\mathbf{T}_{\mathbf{a}}$ & $3600 \mathrm{lb} \cdot \mathrm{in}$ \\
\hline $\mathbf{T}_{\mathbf{m}}$ & $3600 \mathrm{lb} \cdot \mathrm{in}$ \\
\hline
\end{tabular}

Next, $K_{f}$ and $K_{f s}$ were found from the Equation 4.10 seen below. 


$$
K_{f}=\frac{K_{t}}{1+\frac{2}{\sqrt{r}} \frac{K_{t}-1}{K_{t}} \sqrt{a}}
$$

Where $K_{t}$ is the stress concentration factor, $r$ is the radius of the shaft, and $\sqrt{a}$ is a constant from Heywood's parameters. $\sqrt{a}$ for this case is defined in the equation below for a shoulder reduction in diameter.

$$
\sqrt{a}=\frac{4}{\bar{S}_{u t}}
$$

The stress concentration factors were found from tables within Shigley [25]. It was assumed that there would be some reduction in shaft diameter in order to attach the propeller assembly. The following assumptions were made:

1. The shaft diameter decreased from 2" to 1"

2. The shoulder radius was 0.25 "

With these assumptions, $\sqrt{a}$ was found via Equation 4.7 and $K_{t}$ and $K_{t s}$ were found from tables within [25]. These values were then substituted into Equation 4.10 for $K_{f}$ and $K_{f s}$. The values are summarized in the Table 4.7 below.

Table 4.7 Stress concentration factors

\begin{tabular}{|c|c|}
\hline $\begin{array}{c}\text { Stress Concentration } \\
\text { Factors }\end{array}$ & Value \\
\hline $\boldsymbol{K}_{\boldsymbol{t}}$ & 1.3 \\
\hline $\boldsymbol{K}_{t s}$ & 1.194 \\
\hline $\boldsymbol{K}_{\mathrm{f}}$ & 1.26 \\
\hline $\boldsymbol{K}_{\mathrm{fs}}$ & 1.17 \\
\hline$\sqrt{a}$ & 0.0177 \\
\hline
\end{tabular}


These factors were then entered into Equations 4.6 and 4.7 for $A$ and $B$ to yield values of 7897.3 and 7295.4 for $A$ and $B$ respectively. Finally, $A$ and $B$ were substituted into Equation 4.1 with a safety factor of four to find a diameter of 1.449 inches. Since this is not a standard diameter for steel shafts, it was found that a 1.5-2.0 inch diameter shaft should be used so that bearing selection and machining requirements are reduced. Bearing consideration led to a choice of a 1.9375 inch diameter shaft due to bearing availability. The added strength and stiffness of the increased diameter raised the safety factor to 9.89 according to Equation 4.12 [25].

$$
\frac{1}{n}=\frac{8 A}{\pi d^{3} S_{e}}\left\{1+\left[1+\left(\frac{2 B S_{e}}{A S_{u t}}\right)^{2}\right]^{\frac{1}{2}}\right\}
$$

\subsubsection{Life calculation}

The drive shaft's service life was also evaluated. For this application, where safety is of utmost importance, it is a requirement to know when various components have reached their fatigue life limit so that they may be inspected and replaced before failure occurs.

For the fully reversed bending moment due to torsion, Equation 4.13 [25] applies.

$$
N=\left(\frac{\sigma_{a}}{a}\right)^{\frac{1}{b}}
$$

$N$ equals the number of cycles, $\sigma_{a}$ is the average component of stress, $a$ and $b$ are constants. The constant $a$ can be found by the following equation. 


$$
a=\frac{f^{2} S_{u t}^{2}}{S_{e}}
$$

Where $f$ is a fraction of the $S_{u t}$ found by the equation below.

$$
f=\frac{\sigma_{F}^{\prime}}{S_{u t}}\left(2 \cdot 10^{3}\right)^{b}
$$

Where $\sigma_{F}^{\prime}$ is found by adding $50 \mathrm{ksi}$ to the $S_{u t}$ of the steel. The constant $b$ was found from a table in [22] that indicated for 4140 steel a value of -0.08 . This led to a calculated value of $\mathrm{f}=0.665$. This was then used to calculate $a$ with its value of $403.24 \mathrm{ksi}$. With a diameter of 1.5 inches, the average stress component in the shaft was found to be 3622 psi. The values were then entered into Equation 4.13 [25]. The number of cycles calculated was found to be $7.56 \times 10^{9}$, meaning infinite life.

Table $4.8 \quad$ Driveshaft specifications

\begin{tabular}{|c|c|}
\hline Material & 4140 Steel Q\&T \\
\hline Length & 72 inches \\
\hline Diameter & 1.9375 inches \\
\hline Machining & Turned down 1", Keyed, splined \\
\hline
\end{tabular}

The details of machining the shaft will become evident after the acquisition of the propeller and mounting flange. It is surmised that the shaft's diameter will need to be reduced and keyed or splined. 


\subsection{Key and Spline Design}

\subsubsection{Spline Design}

To reduce the possibility of placing thrust loads on the electric motor shaft, one end of coupler that joins the motor and driveshaft must be splined. This allows the shaft to slide freely within the coupler, while still transmitting the needed torque.

It was assumed that a minimum of 3 inches of splined shaft would be engaged at all times, 16 splines would be used, and that spline would slide under load. SAE guidelines were used to calculate spline size and length [27]. Equations 4.16 and 4.17 [27] calculate the minimum shaft diameter and torque capacity of the spines.

$$
\begin{aligned}
& D=\sqrt{\frac{T}{688}} \\
& T=688 D^{2}
\end{aligned}
$$

Where $D$ is the shaft diameter in inches and $T$ is the torque in lb.in. Given the torque of $7200 \mathrm{lb}$-in from Section 3.6, the diameter for one inch of engaged spline was found to be 3.234 inches. Dividing by 3 for each inch of engaged spline, the minimum shaft diameter is 1.078 inches, since the drive shaft is specified at 1.9375 inches, there is an additional margin of safety. The torque capacity for one inch of spline at 1.9375 inch diameter was found to be $2582 \mathrm{lb} \cdot \mathrm{in}$. A minimum of 2.8 inches of spline must be engaged at all times for the specified torque of $7200 \mathrm{lb} \cdot$ in.

Finally, the spline dimensions as seen in Figure 4.6 [27] were calculated using Equations 4.18, 4.19, and 4.20. 


$$
W=0.098 D
$$

$$
d=0.810 D
$$

$$
h=0.095 D
$$

Where $W$ is the spline width, $d$ is the inner shaft diameter, $h$ is the spline height, and $D$ is the shaft diameter. The results of the spline calculations are summarized in Table 4.9, below. In the event that machining costs are prohibitive, the number of splines may be reduced and dimensions recalculated to find the minimum engaged spline length and spline dimensions.

Table 4.9 Spline dimension summary

\begin{tabular}{|c|c|}
\hline $\boldsymbol{D}$ & $1.937 \mathrm{in}$ \\
\hline $\boldsymbol{W}$ & $0.1899 \mathrm{in}$ \\
\hline $\boldsymbol{d}$ & $1.569 \mathrm{in}$ \\
\hline $\boldsymbol{h}$ & $0.1840 \mathrm{in}$ \\
\hline Number of Splines & 16 \\
\hline
\end{tabular}

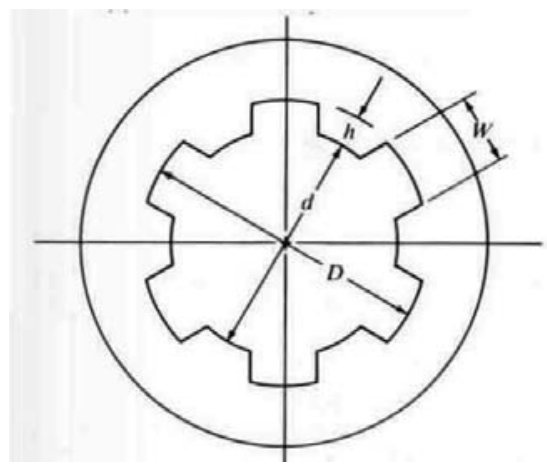

Figure 4.6 Spline dimension schematic ${ }^{27}$ 


\subsubsection{Key Design}

The one foreseen keyed connection would occur from the motor to the coupler joining the driveshafts. Since final motor selection will determine the motor shaft diameter and keyway dimensions, it is left to future design to choose the keyway dimensions of the coupler based on the motor keyway dimensions. For this task, the reader is referred to Shigley [25] and Mott [27] for the keyway design process.

\subsection{Coupler Selection}

In order to join the motor driveshaft to the main driveshaft a coupler was chosen. There exist several options depending on the types of loads applied and the amount of shaft misalignment during construction. A rigid coupling is not recommended due to the fact that the frame will flex under load and may cause shaft misalignment during operation. It is therefore better to use a flex coupler that allows a few degrees of misalignment.

There is a multitude of coupling manufacturers in existence but Kop-Flex couplers were specified here due to their availability through a local distributor. The KD4 series coupler [28] was chosen due to cost effectiveness and the need for angular misalignment compensation only.

The 153 size coupler would certainly be needed for each side as it has a maximum bore diameter of 2.5 inches. An unfinished bore of proper size would need to be obtained then sent to the proper machining facilities to add splines and keyways of proper dimension. 
The coupler's speed and load ratings are summarized in the Table 4.10 below or can be found in the Appendix A in Figure A.5. All specifications and are well above the envisioned operating conditions of the test facility.

Table $4.10 \quad$ Kop-Flex KD4 153 coupler specifications ${ }^{28}$
\begin{tabular}{|c|c|}
\hline Continuous Torque & $13600 \mathrm{lb} \cdot$ in \\
\hline Maximum Torque & $27200 \mathrm{lb} \cdot$ in \\
\hline Maximum speed & $14800 \mathrm{rpm}$ \\
\hline Weight & $11.4 \mathrm{lb}$ \\
\hline Max Bore size & $2.5 \mathrm{in}$ \\
\hline
\end{tabular}

\subsection{Bearing Selection}

The next critical component in the driveline is the bearings and carriers that will suspend and constrain the driveshaft and propeller assembly during operation. The most capable of the options presented, ball, roller, tapered roller, and thrust was the tapered roller bearing (TRB), Figure 4.7. By placing the tapered rollers at an angle, the bearing is capable of resisting both axial and thrust loads.

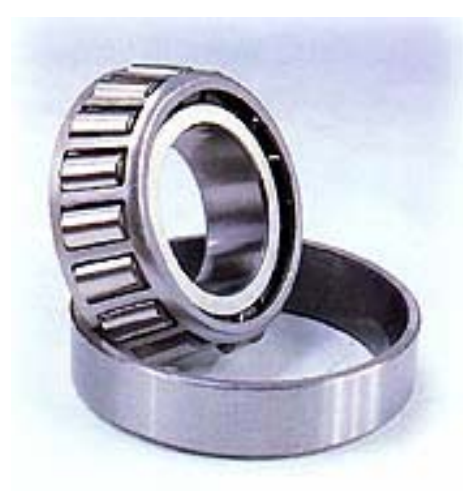

Figure 4.7 Tapered roller bearing ${ }^{29}$

To expedite the design process, software from the Timken Bearing Company was obtained. The Tapered Roller Bearing Selection Guide [30] provided a means to select 
bearings based on multiple parameters such as loads encountered and bore diameters. With shaft diameter chosen to be 1.9375 inches, it was a matter of entering the bore diameter into the program then viewing the options that Timken has available.

The operational loads are entered as well, allowing for life estimations. It was decided that a single TRB must be capable withstanding the total loads although thrust loads may be distributed over other bearings. This redundancy was seen as necessary in the event of thrust collar or bearing failure that could lead to the thrust loads being transmitted to the electric motor. Table 4.4 contains the loads that were entered into the program to produce the following options. All the following are 1.9375 inch bores.

Table 4.11 Timken bearing options ${ }^{30}$

\begin{tabular}{|c|c|}
\hline Timken model number & Life \\
\hline $365-\mathrm{S} / 362 \mathrm{~A}$ & $5370 \mathrm{hrs}$ \\
\hline $3781 / 3720$ & $20700 \mathrm{hrs}$ \\
\hline HM807044/ HM807010 & $206000 \mathrm{hrs}$ \\
\hline
\end{tabular}

The load ratings for these bearings are quite high due to their diameter and typical application in heavy industry. With proper lubrication, the smallest of the bearings, the 365-S/ 362A would withstand 1.84 years of use at eight hours a day, seven days a week at the specified loading conditions. For more detail, see the printed report in the Appendix A, Figures A.6 and A.7. It is therefore recommended to use the 365-S/ 362-A bearing to minimize the cost. The use of at least one other TRB of this kind in the driveline in conjunction with a thrust collar will provide at least one backup in the event of primary thrust collar failure. It should be noted that Timken is not the only 
manufacturer that can be used but is specified due to its reputation and quality of manufacture.

\subsubsection{Bearing Lubrication}

Timken provides a recommended lubrication regimen depending on the inner race speed of the bearing. From a scaled drawing, the dimensions of the race were found and input into Equation 4.21 [30] to produce a race speed of $1,806 \mathrm{ft} / \mathrm{s}$, where $D_{m}$ is the inner race rib diameter and $n$ is the rpm. At this speed, according to Figure 4.8 from Timken [30], the bearing lubrication options fall into two regions. The first is the experimental grease region. It indicates that further testing is needed to verify the effectiveness of grease at those operating speeds. The second option indicates that the bearings would require passive oiling.

$$
V r=\frac{\pi D_{m} n}{12}
$$

The difficulty is that each system has advantages and disadvantages. With grease, it is a matter of specifying a regular greasing regimen that keeps the bearings packed and running smoothly. The bearing carriers can be smaller due to lack of reservoirs that passive oil would require. However, this speed range for grease is untested and could lead to early bearing failure and perhaps cause other damage within the system. 


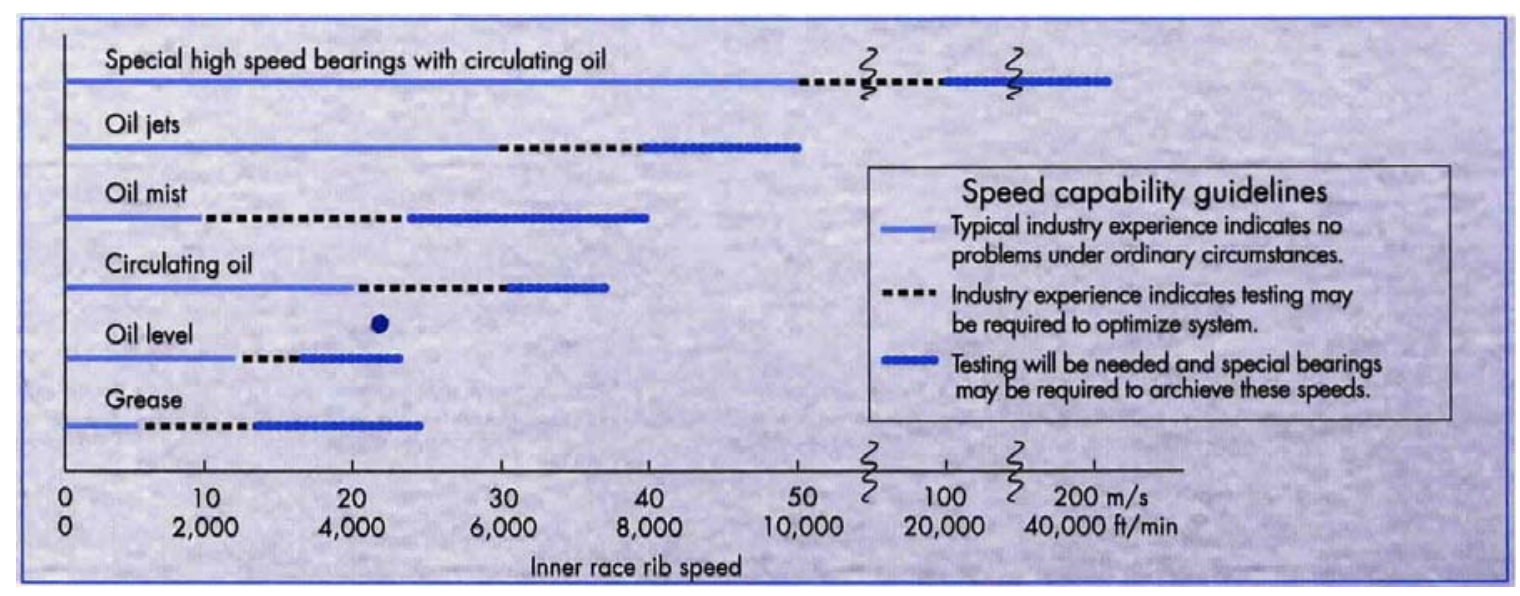

Figure 4.8 Timken recommended lubrication table ${ }^{30}$

Passive oiling would provide the necessary lubrication and is well tested but requires the added complication of oil reservoirs, with regular oil changes and inspection of fluid levels. Regular greasing can act as a seal against moisture and particles from the environment while oil requires adequate sealing to reduce the chances of contamination of the bearing and lubricant. It is therefore recommended that the manufacturer be contacted and operating conditions discussed to provide more definitive options. If left to the author, oil lubrication would be used due to the manufacturer's recommendation, ensuring the longevity of the bearings.

\subsubsection{Shaft Constraint}

In addition to resisting the loads created by the propeller in operation, other bearings provide a necessary purpose of constraining the shaft during operation due to what is known as critical speed. Consider a length of rotating shaft. At a given rpm, any imbalances in the shaft will produce a vibrational mode that will grow out of control. The speed at which this first mode of vibration occurs is the critical speed. Using Equation 
4.22 from Greenwood [31] the critical speed of the shaft was found for a range of distances between bearings. Figure 4.9 illustrates this relationship.

$$
\text { Critical Speed }=\frac{46.886(10)^{5} \sqrt{D_{o}^{2}+d_{i}^{2}}}{L^{2}}
$$

Where $D_{o}$ is the outer shaft diameter, $d_{i}$ is the inner shaft diameter and $L$ is the shaft length between bearings. $D_{i}$ equals zero for solid shafts.

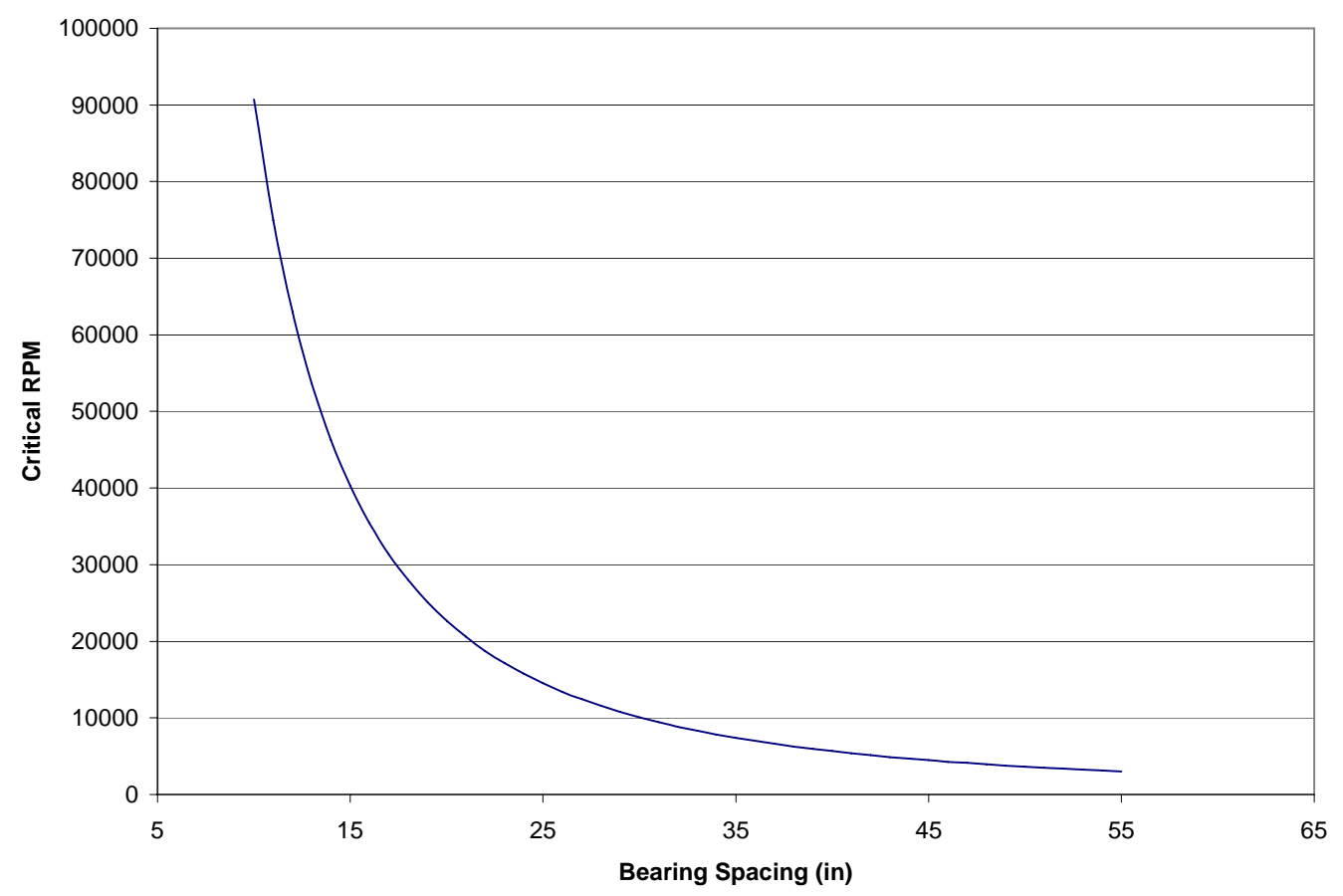

Figure 4.9 Bearing spacing effect on critical speed

As can be seen from the Figure 4.9, shaft constraint for critical speeds for the given shaft diameter and rpm was a non-issue. Three evenly spaced bearings along the 72 inch driveshaft length (36 inch shaft between bearings) would be sufficient to create a 7000 rpm critical speed or 2.3 times the maximum operating speed of $3000 \mathrm{rpm}$. 


\section{Chapter 5. Frame Design}

It was realized that in trying to simulate a V-22 in hover, it would be necessary to create as little obstruction to incoming propeller air as possible. Section 3.8 contains the geometric restrictions found necessary to minimize the frame's influence on the propeller wake properties. In addition to these aerodynamic considerations, personnel safety amongst others was considered paramount. The following is a list of frame design requirements listed in order of importance.

1. Safety for bystanders and test engineers

2. As little incoming flow obstruction to the propeller as possible in the test area

3. Sufficient distance between frame members and propeller inflow

4. Minimal frame deflection during operation to reduce loads on rotating components

5. Ease of construction

6. Cost of materials an labor

\subsection{Frame Configuration}

Figure 5.3 is an illustration of the proposed design. The frame geometry has been chosen to facilitate quick construction and employs I-beams as structural members. The simplicity of a box frame was chosen because it reduces the need for mitered beams and connections reducing the time and cost of construction while providing an un obstructed inflow region below the propeller as seen in Figure 5.5.

The use of I-beams decreases the cost of materials and assembly due to the fact that I-beams are easily specified and purchased. Construction utilizing I-beams is well 
known and expertise in this field easy to find. As an example, numerous joining techniques for I-beams can be found in the AISC Manual of Steel Construction. [32]. These connection and construction techniques are well researched and documented. In addition, the use of non-permanent fasteners is prevalent throughout the design due to the consideration of future testing requiring different geometries.

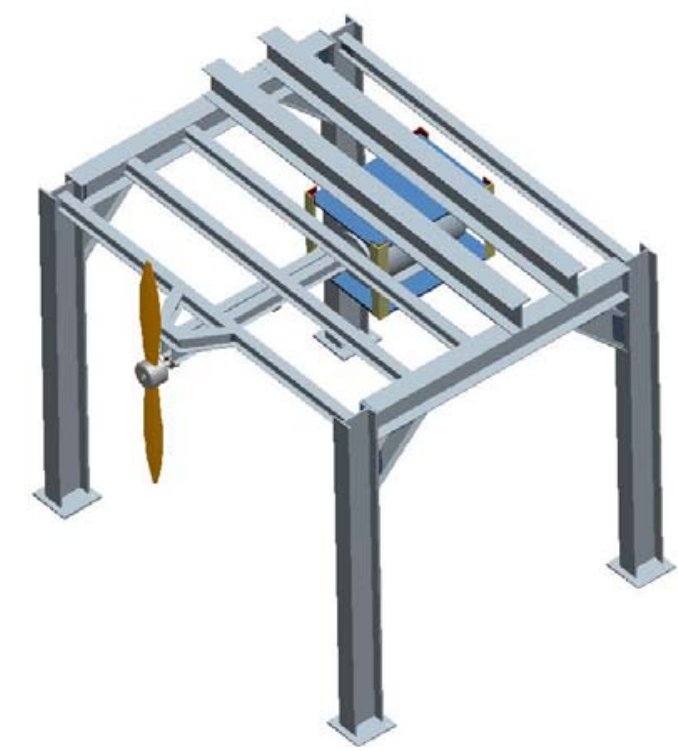

Figure 5.1 Current frame configuration

\subsubsection{Further Aerodynamic Considerations}

Much of the geometric design stemmed from the design specification to reduce as many airflow restrictions from behind the propeller as possible. It was therefore decided to hang the drive system from the frame. By elevating the motor and drive system, it freed the area underneath completely as seen in Figure 5.5. Effort was made to reduce the obstructions directly behind the propeller as well, by creating a standoff as seen in Figure 5.4 behind the propeller to try and reduce the effects of the cross-members behind it. Currently, the stand-off is only 0.23 radii, but the frame's influence on the lower area of 
the propeller will be negligible for $\mathrm{V}-22$ downwash testing. If rotor blade testing is to be done, the two supporting I-beams from which the drive shaft is hung should be lengthened to reach a distance of at least one propeller radius as per Section 3.8.

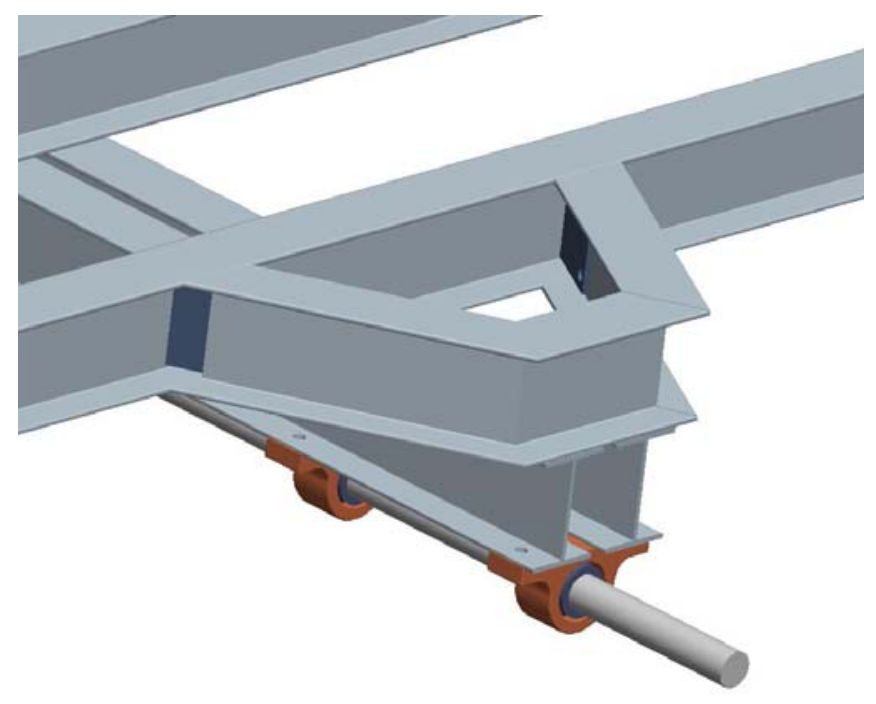

Figure 5.2 Propeller frame stand-off

The width of the frame was specified from Section 3.8 to reduce inflow obstructions from the side of the propeller. The outer supports are located a distance of 69.5 inches from the propeller circumference, placing it 1.58 radii away, 0.08 radii greater than the minimum recommended. As noted in Section 3.8, the height of the driveshaft from the ground was chosen to be 118 inches in order to meet the model size.

Motor mounting for this configuration is relatively simple, as angle pieces are hung from the horizontal I-beams to suspend a 0.75 inch thick steel plate. The motor is then mounted to that plate. The use of non-permanent fasteners at the angles allows the motor and mounting frame to be removed from the bottom via forklift. 


\subsubsection{I-beam Selection}

The I-beam sections chosen for construction were initially selected based on web and flange dimensions and thickness. The selection was based entirely on proportion of the size of the facility to beam size and by estimating the places on the frame where deflections should be reduced to a minimum. The most important areas to reduce this deflection are along the drivetrain. If this section of the frame distorts excessively during operation, the driveshaft and bearings may be placed under bending loads that could lead to premature failure.

The beams chosen for the analysis were reduced from a considerable list as found in [32] to two, the W12x40 and the W6x12 with dimensions and drawings as seen below in Figures 5.3 and 5.4.

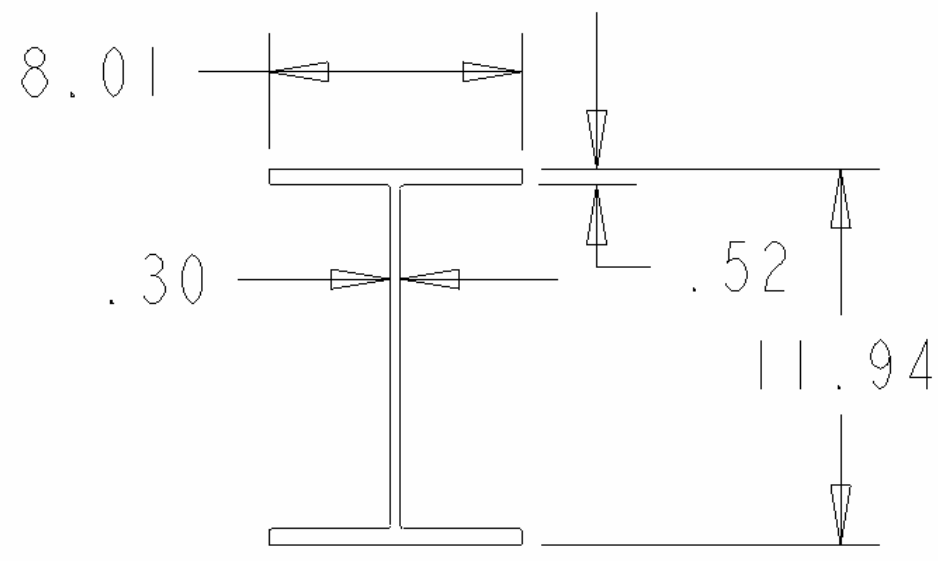

Figure 5.3 W40x12 I-beam section 


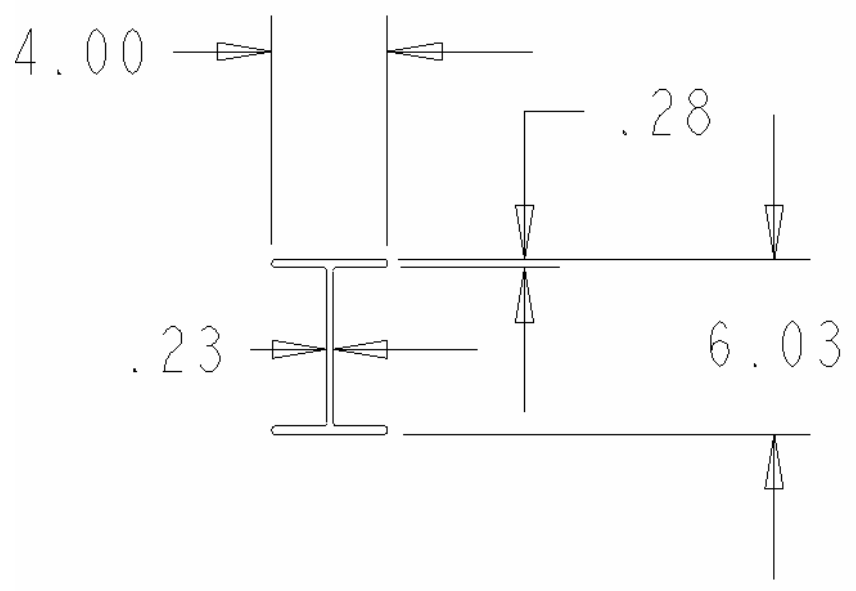

Figure 5.4 W6x12 I-beam section

\subsection{Finite Element Analysis}

Once geometry for this configuration was completed, Pro/Mechanica was used to run simple finite element analyses (FEA) to determine deflections and stresses of the frame under operational load. The FEA was seen as a design tool rather than an optimization tool at this stage. It was able to provide the fastest means of visualizing basic model response under static load conditions. 


\subsubsection{Model Idealizations}

In order to accurately portray the results of the FEA, the assumptions made for the analysis must be stated, as seen in the following list.

- I-beams were reduced to beam elements with proper dimensions and material properties.

- Certain geometry and beam location was simplified to facilitate ease of simulation.

- Connections were assumed perfect, i.e. beams are perfectly joined.

- Forces and moments were assumed constant point loads.

- Gravity was applied.

- Constraints were considered perfect, i.e. no movement.

To help safeguard against erroneous results, beam elements were implemented instead of shell or solid elements as recommended by Ganon [33]. Beam elements provide rapid and reliable results but are idealized. As long as the limitations are recognized, corrections can be made. The dimensions of the beams were entered into Pro/Mechanica, along with the ASTM A992 steel material properties and applied to the wireframe as seen in Figure 5.5. 


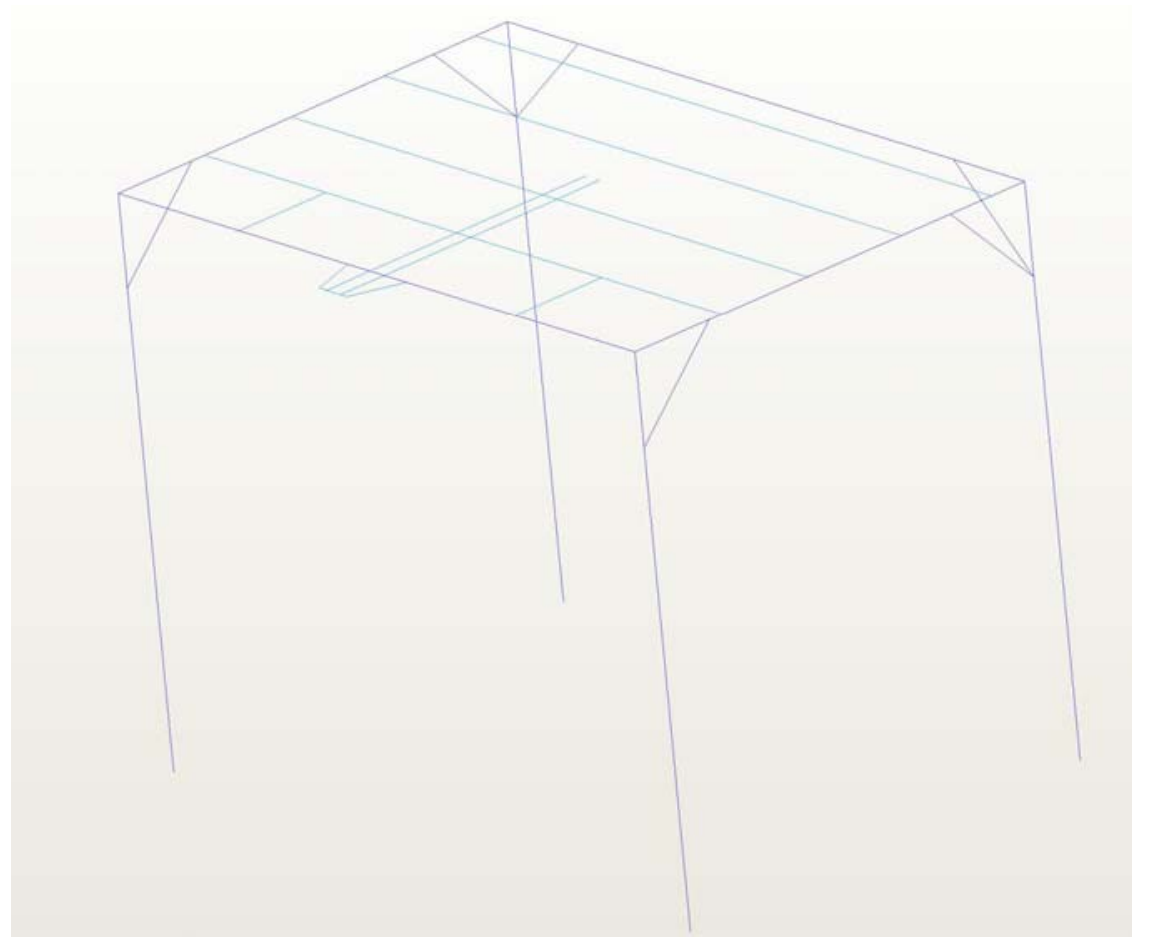

Figure 5.5 Wireframe geometry idealization

The loads applied to the frame are relatively simple. The first is the weight of the propeller and the thrust it applies. Since the frame was simplified, moments were applied as point loads to beam elements to simulate a $1200 \mathrm{lb}$ thrust load a distance away from the centerline of the beam. The thrust and weight loads were reduced to point loads and placed where the approximate locations of the bearing carriers would be on the actual frame. Next, the weight of the driveshaft and its bearings were distributed equally among the bearing locations along the driveshaft support beam.

The motor mount loading was more complicated, as not only the dead weight of the motor was accounted for, but the torque of the motor during operation. The torque was resolved into horizontal and vertical components and applied at the mounting 
locations. A summary table of all the loads applied to the model can be found below in Table 5.1.

Table $5.1 \quad$ Loads applied to FEA model

\begin{tabular}{|c|c|c|}
\hline Load Description & Value & Location \\
\hline Thrust & $1200 \mathrm{lb}$ & Front bearing location \\
\hline Thrust Moment & $7200 \mathrm{lb} \cdot$ in & Front bearing location \\
\hline Propeller Weight & $200 \mathrm{lb}$ & Front bearing location \\
\hline Driveshaft / Bearing Weight & $200 \mathrm{lb}$ & Distributed along driveline \\
\hline Motor Weight & $3000 \mathrm{lb}$ & Motor mounts \\
\hline Motor Torque & $7200 \mathrm{lb} \cdot \mathrm{in}$ & Motor mounts \\
\hline
\end{tabular}

\subsubsection{Finite Element Results}

The static analysis for the frame was completed with the estimated loads. The deflections and stresses of the frame were found and visualized. These results were then analyzed to determine where frame optimization could take place to reduce deflections and stresses. It was found that the cross-members suspending the drivetrain required the most scrutiny due to the larger deflections caused by smaller beams.

\subsubsection{Frame Deflections}

The deflection of the frame was visualized in four ways, by breaking the displacement into the three coordinate axes, $x, y$, and $z$ and then a final displacement magnitude which is a combination of the three deflections. Figure 5.6 displays the magnitude of deflection, illustrating the overall model response. The deflections are exaggerated in order to see the result. 


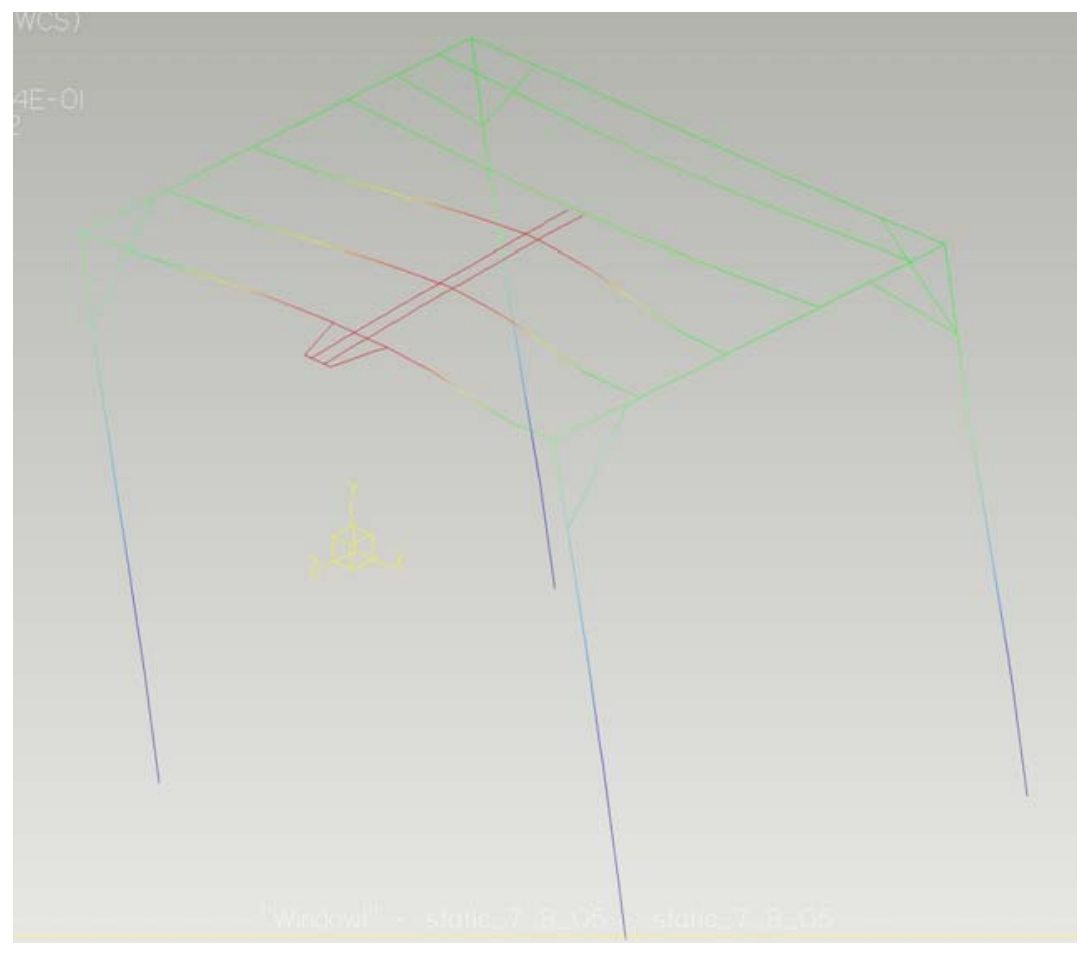

Figure 5.6 Deflection magnitude

The maximum deflection of 0.134 inches was found near the front of the propeller standoff due to the W6x12 beams used compared to the motor cross members. The components of deflection were well below this overall magnitude value and can be found in Appendix A, Figures A.8, A.9, and A.10 for greater detail.

\subsubsection{Stresses}

Much like the deflection of the frame, the stresses are resolved into components as well. The first stress visualizations that were scrutinized were the von Mises (VM) stresses. Von Mises stresses are essentially the combination of the principal stresses and used for material yield criteria. These stresses provide a means of determining the safety of a structure by gauging how close the VM stresses are to the yield strength of the material. 


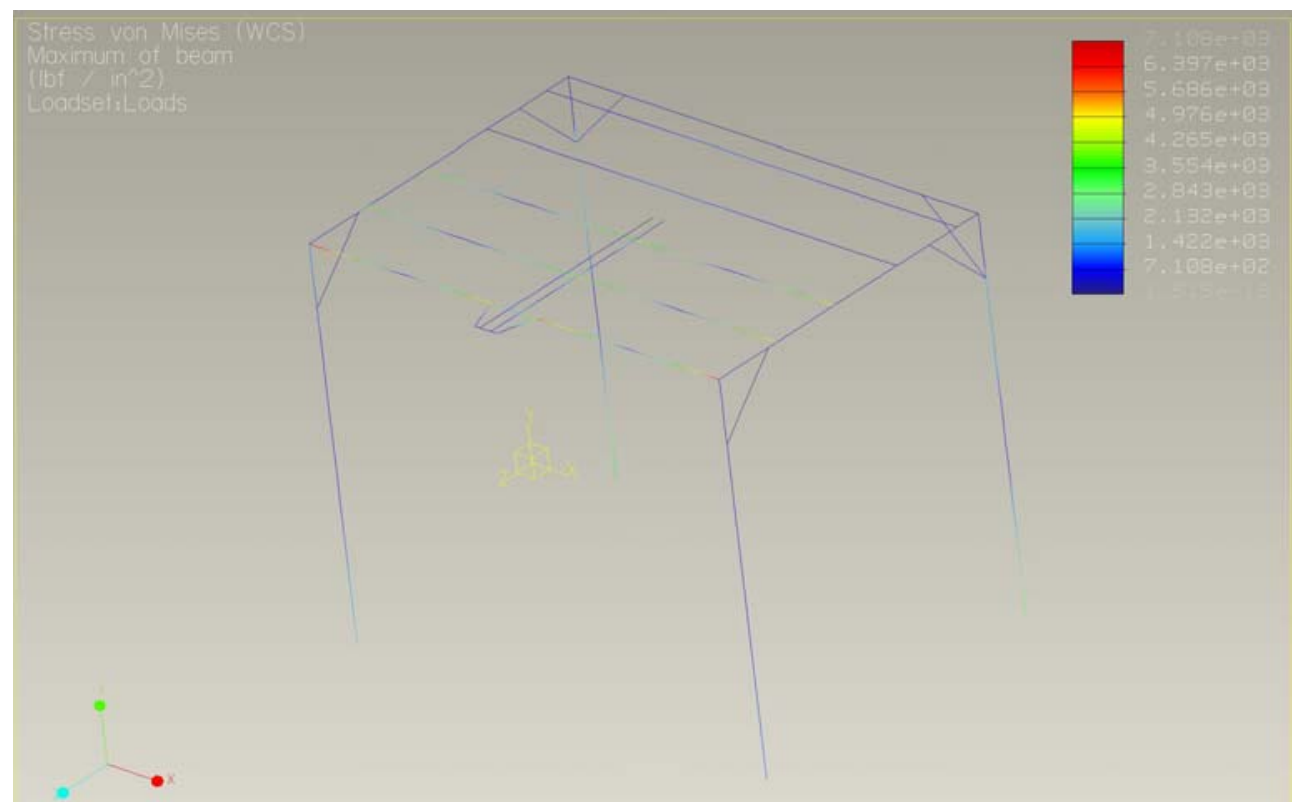

Figure 5.7 Von Mises stress visualization

Again, due to the strength of the beams used and the relatively light loads encountered, the maximum VM stress found was 7191 psi, well below the minimum A993 steel yield strength of $50 \mathrm{ksi}$. The other stress visualizations can be found in Appendix A, Figures A.11 and A.12. For completeness, the numerical output of the FEA is found in Table 5.2 below. It contains all the maximum deflection and stress results. 
Table 5.2 Numerical results from FEA

\begin{tabular}{|l|c|}
\hline \multicolumn{1}{|c|}{ Measure } & Value \\
\hline Max beam bending: & $7045.8 \mathrm{psi}$ \\
\hline Max beam tensile: & $-310.8 \mathrm{psi}$ \\
\hline Max beam torsion: & $827.3 \mathrm{psi}$ \\
\hline Max beam total: & $-7191.5 \mathrm{psi}$ \\
\hline Max disp mag: & $0.1349 \mathrm{in}$ \\
\hline Max disp x: & $-0.0675 \mathrm{in}$ \\
\hline Max disp y: & $-0.0490 \mathrm{in}$ \\
\hline Max disp z: & $-0.1142 \mathrm{in}$ \\
\hline Max prin mag: & $-7191.6 \mathrm{psi}$ \\
\hline Max rot mag: & $0.0024 \mathrm{rad}$ \\
\hline Max rot x: & $0.0008 \mathrm{rad}$ \\
\hline Max rot y: & $-0.0023 \mathrm{rad}$ \\
\hline Max rot z: & $0.0009 \mathrm{rad}$ \\
\hline Max stress prin: & $6900.2 \mathrm{psi}$ \\
\hline Max stress vm: & $7191.6 \mathrm{psi}$ \\
\hline Min stress prin: & $-7191.6 \mathrm{psi}$ \\
\hline Strain energy: & 162.7 \\
\hline
\end{tabular}

When the maximum VM stresses were compare to the yield strength of the steel, a safety factor of 6.95 under static loading conditions was computed. This safety factor is not considered a detriment to the design when one considers the possible loss of materials, equipment, and personnel in the event of frame failure. 


\section{Chapter 6. Conclusion and Recommendations}

\subsection{Summary of Design}

It is impossible to discuss all the fine details that still must be worked out on a project of this magnitude. The preceding design process is clear enough to provide a map to what sections of design still need addressed. In the event that redesign must take place of major components, it is hoped that the preceding is documented thoroughly enough to facilitate a quick solution.

In summary, the design is necessarily robust due to its use in experimental rotorcraft aerodynamics. Time was taken to consider as many loading and failure possibilities as could be found. Table 6.1 below provides list of the safety factors or life expectancies of various components of the design while Table 6.2 provides a list of operational limitations that will maintain the safety factors and life expectancy of components calculated in the preceding. 
Table 6.1 Summary of safety factors

\begin{tabular}{|c|c|}
\hline Component & Value \\
\hline & \\
\hline Driveshaft & $\mathrm{Sf}=9.89$ \\
\hline Bearings & $\mathrm{Life}=5370 \mathrm{hrs}$ \\
\hline Coupler & $\mathrm{Sf}=1.9$ \\
\hline Frame & $\mathrm{Sf}=6.95$ \\
\hline
\end{tabular}

Table 6.2 Recommended operational limits

\begin{tabular}{|c|c|}
\hline Maximum rpm & 3000 \\
\hline Maximum Propeller Weight & $200 \mathrm{lb}$ \\
\hline Maximum Thrust & $1200 \mathrm{lb}$ \\
\hline
\end{tabular}

The designed frame configuration for downwash testing is seen in the following figures. Note that the simplicity of the frame allows for fast construction while maintaining the flexibility of bolted connections of the beams in the event of necessary geometry change for later research. Note: all dimensions are in inches.

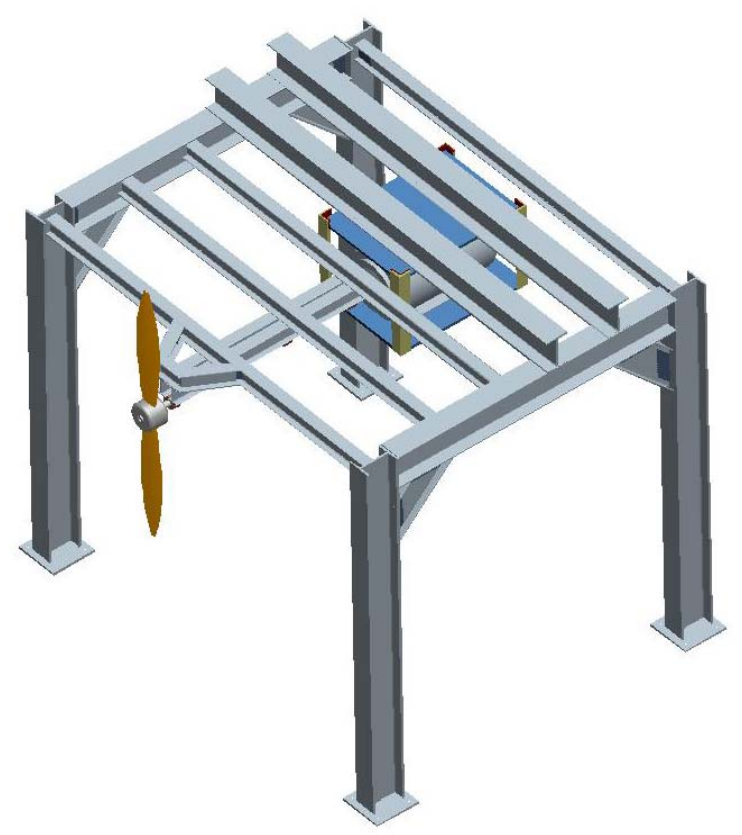

Figure 6.1 Isometric view 


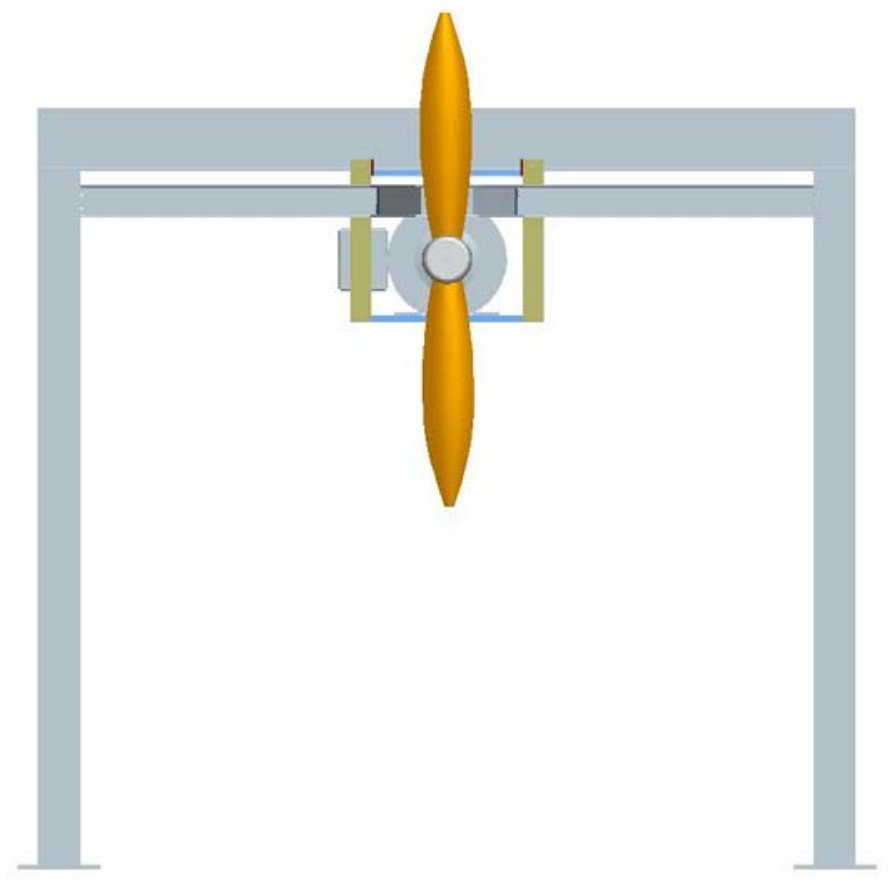

Figure 6.2 Front view

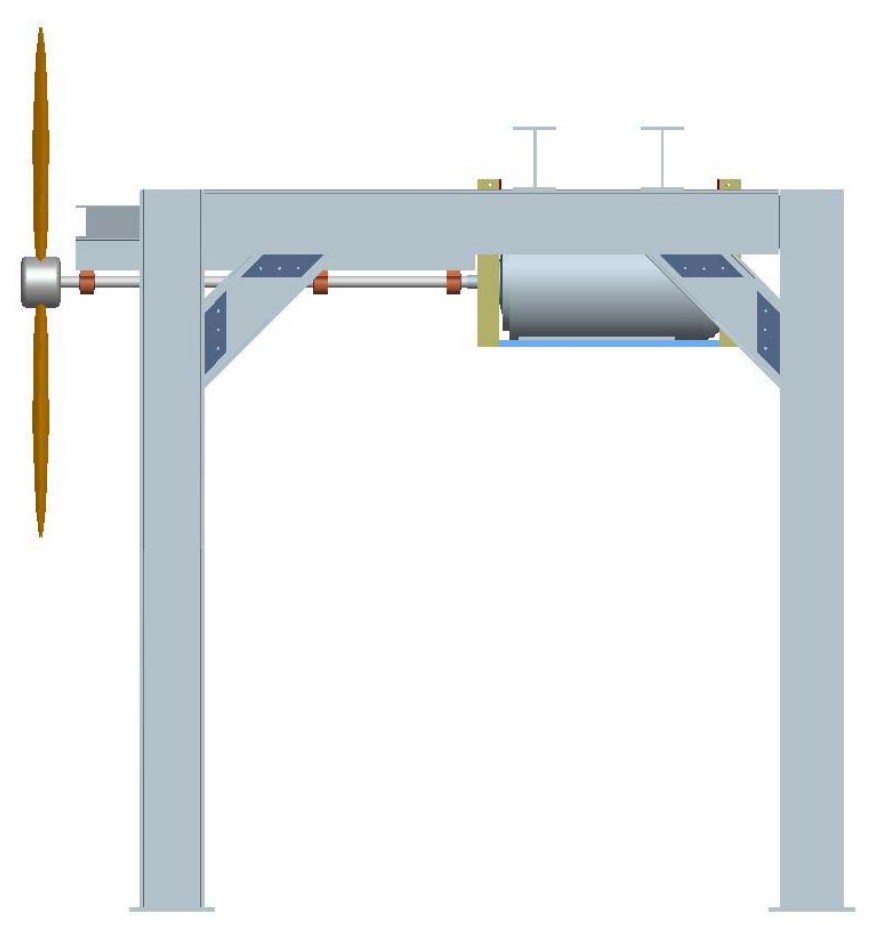

Figure 6.3 Right side view 


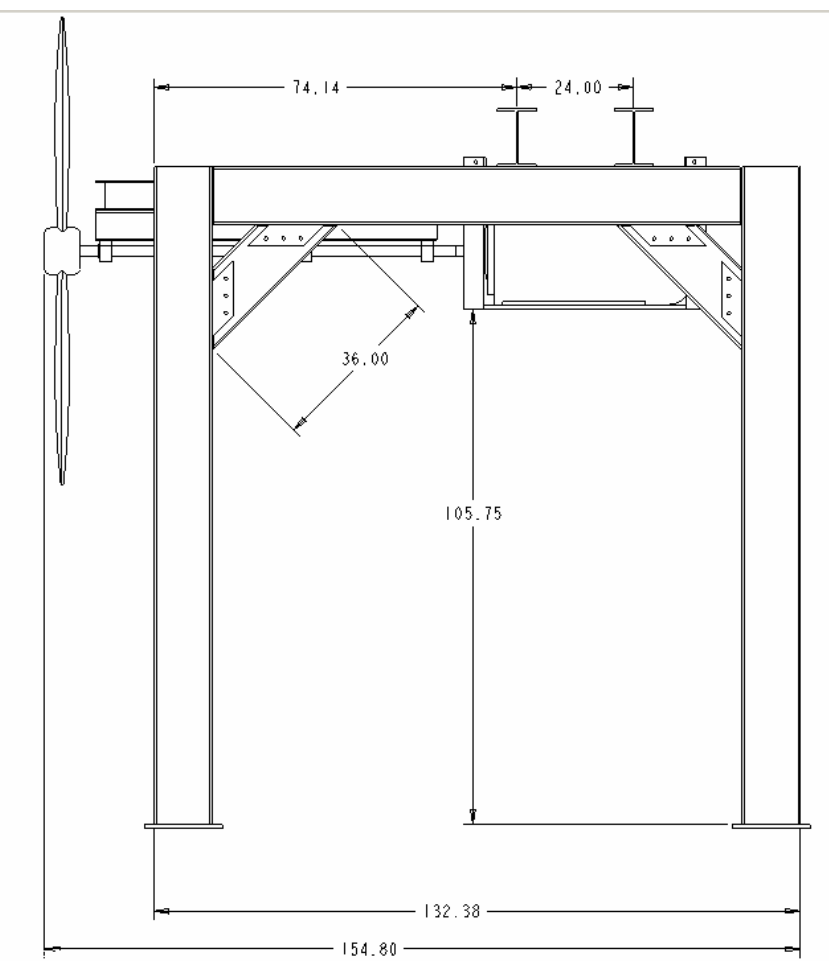

Figure 6.4 Side dimensions

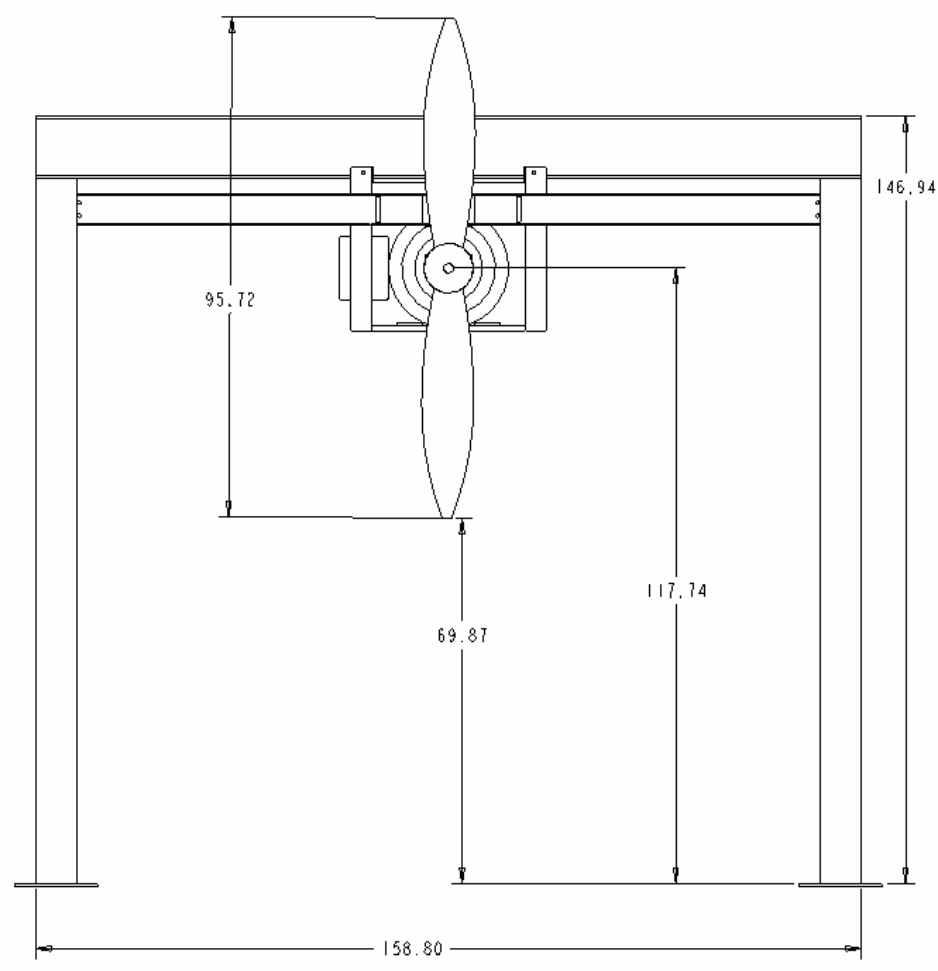

Figure 6.5 Front Dimensions 


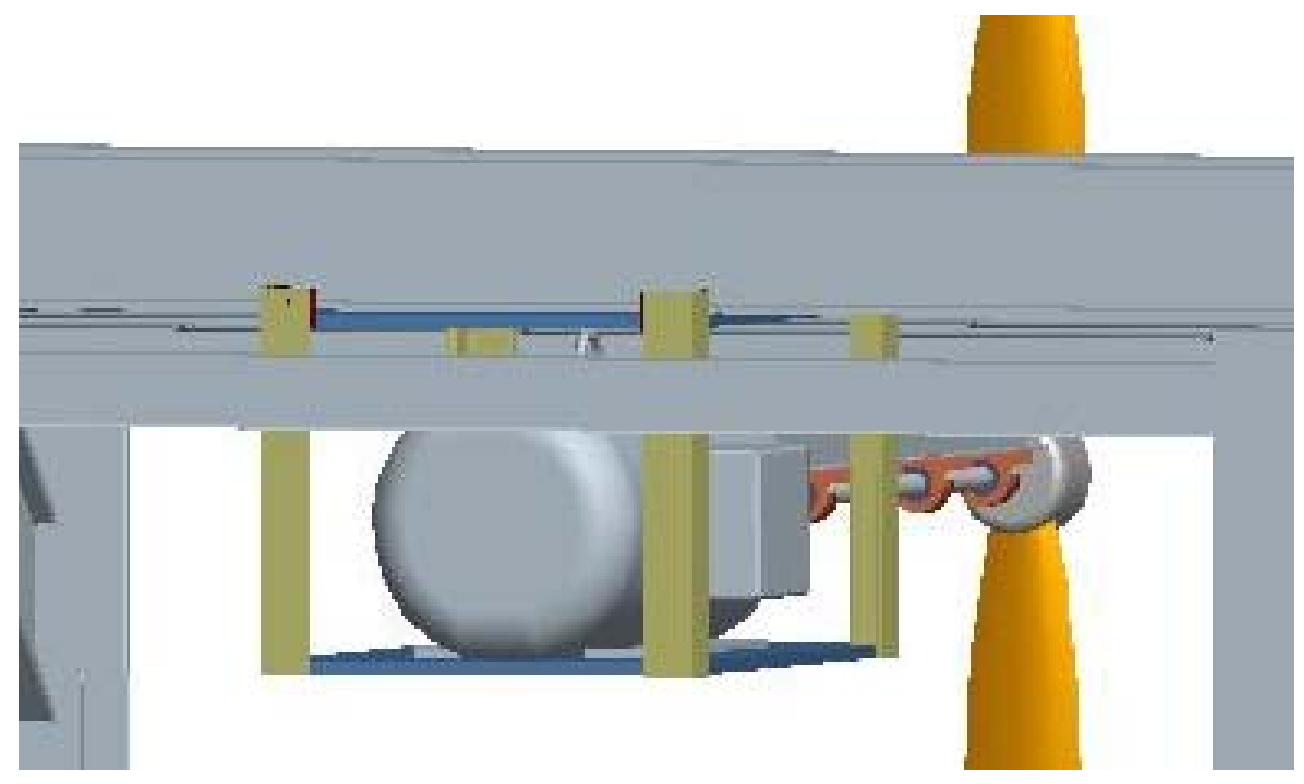

Figure 6.6 Motor mounting rear detail

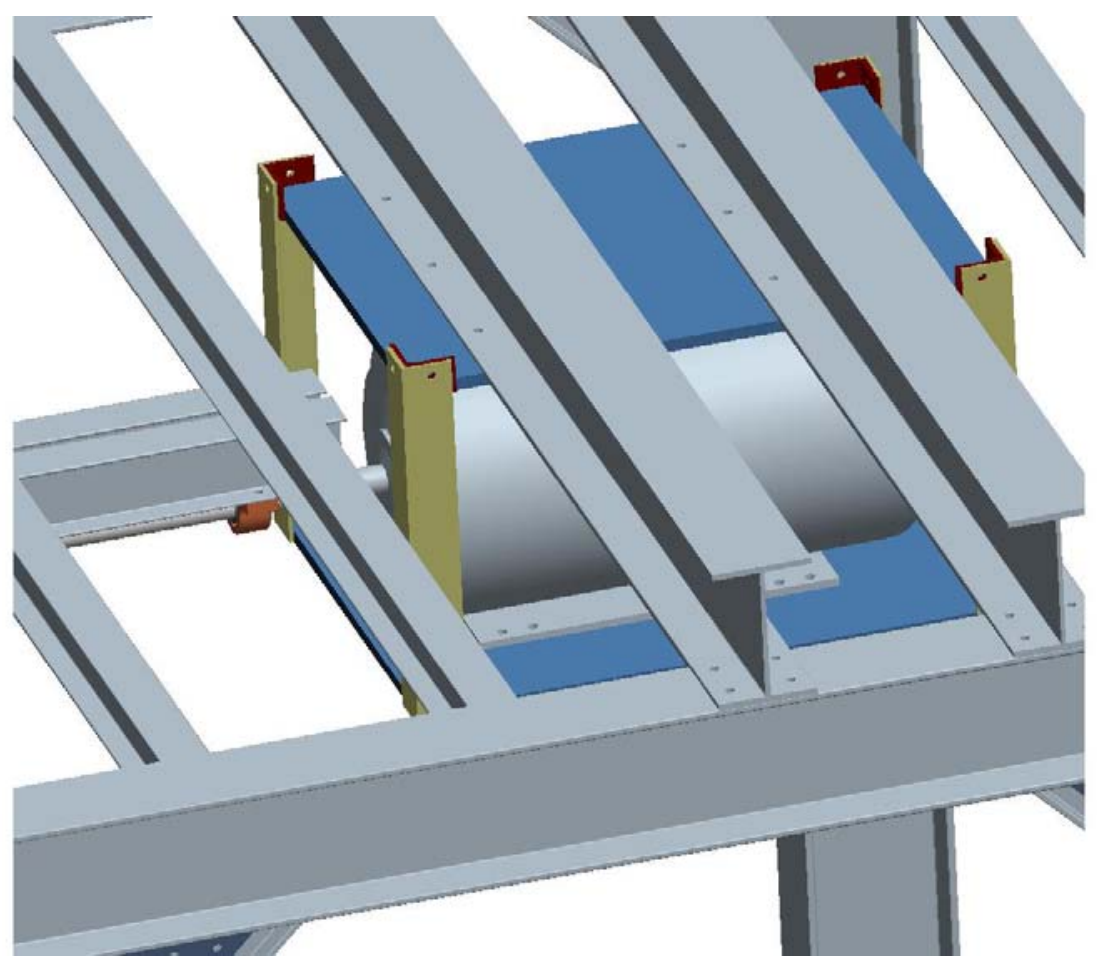

Figure 6.7 Motor mounting detail 


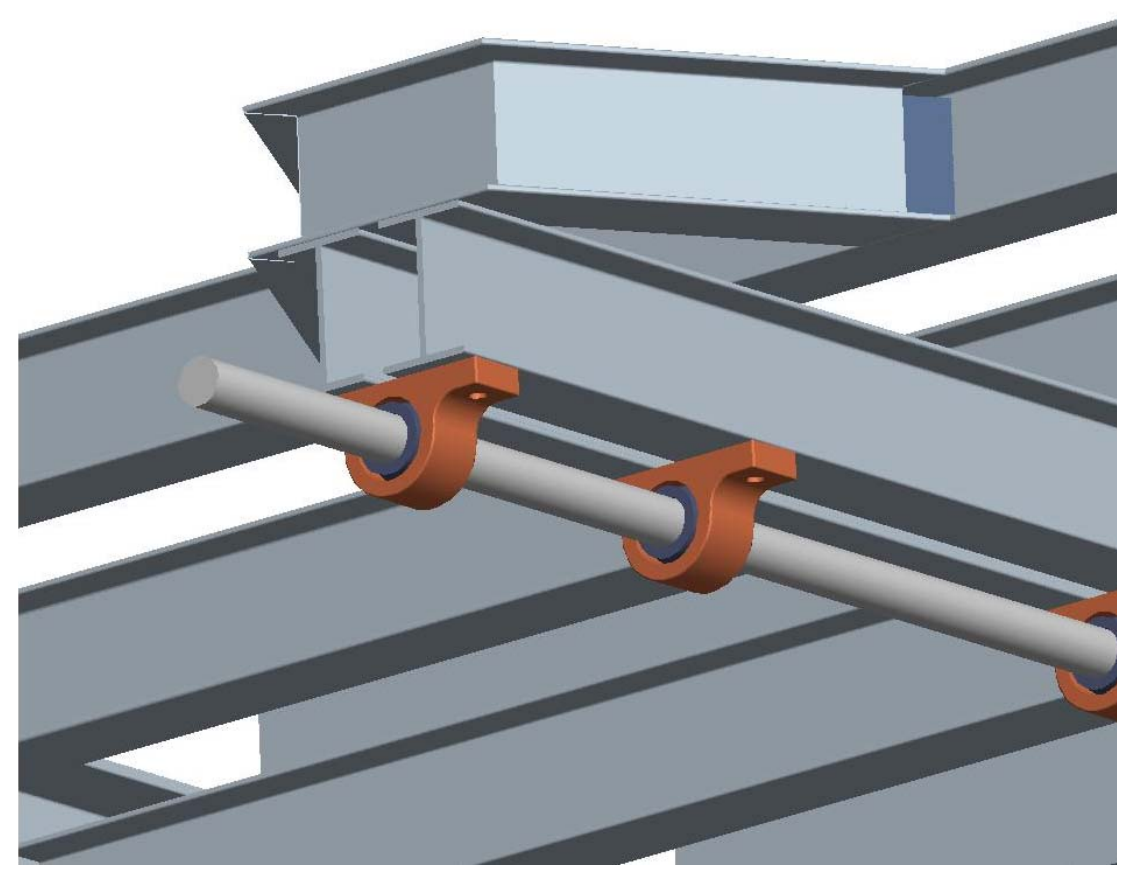

Figure 6.8 Front main bearing and standoff

The objectives specified in Chapter 1 are found below.

1. Design a facility that can continue V-22 research with greater similarity to actual flow conditions

2. Provide testing options for other rotorcraft models

3. Allow for future propeller/ rotor research

4. Design this facility with safety in mind

Objective one was fulfilled by the proper scaling of the V-22 model size to the available propeller. The flow conditions will more closely mimic rotor wash encountered by the actual aircraft providing more realistic results from the use of circulation control. The size and power of the facility allows for various sized models to be constructed and tested fulfilling objective two. Using non-permanent fasteners for frame geometry changes and the calculation of standoff distances required for frame non-interference allows for future 
rotor testing. And finally, all safety factors and life expectancies of components are sufficient, meaning that the facility is designed to reduce the chances of component failure and to account for unknowns in operating conditions fulfilling objective four. Additional safety considerations and recommendations can be found in Appendix B.

\subsection{Recommendations}

The following is a list of areas that will require further attention:

1. Dynamic/ vibration analysis of the frame

2. Bearing lubrication/sealing finalization

3. Propeller mounting flange details including driveshaft machining

4. Routing of power and sensor cables

5. Facility placement for optimum safety and convenience

6. Propeller wake analysis

7. Provisions for thrust and torque measurement

Most of the above can be accomplished while the basic frame is being constructed. Results from the dynamic analysis may indicate that other stiffening members may be required but these can be implemented during construction due to the structure's simplistic design.

Bearing lubrication and sealing details should be discussed further with application engineers from the bearing manufacturer to ensure the longevity and safe operation of the drivetrain over the lifespan of the facility. It is recommended that the most conservative road be taken in this case to reduce the chances of untimely bearing failure. 
The propeller mounting to the driveshaft will become an issue and it is recommended that the machining of the shaft be undertaken with future test configurations in mind. The testing of helicopter rotors may require the use of different hub designs than that of the propeller mounting hub, so driveshaft applicability should be explored in further detail. A non-standard propeller hub may need to be constructed, but can be overbuilt due to the release of weight restrictions. This custom hub will allow the designer to tailor the hub and shaft to be flexible in terms of mechanical connection so that other different hubs may be used.

Perhaps the most critical requirements currently are facility placement and routing of power cables as both of these will determine certain safety and design restrictions such as minimum distances from departmental buildings and power supplies. Interference between the high voltage supply lines and sensors should be investigated as well.

After the construction of the facility, a propeller wake analysis is recommended to determine inflow and outflow characteristics across the propeller diameter. Some type of flow visualization is recommended as well to estimate the effects of structural members on propeller inflow.

Finally, provisions for thrust and torque measurement of the propeller should be investigated. These sensors will become indispensable when measuring forces and torques created by experimental propellers. 


\section{References}

1. Global Security. 27 April. 2005 GlobalSecurity.org

< http://www.globalsecurity.org/military/systems/aircraft/v-22-pics.htm>.

2. Riba, Chad A. "Circulation Control for Download Wake Reduction on a Scaled V-22 Model". West Virginia University, Morgantown 2003.

3. Felker, Fort F., Jeffery S. Light, Robert E. Faye. "Reduction of Tilt Rotor Download Using Circulation Control". NASA Conference Publication-Proceedings of the Circulation-Control Workshop 1986 (1987) 429-447.

4. Johnson, Wayne Helicopter Theory. Princeton: Princeton University Press, 1980.

5. Felker, Fort F., Patrick R. Shinoda, Ruth M. Heffernan, Hugh F. Sheehy. "Wing Force and Surface Pressure Data from a Hover Test of a 0.658-Scale V-22 Rotor and Wing". NASA Technical Memorandum No. 102244, February, 1990.

6. Felker, Fort. F., Martin D. Maisel, Mark D. Betzina. "Full-Scale Tilt-Rotor Hover Performance". $41^{\text {st }}$ Annual Forum of the American Helicopter Society Ft. Worth, May 1985.

7. NASA AMES Image Server. NASA. 10 July 2005

<http://ails.arc.nasa.gov/Images/WindTunnels/\#oarf>.

8. Mantay, Wayne R., Philip A. Shidler, Richard L. Campbell. "Some Results of the Testing of a Full-Scale Ogee-Tip Rotor". Journal of Aircraft. 16 (1979) 215-221.

9. Brusse, J., A.E. Cronk, C.F. Kettleborough. "Tests on Propellers Under Static Thrust Conditions". NASA Contractor Report 1499-1501 (1969).

10. Castles, Walter Jr. "Approximate Solution for Streamlines about a Lifting Rotor Having Uniform Loading and Operating in Hovering or Low-Speed Vertical-Ascent Flight Conditions". NACA Technical Note 3921, Feb 1957.

11. Barlow, Jewel B., William H. Rae, Alan Pope. Low-Speed Wind Tunnel Testing. $3^{\text {rd }}$ ed. New York: John Wiley \& Sons, INC., 1999.

12. Felker, Fort. F. "Wing Download Results from a Test of a 0.658-Scale V-22 Rotor and Wing". Proceedings of the $47^{\text {th }}$ Annual Forum of the American Helicopter Society., Phoenix, Arizona May 6-8, 1991.

13. Lambert, Mark. Ed. Jane's All the World's Aircraft. London: Butler \& Tanner, 1994.

14. AZ Hangar- Pictures of Aircraft, Airports, Landmarks, and the Scenic Countryside. AZ Hangar. 10 July 2005 <http://www.azhangar.com/pictures/cessna_185_1.jpg>.

15. Taylor, John W.R. ed. Jane's All the World's Aircraft. New York: McGraw-Hill, 1967.

16. P. Ponk Aviation. 24 Aug. 2004 P. Ponk Aviation 28 June 2005 <http://www.pponk.com/HTML\%20PAGES/propellers.html> .

17. Heywood, John B. Internal Combustion Engine Fundamentals. New York: McGraw-Hill, 1988. 
18. Gentry, Garl L. Jr., Earl R. Booth Jr., M. A. Takallu. "Effect of Pylon Wake With and Without Pylon Blowing and Propeller Thrust". NASA Technical Memorandum No. 4162, February, 1990.

19. Summit Racing Equipment. Summit Catalog July/August 2005. Summit Racing Equipment, 2005.

20. Pertl, Andy. "Electric Power Considerations for Aero Test Facility". CIRA Internal Report no. 050709, West Virginia University, July 2005.

21. Baldor Electric Company. "Products: AC motors: VM44352T-4". Baldor Electric Company. 10 July 2005. <http://www.baldor.com/>.

22. Weg Industries. "Weg's e-Technical Catalog". Weg Industries. 10 July 2005 $<$ http://www.wegelectric.com>.

23. Weg Industries. Soft Starters 2004 Product Guide. Weg Industries, 2004.

24. Weg Industries. Variable Frequency Drives 2004 Product Guide. Weg Industries, 2004.

25. Shigley, Joseph E., Charles R. Mischke. Mechanical Engineering Design. $6^{\text {th }}$ ed. New York: Mc-Graw Hill, 2001.

26. Budynas, Richard G., Advanced Strength and Applied Stress Analysis. $2^{\text {nd }}$ ed. New York: Mc-Graw Hill, 1999.

27. Mott, Robert L. "Machine Elements in Mechanical Design". Columbus, Ohio: Charles E. Merrill Publishing Co. 1985.

28. Emerson Power Transmission, Kop-Flex Size 023 Through 935 Catalog. Emerson Power Transmission, 2004.

29. Shuanlong Bearings. 10 July 2005 . Shuanlong Bearings. <http://www.cnddbearing.com/images/4.jpg $>$.

30. The Timken Company. Tapered Roller Bearing Selection Guide. The Timken Company, 2005.

31. Greenwood, Douglas C. Mechanical Power Transmission. New York: McGraw-Hill, 1962.

32. American Institute of Steel Construction. Manual of Steel Construction, Allowable Stress Design. Chicago, 1989.

33. Ganon, Yves, "Part I - Idealizations, A Tutorial for Pro/Mechanica Integrated Mode" $1^{\text {st }}$ ed. SDC Publications, May 2003.

34. Federal Aviation Administration, "Hazards of Rotating Propeller and Helicopter Rotor Blades". FAA Advisory Circular AC-91-42C, May 1981. 


\section{Appendix A}

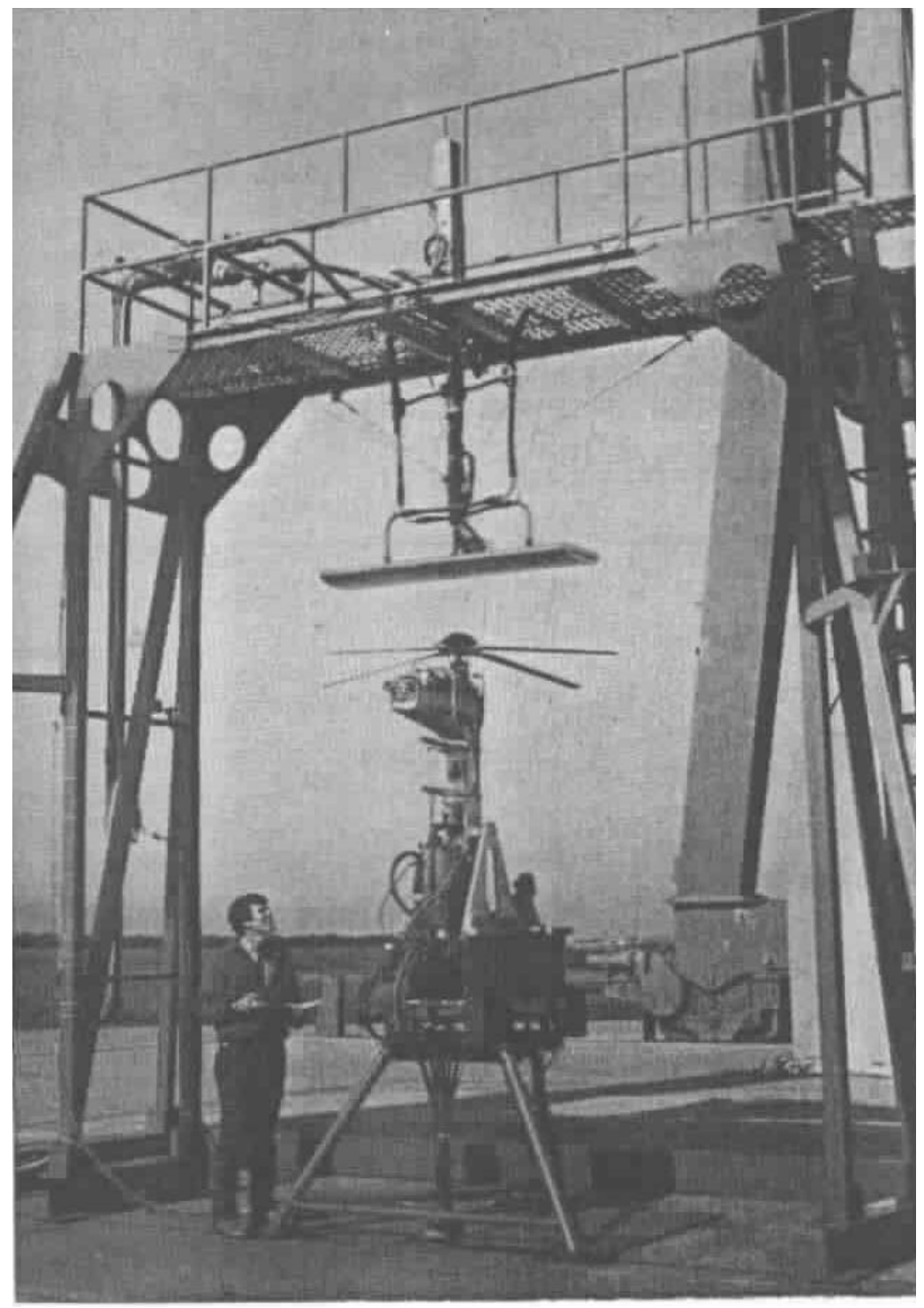

Figure A. 1 Circulation control test apparatus ${ }^{3}$ 


\section{Table A 1 Bearing slope spreadsheet}

\begin{tabular}{|l|r|}
\hline Propeller Weight (lbs) & 200.00 \\
\hline shaft length (in) & 6.00 \\
\hline Shaft Diameter (in) & 1.94 \\
\hline M.O.I in^4 & 0.6917 \\
\hline Mod of Elas. & $2.92 \mathrm{E}+07$ \\
\hline Stress (psi) & 1681 \\
\hline
\end{tabular}

\begin{tabular}{|l|r|}
\hline Shaft Density (lb/in^3) & 0.282 \\
\hline Shaft volume ( $\left(\mathrm{in}^{\wedge} 3\right)$ & 17.690 \\
\hline Shaft weight $(\mathrm{b})$ & 4.989 \\
\hline W (lb/in) & 0.831 \\
\hline
\end{tabular}

\begin{tabular}{l|l|l|l|l|l|l|l|}
\hline \% of length & $\mathrm{x}$ location (in) & deflection (in) (no grav) & slope (rad) (no grav) & deflection (grav) & slope (grav) & deflection total & slope total \\
\hline
\end{tabular}

\begin{tabular}{|c|c|c|c|c|c|c|c|}
\hline 0.05 & 0.3 & $-2.629 \mathrm{E}-06$ & $-1.738 \mathrm{E}-05$ & $-3.224 \mathrm{E}-08$ & $-2.113 \mathrm{E}-07$ & $-2.661 \mathrm{E}-06$ & $-1.759 \mathrm{E}-05$ \\
\hline 0.1 & 0.6 & $-1.034 \mathrm{E}-05$ & $-3.386 \mathrm{E}-05$ & $-1.247 \mathrm{E}-07$ & $-4.016 \mathrm{E}-07$ & $-1.046 \mathrm{E}-05$ & $-3.427 \mathrm{E}-05$ \\
\hline 0.15 & 0.9 & $-2.286 \mathrm{E}-05$ & $-4.946 \mathrm{E}-05$ & $-2.712 \mathrm{E}-07$ & $-5.718 \mathrm{E}-07$ & $-2.313 \mathrm{E}-05$ & $-5.003 \mathrm{E}-05$ \\
\hline 0.2 & 1.2 & $-3.992 \mathrm{E}-05$ & $-6.416 \mathrm{E}-05$ & $-4.659 \mathrm{E}-07$ & $-7.231 \mathrm{E}-07$ & $-4.039 \mathrm{E}-05$ & $-6.489 \mathrm{E}-05$ \\
\hline 0.25 & 1.5 & $-6.127 \mathrm{E}-05$ & $-7.798 \mathrm{E}-05$ & $-7.033 \mathrm{E}-07$ & $-8.567 \mathrm{E}-07$ & $-6.197 \mathrm{E}-05$ & $-7.883 \mathrm{E}-05$ \\
\hline 0.3 & 1.8 & $-8.662 \mathrm{E}-05$ & $-9.090 \mathrm{E}-05$ & $-9.782 \mathrm{E}-07$ & $-9.736 \mathrm{E}-07$ & $-8.760 \mathrm{E}-05$ & $-9.187 \mathrm{E}-05$ \\
\hline 0.35 & 2.1 & $-1.157 \mathrm{E}-04$ & $-1.029 \mathrm{E}-04$ & $-1.286 \mathrm{E}-06$ & $-1.075 \mathrm{E}-06$ & $-1.170 \mathrm{E}-04$ & $-1.040 \mathrm{E}-04$ \\
\hline 0.4 & 2.4 & $-1.483 \mathrm{E}-04$ & $-1.141 \mathrm{E}-04$ & $-1.622 \mathrm{E}-06$ & $-1.162 \mathrm{E}-06$ & $-1.499 \mathrm{E}-04$ & $-1.152 \mathrm{E}-04$ \\
\hline 0.45 & 2.7 & $-1.841 \mathrm{E}-04$ & $-1.243 \mathrm{E}-04$ & $-1.982 \mathrm{E}-06$ & $-1.235 \mathrm{E}-06$ & $-1.860 \mathrm{E}-04$ & $-1.256 \mathrm{E}-04$ \\
\hline 0.5 & 3 & $-2.228 \mathrm{E}-04$ & $-1.337 \mathrm{E}-04$ & $-2.362 \mathrm{E}-06$ & $-1.297 \mathrm{E}-06$ & $-2.252 \mathrm{E}-04$ & $-1.350 \mathrm{E}-04$ \\
\hline 0.55 & 3.3 & $-2.642 \mathrm{E}-04$ & $-1.421 \mathrm{E}-04$ & $-2.758 \mathrm{E}-06$ & $-1.347 \mathrm{E}-06$ & $-2.669 \mathrm{E}-04$ & $-1.435 \mathrm{E}-04$ \\
\hline 0.6 & 3.6 & $-3.080 \mathrm{E}-04$ & $-1.497 \mathrm{E}-04$ & $-3.169 \mathrm{E}-06$ & $-1.387 \mathrm{E}-06$ & $-3.112 \mathrm{E}-04$ & $-1.511 \mathrm{E}-04$ \\
\hline 0.65 & 3.9 & $-3.539 \mathrm{E}-04$ & $-1.564 \mathrm{E}-04$ & $-3.590 \mathrm{E}-06$ & $-1.418 \mathrm{E}-06$ & $-3.575 \mathrm{E}-04$ & $-1.578 \mathrm{E}-04$ \\
\hline 0.7 & 4.2 & $-4.017 \mathrm{E}-04$ & $-1.622 \mathrm{E}-04$ & $-4.019 \mathrm{E}-06$ & $-1.442 \mathrm{E}-06$ & $-4.058 \mathrm{E}-04$ & $-1.636 \mathrm{E}-04$ \\
\hline 0.75 & 4.5 & $-4.511 \mathrm{E}-04$ & $-1.671 \mathrm{E}-04$ & $-4.454 \mathrm{E}-06$ & $-1.459 \mathrm{E}-06$ & $-4.556 \mathrm{E}-04$ & $-1.686 \mathrm{E}-04$ \\
\hline 0.8 & 4.8 & $-5.019 \mathrm{E}-04$ & $-1.711 \mathrm{E}-04$ & $-4.894 \mathrm{E}-06$ & $-1.470 \mathrm{E}-06$ & $-5.068 \mathrm{E}-04$ & $-1.726 \mathrm{E}-04$ \\
\hline 0.85 & 5.1 & $-5.537 \mathrm{E}-04$ & $-1.742 \mathrm{E}-04$ & $-5.336 \mathrm{E}-06$ & $-1.477 \mathrm{E}-06$ & $-5.591 \mathrm{E}-04$ & $-1.757 \mathrm{E}-04$ \\
\hline 0.9 & 5.4 & $-6.063 \mathrm{E}-04$ & $-1.764 \mathrm{E}-04$ & $-5.779 \mathrm{E}-06$ & $-1.480 \mathrm{E}-06$ & $-6.121 \mathrm{E}-04$ & $-1.779 \mathrm{E}-04$ \\
\hline 0.95 & 5.7 & $-6.595 \mathrm{E}-04$ & $-1.778 \mathrm{E}-04$ & $-6.224 \mathrm{E}-06$ & $-1.482 \mathrm{E}-06$ & $-6.657 \mathrm{E}-04$ & $-1.793 \mathrm{E}-04$ \\
\hline 1 & 6 & $-7.129 \mathrm{E}-04$ & $-1.782 \mathrm{E}-04$ & $-6.668 \mathrm{E}-06$ & $-1.482 \mathrm{E}-06$ & $-7.196 \mathrm{E}-04$ & $-1.797 \mathrm{E}-04$ \\
\hline
\end{tabular}

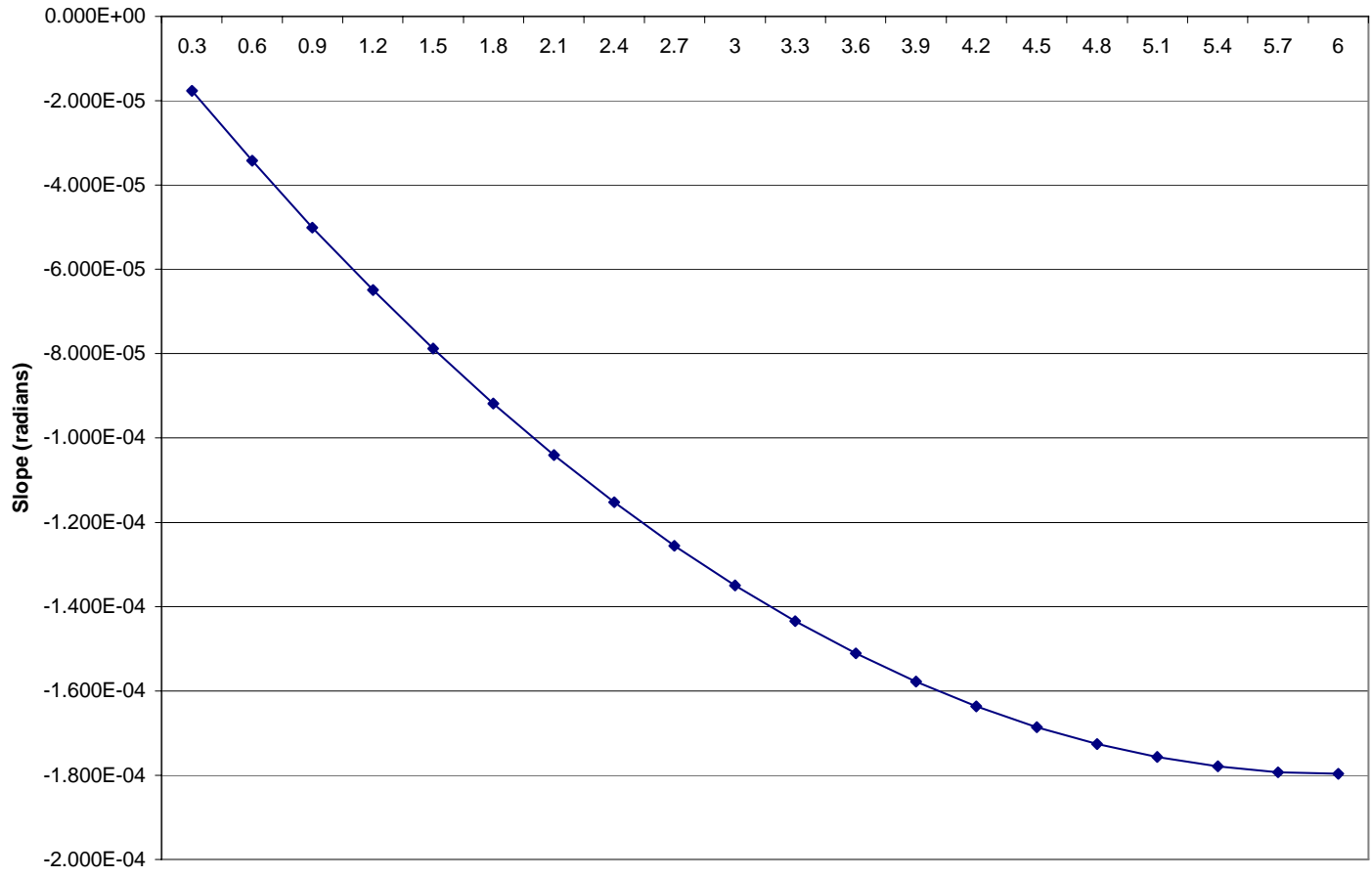

Length (in)

Figure A. 2 Shaft slope 


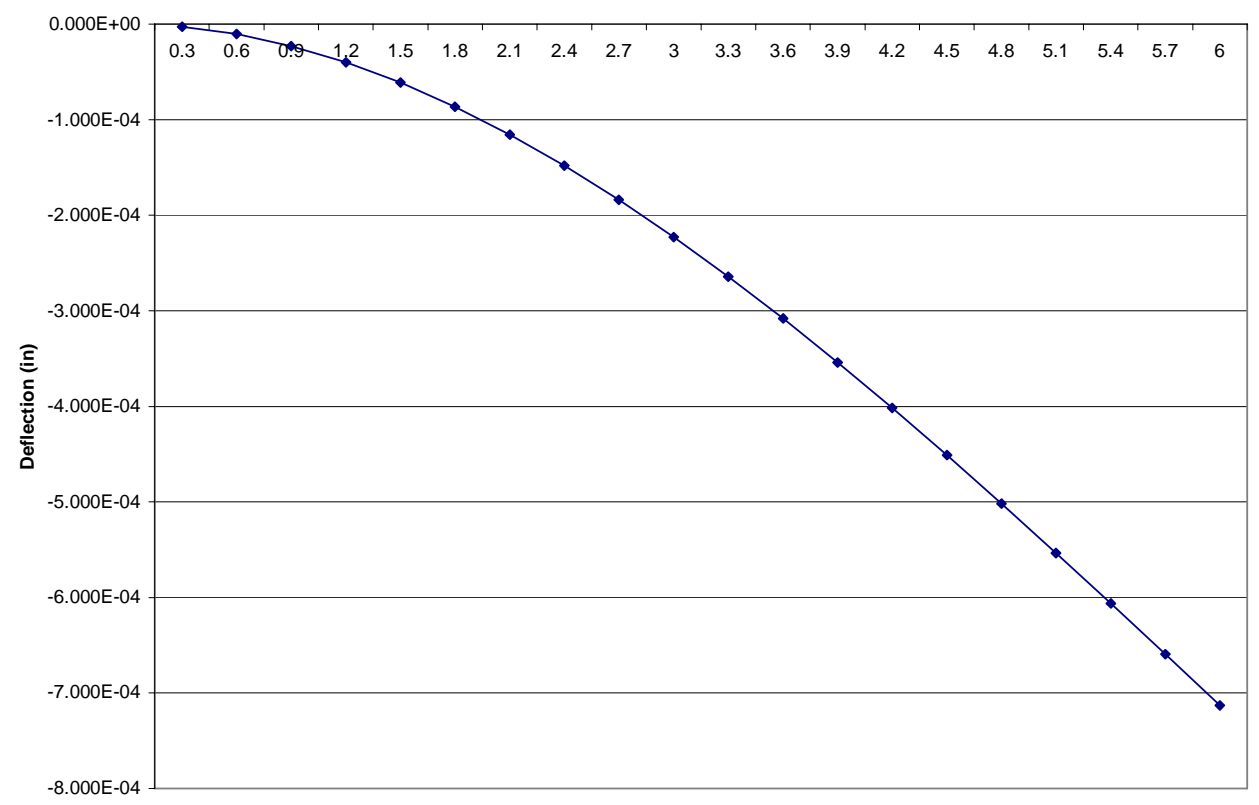

$X$ location (in)

Figure A. 3 Shaft deflection

The KD4 coupling is designed for medium and heavy duty applications requiring only angular misalignment capacity as in three bearing installations or floating shaft arrangements.

The larger size couplings available in the KD4 Series allow application to larger, high power machines.

Consisting of three main parts, two hubs and a unitized disc pack which installs or drops out, the KD4 simplifies installation or maintenance. The close tolerance bolts and safety overload washers insure superior performance and trouble free operation.

For complete floating shaft assemblies, consider a KD41 or KD42 disc coupling. For lower power requirements, consider a KD5 disc coupling.

\section{KD4 Couplings use HT Disc Packs.}

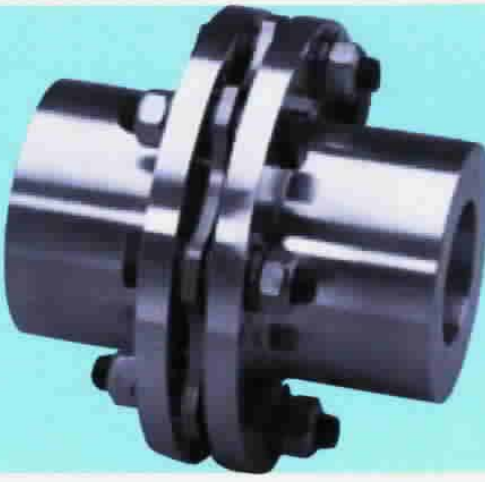

- Angular Misalignment Capacity

- Heavy Duty, Small to Large Sizes

- Drop-Out, Unitized Disc Packs

\section{Selection Data}

\begin{tabular}{|c|c|c|c|c|c|c|c|c|}
\hline \multirow[b]{2}{*}{ Size } & \multirow{2}{*}{$\begin{array}{l}\text { Max. } \\
\text { Bore } \\
\text { (in) }\end{array}$} & \multirow{2}{*}{$\begin{array}{c}\text { Coupling } \\
\text { Rating } \\
\text { (HP/100 RPM) }\end{array}$} & \multicolumn{2}{|c|}{ Torque Rating } & \multirow{2}{*}{$\begin{array}{l}\text { Maximum } \\
\text { Speed } \\
\text { RPM }\end{array}$} & \multirow{2}{*}{$\begin{array}{l}\text { Totald } \\
\text { Weight } \\
\text { (lbs) }\end{array}$} & \multirow{2}{*}{$\begin{array}{l}\text { TotalФ } \\
\text { WR } \\
\left(1 \mathrm{~b}-\mathrm{in}^{2}\right)\end{array}$} & \multirow{2}{*}{$\begin{array}{c}\text { Axial } \\
\text { Capacitye } \\
\text { (in) }\end{array}$} \\
\hline & & & $\begin{array}{l}\text { Continuous } \\
\text { (in-lb) }\end{array}$ & $\begin{array}{c}\text { Peak } \\
\text { (in-lb) }\end{array}$ & & & & \\
\hline 103 & 1.75 & 6.3 & 4000 & 8000 & 18200 & 5.2 & 9.5 & \pm .040 \\
\hline 153 & 2.50 & 21.6 & 13600 & 27200 & 14800 & 11.4 & 38.5 & \pm .070 \\
\hline 204 & 3.00 & 57.1 & 36000 & 72000 & 13000 & 24.1 & 124 & \pm .055 \\
\hline 254 & 3.75 & 82.5 & 52000 & 104000 & 11200 & 32.2 & 212 & \pm .070 \\
\hline 304 & 4.50 & 141 & 89000 & 178000 & 9900 & 50.5 & 462 & \pm .085 \\
\hline 354 & 5.00 & 238 & 150000 & 300000 & 8800 & 78.5 & 980 & \pm .100 \\
\hline 404 & 5.50 & 340 & 215000 & 430000 & 7800 & 118 & 1880 & \pm .113 \\
\hline 454 & 6.38 & 405 & 255000 & 510000 & 7200 & 150 & 2780 & \pm .125 \\
\hline
\end{tabular}

Figure A. 4 Kop-Flex KD4 catalog page ${ }^{28}$ 


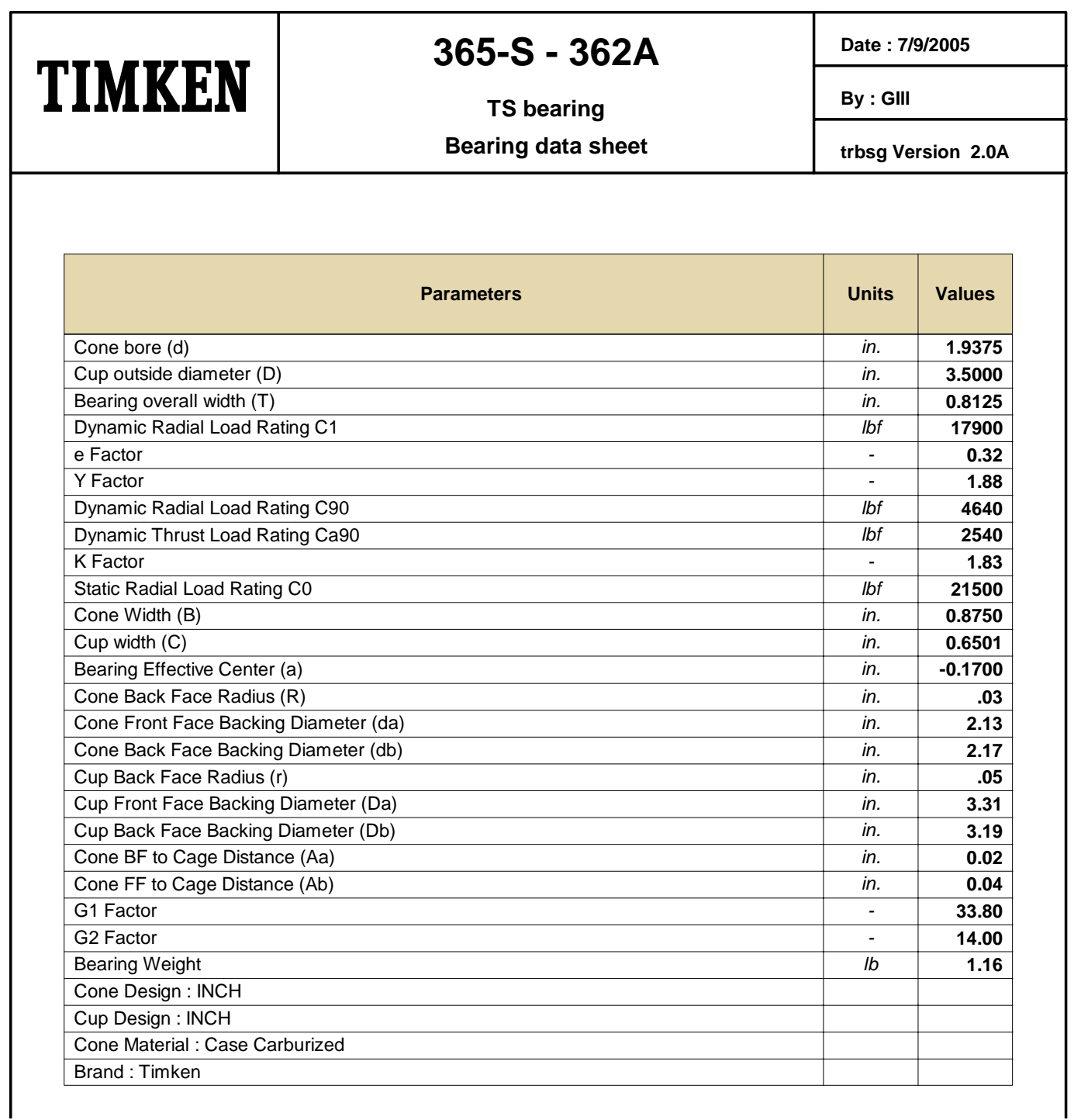

Figure A. 5 Timken TRB selection guide report ${ }^{30}$ 


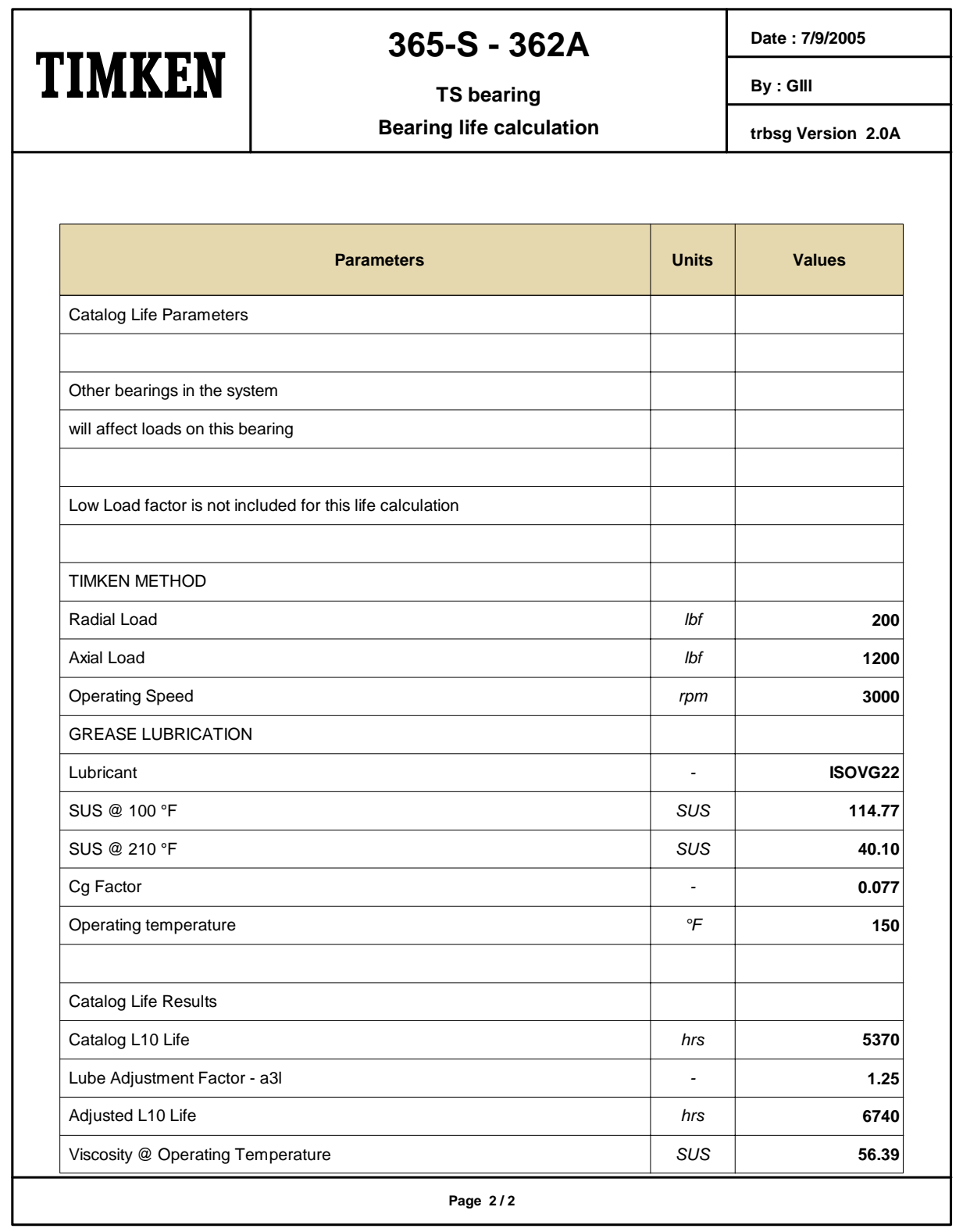

Figure A. 6 Timken TRB selection guide report cont. ${ }^{30}$ 


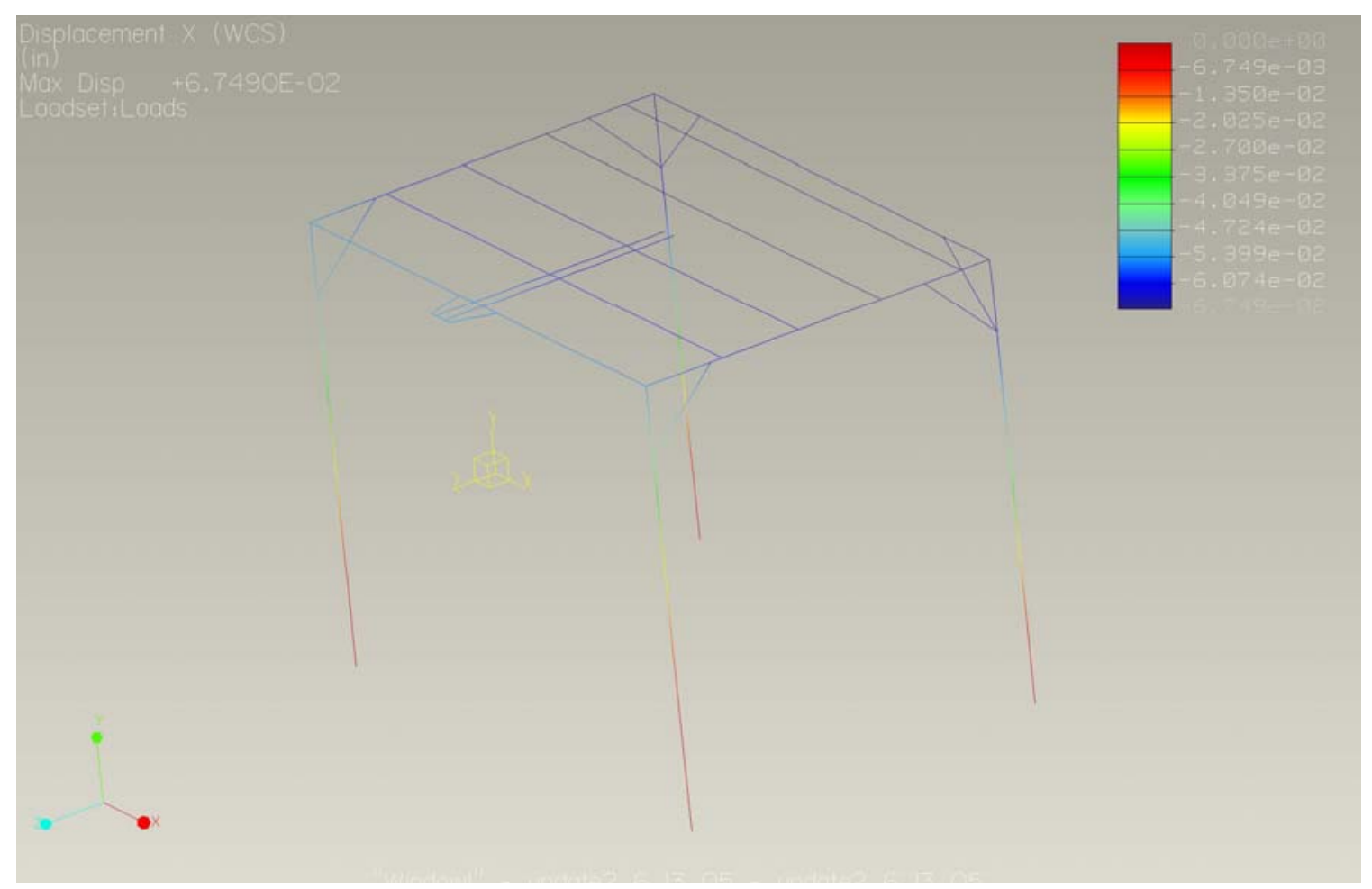

Figure A. 7 X-component deflection

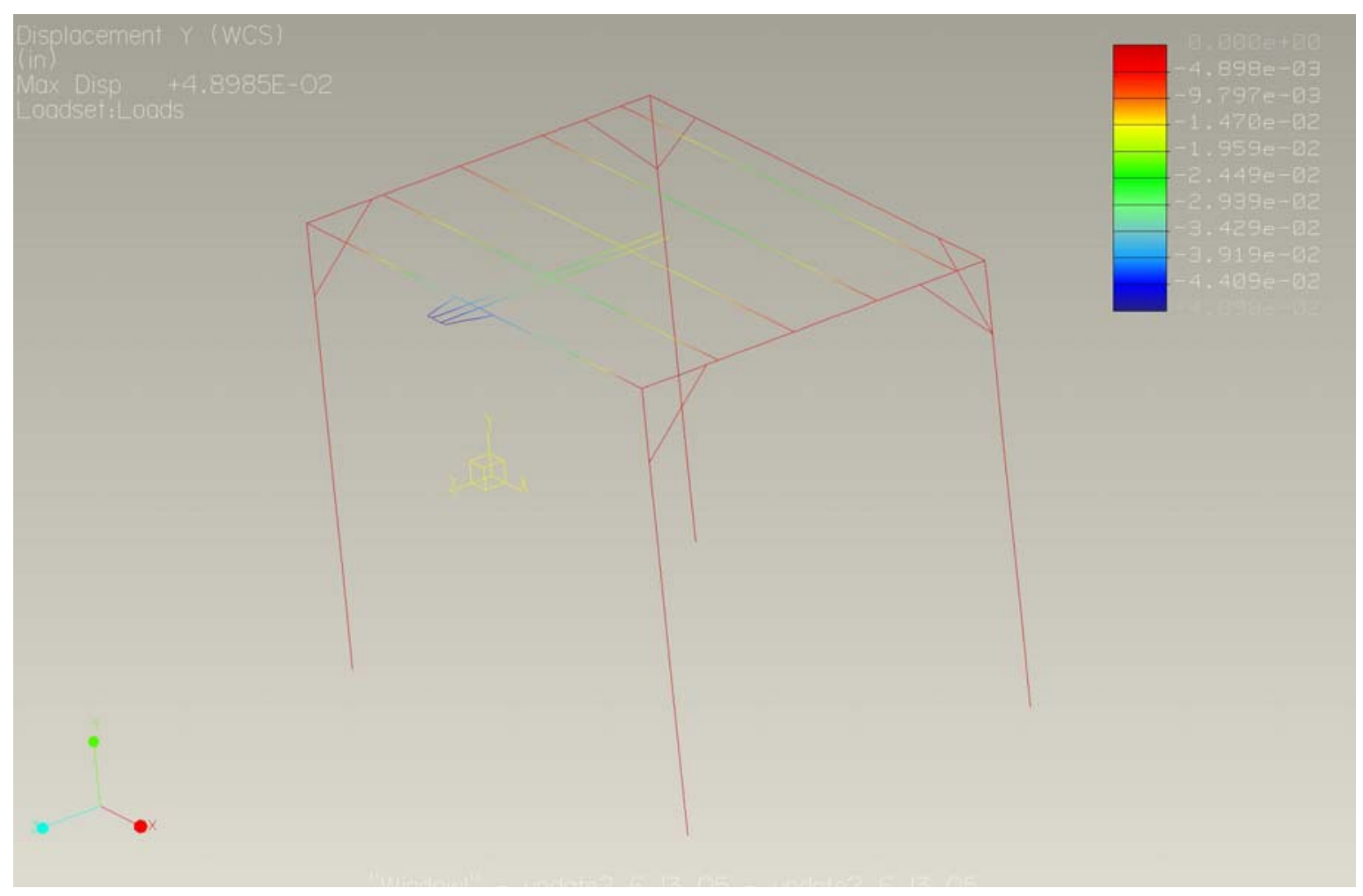

Figure A. 8 Y-component deflection 


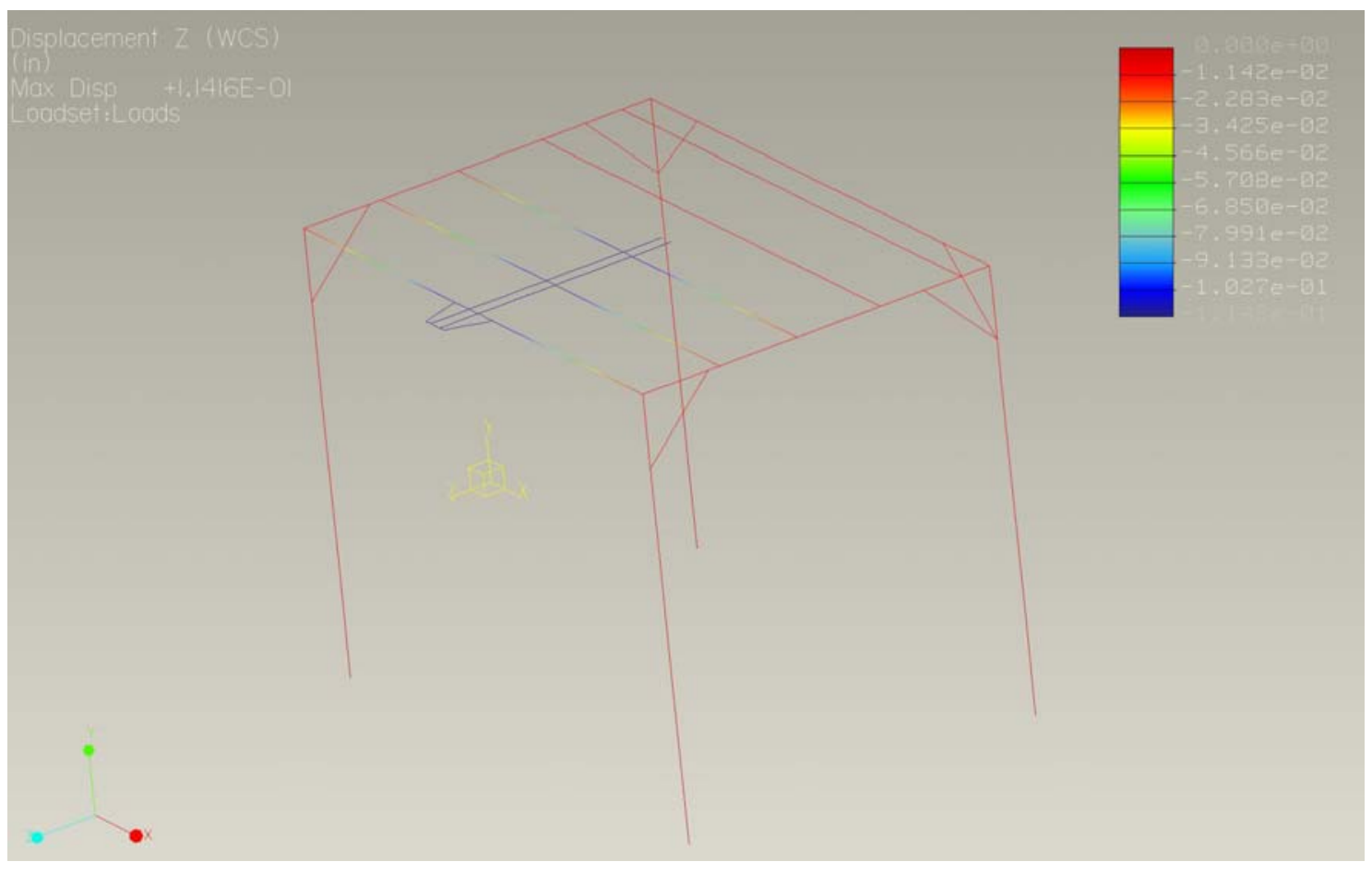

Figure A. 9 Z-component deflection 


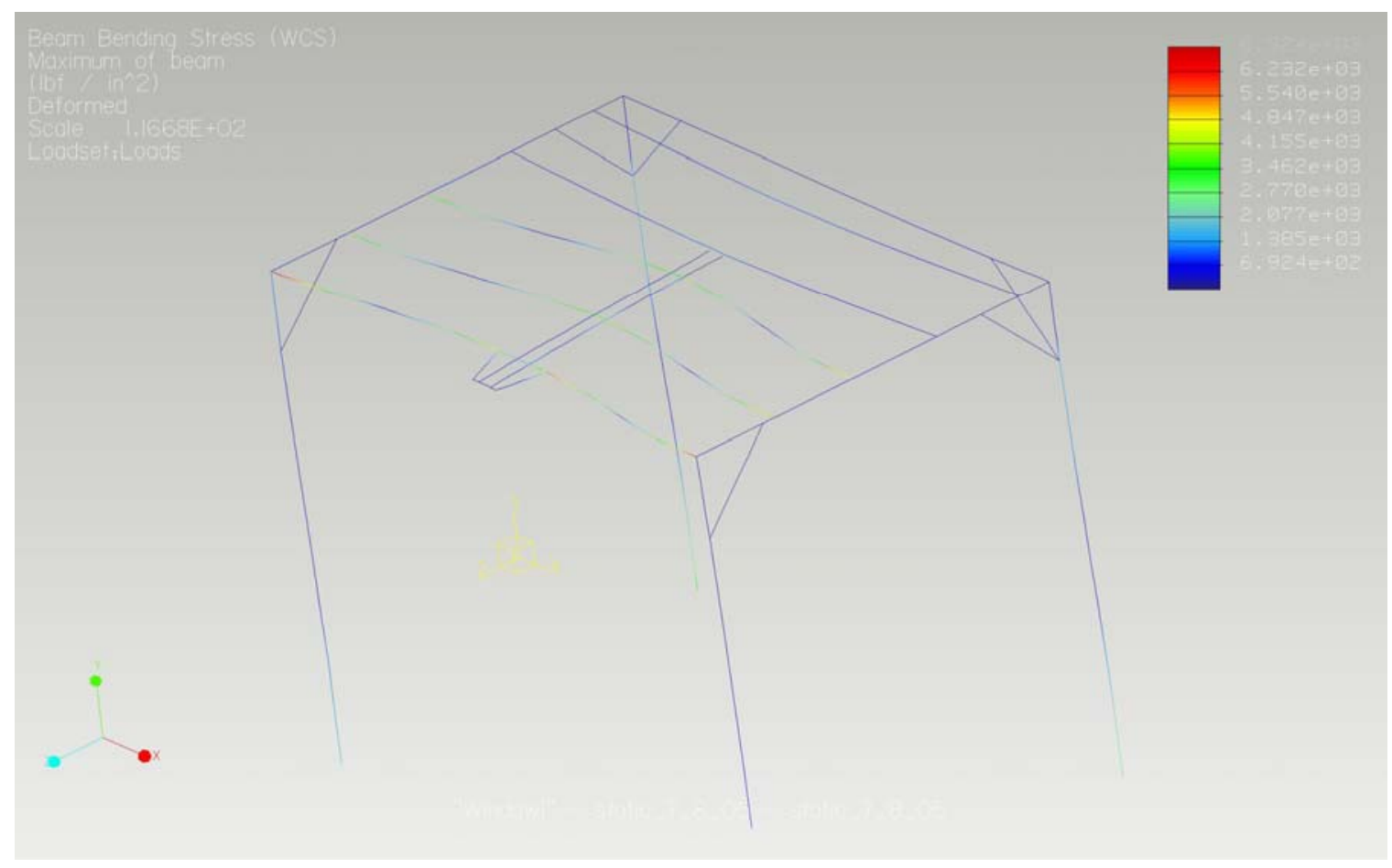

Figure A. 10 Beam bending stress

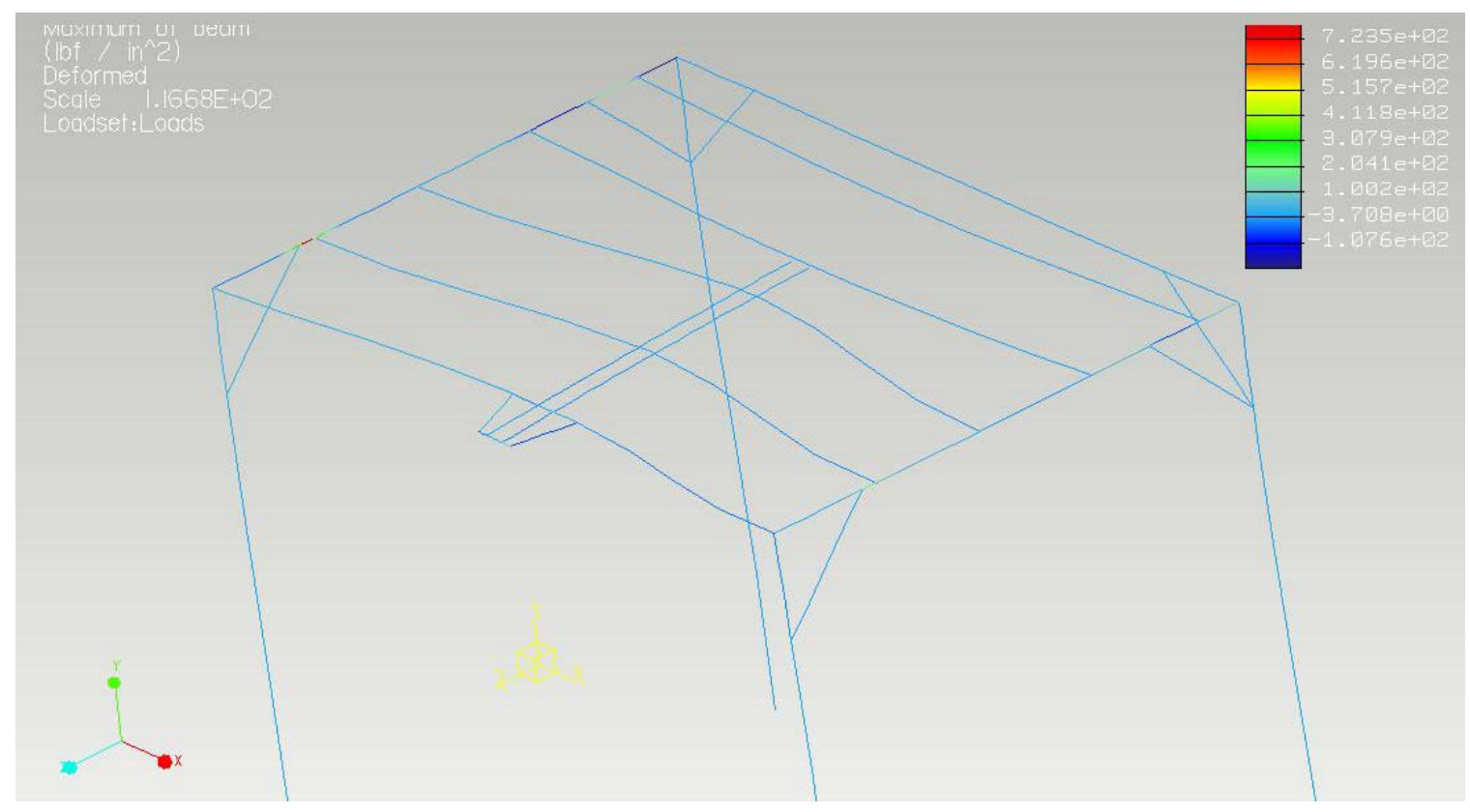

Figure A. 11 Beam torsional stress 


\section{Appendix B}

\section{A 1.1 Facility Safety}

Given the nature of experimental test facilities, the possibility of component failure increases due to the fact that, often times components are used outside of their initial design criteria. One of the driving forces behind the design of this apparatus has been safety during operation. A few hazards listed in ascending order of possible danger to facilities and personnel.

1. Blowing debris/ foreign object damage

2. Non-catastrophic drivetrain component failure

3. Model structural failure

4. Catastrophic electrical malfunction during operation or maintenance

5. Catastrophic frame failure during operation or maintenance

6. Catastrophic propeller failure during operation

7. Personnel contact with moving drivetrain

8. Personnel contact with moving propeller

A few of these situations are easily avoided given certain precautions are taken during all phases of operation. Others require more comprehensive methods to ensure the safety of operators and maintenance personnel.

\section{A 1.2 Personnel Safety Radius}

The most obvious and easily implemented safety measure is to ensure that no person is within a certain distance of the test stand during operation. Signs should be posted at radial intervals around the facility as well as near a restricted area that coincides 
with the line of the propeller during operation. If possible, the use of fence around the radius should be implemented to reduce the chances of unknown persons entering unsafe areas during operation or maintenance.

\section{A 1.3 Personnel Education}

A test facility is only as safe as its most careless operator or technician. Those working on the project as engineers or test facility technicians should be well briefed about the potential hazards of moving machinery and high voltage power supplies as well as "lock-out" procedures in the event that power to the device must be turned off for maintenance, apparatus adjustment, or actions related to model adjustment.

All facility personnel should be briefed about emergency procedures in the event of different scenarios. All personnel should know the locations of emergency stop buttons, fire extinguishers, first aid kits, and emergency phone numbers.

\section{A 1.4 Grounds Maintenance}

The grounds around the test stand should be kept free of debris and loose particles if possible. It is recommended that the area around the test facility be inspected before every test run and proper cleaning to the grounds be done to ensure that foreign particles do not become entrained in the airflow, causing damage to rotating machinery or model and equipment.

\section{A 1.5 Emergency Stop Procedures}

In the event that an emergency occurs and the apparatus must be quickly stopped, emergency stop buttons should be placed in several locations within the control room 
area and on the apparatus itself. The switches should be thus that any single switch activation leads to the safe removal of power from the electric motor and/or the application of mechanical and electrical braking to bring rotating components to a rapid yet safe stop.

\section{A 1.6 Maintenance Safety}

During routine inspection and maintenance, all power to the electric motor and controller should be suspended as well as mechanical means implemented to restrain the propeller from "free wheeling" in the event of windy conditions. Simple propeller sleeves with tie-downs should suffice. A more complex solution involves the use of a mechanical brake either in the driveline or integrated into the motor that can provide the necessary friction to restrain the driveline during inspection and maintenance.

\section{A 1.7 Component Visibility}

Referring to an FAA Advisory Circular AC- 91-42C [34] on conspicuity, "The propeller or rotor is difficult to see in operation and the non-professional public is often not aware of its danger. Even personnel familiar with the danger of a turning propeller or rotor are likely to forget."

The circular states that if the propeller manufacturer included a paint scheme that increased the propeller's visibility that it should be maintained. Owners wanting to apply a paint scheme should consult proper facilities to determine if the visibility enhancements will have a negative effect on propeller balance. A report of several visibility schemes can be found in the FAA issued report, FAA-AM-78-29. 
Furthermore, electronic cameras should be mounted around the test area to ensure that all persons clear of any test equipment during any testing. Placement of the facility and control area will help dictate the most efficient camera placement.

\section{A 1.8 Safety Cage}

The most drastic and dangerous component failure would be if the propeller or hub assembly was to fail catastrophically during operation. This could cause a $100 \mathrm{lb}$ propeller assembly spinning at $3000 \mathrm{rpm}$ to impact with the test stand or model, or worse, control room or personnel. In the event of blade or hub failure in which multiple blades could be ejected from the test area, the risks are the same, as a single blade traveling at that speed can be deadly.

To help contain this manner of failure, a space frame around the perimeter of the propeller is proposed. The frame would then contain some matter of grating or weave that would catch any blade or component that might be ejected. The purpose is not to stop the projectile dead so much as it is to shatter it or slow its velocity down to an acceptable value that would reduce its ejection distance to a specified radius. 